Fit

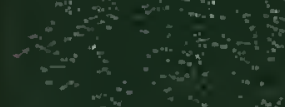

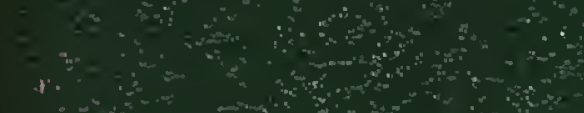

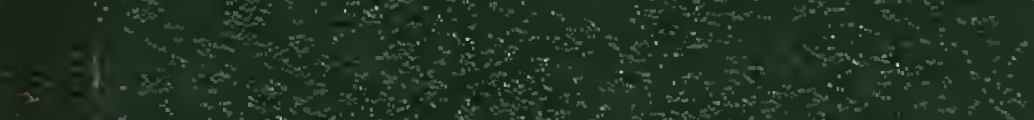
-

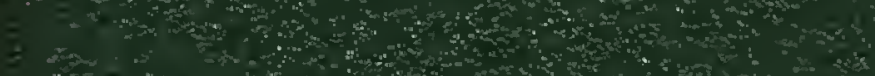

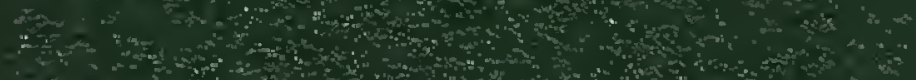
$\therefore$ (n) 3. 20 and

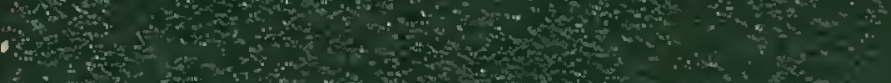

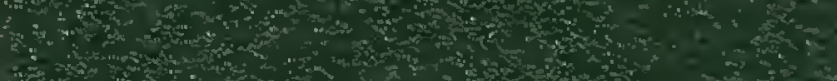

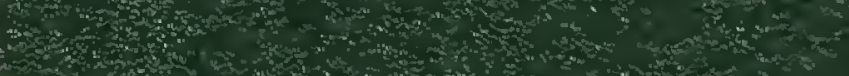

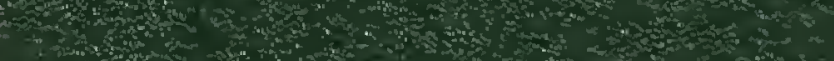

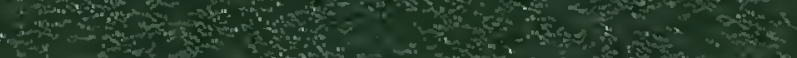
and $\because \cos 20$

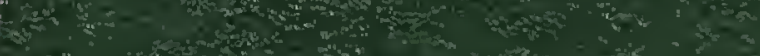
by 
S CIIS IP

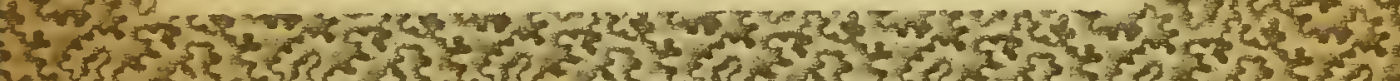

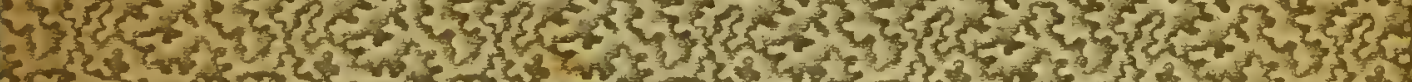

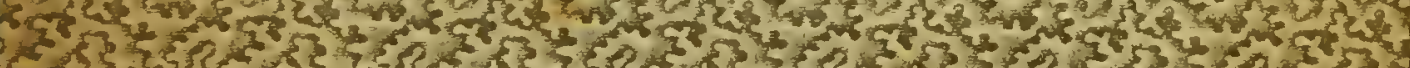

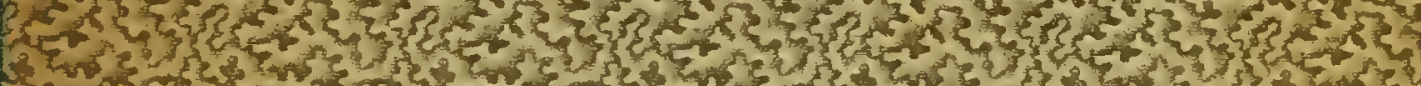

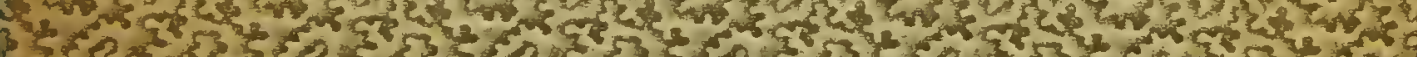

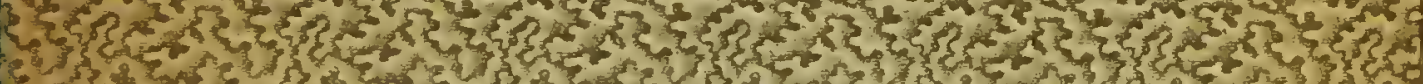

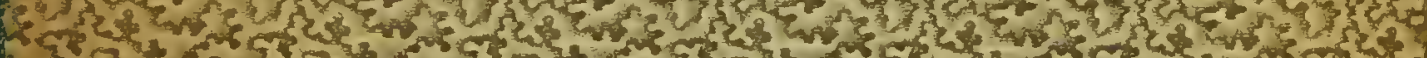

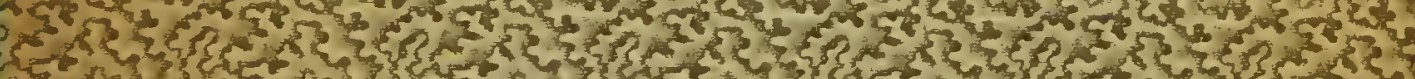

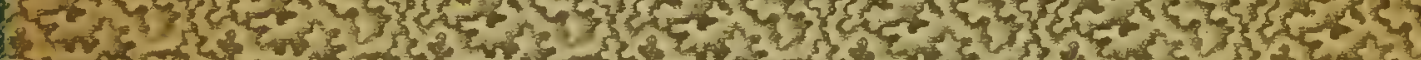

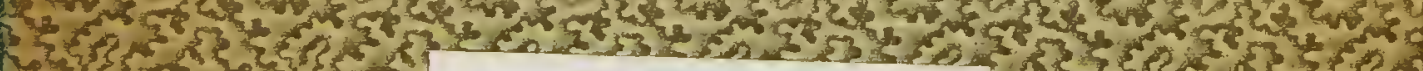

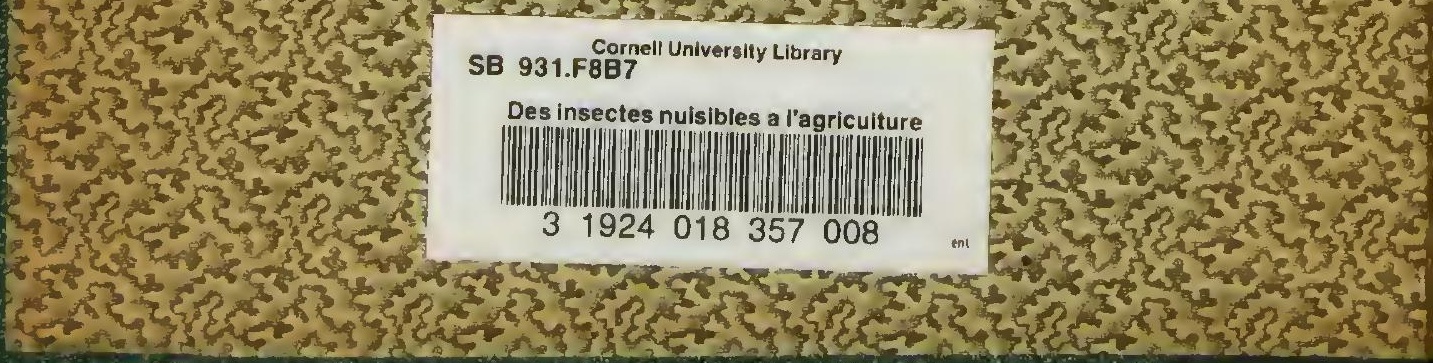





$$
\begin{aligned}
& 9596 \\
& D 13 \\
& \text { Ent. }
\end{aligned}
$$




B.U. Shingerane

Soyers Tonscolombe.

Dos Infectes minifbles al' agreicidtrore

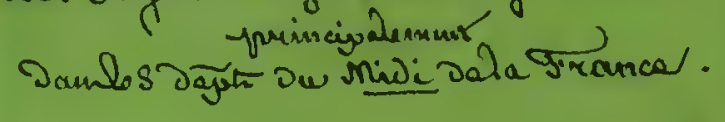

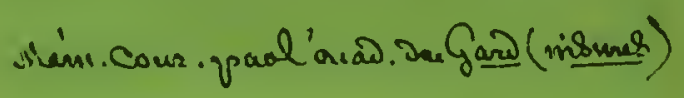
(m_ $8^{\circ}$, aix $\left.=1840.\right)$ 


$$
\begin{aligned}
& \text { Ca } \\
& \text { FB931 4596 } \\
& \text { F8 } 17
\end{aligned}
$$

Ent, 106r 


\section{Ent. 1068}

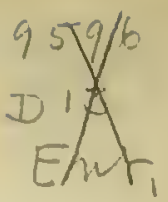

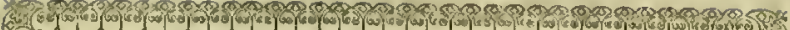

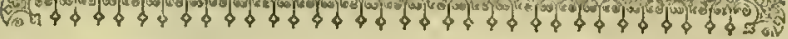

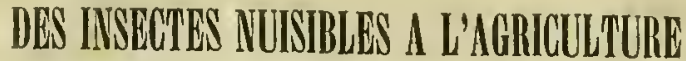

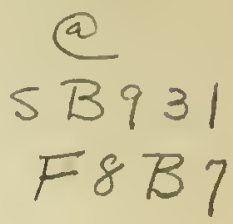

DANS LES DÉPARTEMENTS DU MHDI DE ICA FRANCE(1),

PAR

LE SIEUR BOYER DE FONSCOLOMBE.

- apeoperare

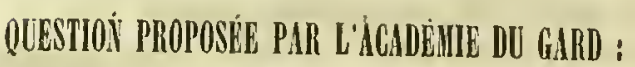

DÉCRIRE LES MOBUNS ET LES IIABITUDES DES DIVERS YNSECTES

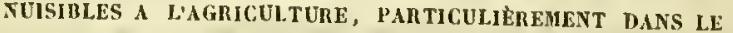
MIDI DE LA FRANCE; RECHERCIER ET INDIQUER LES MOYENS LES PLUS PROPRES A DIMNUER OL A FAIRE CESSER LEURS RAYAgES.

Venit loeusta et bruchus, cujus non erat numerus; et comedit omne fonum in ters eorum, et comedit omnem fruetum in terra eorum. (Ps. 104)

$L$

A nature a repandu ses richesses avec. une merveilleuse fécondilé sur le globe que nous habitons. Les vẻgètaux que la main du Créateur y a senies, les animaux dont il l'a peuplé, offrent i l'homme tout ce qui est nécessaire pour soutenir et embellir son existence. Mais il est aussi des contrastes i ses bienfaits: les poisons croissent à còté des plantes utiles; auprés du bocuf qui laboure nos champs, de la brebis qui nous vêtit

(1) Ce Mémoire a obtenu le prix proposé par l'Académie royale du Gard, en 1855 et 1856 .

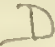


et nous nourrit, rodent le loup et le tigre; rampent le serpent, la vipère venimeuse. Ces disparates out leur place dans l'ordonnance générale des êtres, réglée par la haute sagesse qui les gouverne. Mais, ne fût-ce que pour faire sentir à l'homme sa dépendance et sa faiblesse, nous n'avons pu jusqu'á présent, nous ne pourrons sans doute jamais pénètrer les raisons secrètes de ces mystères de la naturc. Nous souffrons de ces contrariẻtẻs qui troublent nos jouissances, qui nous nuisent même dans nos besoíns essentiels : ce n'est qu'd la sueur de notre front, ce n'est qu'en les défendant contre des ennemis qui nous les disputent, que nous pouvons recueillir, avec bien des pertes, le fruit de nos labeurs. Notre étude continuelle doit être de les èloigner, de les combattre, de les détruire. Les insectes, quoique les plus petits de ces êtres malfaisants, ne sont pas les moins nuisibles; leur nombre multiplič à l'infini compense leur petitesse; tellement que les dégàts qu'ils occasionnent ne peuvent quelquefois être arrêtẻs par aucun pouvoir humain. Mais, quand il est possible de s'elr prèserver, nous scrions inexcusables d'en négliger les moyens. Appliquons-nous donc à comaître ces ennemis que leur petitesse nous dẻrobe souvent; distinguons-les ( pour ne pas frapper en vain et perdre nos peines) de la multitude d'espèces qui ne nous nuisent pas. Il ne sera sans doute pas aussi aisé d'indiquer toujours de sûrs procédés pour les détruire, ou les éloigner. Cherchon cependant à rassembler tout ce que l'expérience 
a pu nous en apprendre, profitons des lumières dẻjả aequises. Ce double but, eelui de faire connaître par des caractères bien déterminés les inseetes muisibles à l'agriculture, surtout dans le département du Gard, et en général dans nos provinees méridionales; et d'indiquer les moyens qu'olr peut employer pour les détruire; sera l'oljet de ce Mémoire. J'aurais voulu pouvoir appliquer à chaque sorte d'insecte un sûr moyen de destruetion; je voudrais au moins dans tous ceux que j'indique, avoir le mérite de l'invention. Mais l'un est au-dessus des faeultes humaines; l'autre surpasse ma science et mes moyens. J'ai donc eru porvoir, tout en payant le tribut de ma propre expérienee, ne pas laisser de eôté, ce qui, avant moi, a été mieux trouvé et mieux expliqué. Enfin j’ai cru devoir ne rien nègliger: Il n'est aucun insecte nuisible, soit a l'agrieulture, soit même à l'économic rurale et domestique, a ma eonnaissanee, que je n'aic signalé. En m'attaclıant surtout aux espèces méridio-. nales, je n'ai cependant pas voulu omettre ee qui concernait des espèces, pius nuisibles dans le reste de la Franee, que chez nous. On trouvera peut-ctre que je me suis trop étendu, que j'ai trop détaillé. J'ai pensè qu'il valait mieux surabonder, que frustrer le moins du monde. l'attente du lecteur curicux; fût-il même minutieux. J'ai pensẻ que je devais faire un tout le plus complet possible. Je puis témoigner de mes efforts et de ma bonne volonté; je serai satisfait si l'exécution a répondu au zèle. 


\section{TABLE DES CHAPITRES。}

1. Des Insectes qui causent des dégâts au blé, soif sur pied, soit dans les greniers.

II. Des Insectes qui attaquent l'olivier.

III. Des Insectes de la vigne.

IV. De l'amandier.

V. Des arbres fruitiers.

VI. Des arbres utiles ou d'agrément.

VII. Des Insectes qui nuisent au jardinage, aux plantes potagères, et à celles que l'on cultive dans les champs.

VIII. Des Iusectes qui nuisent aux prairies.

IX. Des Insectes nuisibles en général ou qui attaquent tous ou presque tous les végétaux.

X. Des Insectesqui vivent aux dépens des animaux domestiques, de l'homme et de nos provisions de ménage.

XI. Des Insectes eunemis des autres insectes. 


\section{CHAPITRE PREMIER.}

DIS INSFCTES QUI CNUSEXT DES DÉGATS AL BLÉ, SOIT SUR PIED, SOIT DANS LES GRF.MIEIS.

Certe plante, principale hase de la nourQ riture du peuple, son grain si nécessaire à la vie, sont sujets à bien des déģìts oceisionnés par des insectes, et dont on a souverit cherehé, presque en vain, à les préserver.

Le blé, dans nos contrées méridionales, a peine sorfi de terre, est déjà exposé aur attaques de deux espèces de petites larves ou vers, pour se servir du langage ordinaire. L'un rouge, mince, alongé, se loge et vit au-dessus de la racine, dans les tuniques du bas de la tige. Il y paraît dès les mois d'octobre et de novembre. La saison souvent encore donce dans ecs mois d'antomne, et lit sécheresse qui se joint quelquefois ì eette température, le favorisent extrèmement. II 
finit alors bcenteonp de mal aux plantes céréales dont un zrrand nombre se flétrissent et se dessèchent, et quelgues autres lingunissent longteraps. Vers le inois de février on le voil encorc dans le bas des tiges de froment, en nymphe brune, ovale, semblable à un grruin d'orge pour la forme et mème la grossenr. Ces nymphes se trouvent souvent phusicurs, à côté les unes des autres, dans la nù̀me plantc. Il en sort vers la fin de mars un petit moneheron de la famille des tipules qui m'a paru être d'nn genre approchant des ceeidomyju de Latreille. Il en diffère par les ncrvures des ailes qui sont an nombre de einy dans

Cecidumyia Lestremie.

Cecidumyia destructur. celui-ci, tandis que le genrc eecidomyir n'en a que trois. Cette espèce n'a été déerite à ce quïl paraît par personnc. Le Mémorial eneyelopédique, annéc 1831, en parle, mais sans en donner la description. Elle scmblerair sc rapporter an gycurc lestremie (Machunt, diptères du nord de lu Frunec... Latreille, rètgue unimal, tom. 2, pag. has). La eecidomyia destruetor scmblerait être de ce genre que d'ailleurs je ne conuais pas, et ec nom spéeififuc conviendrait bien ì notre insecte. Le moucheron du blé est moir; le corcelet est assez grand, l'abdomen cylindrique, mince, alongé, oblus ì l'extrémitć, dans les miles; celui de la femolle est plus gros, conique et lerminé en pointe; les antennes sont 
yrenues, eliaque arlicle étant renflé ì son exfrémité et garni de poils en aigrelte dans les deux sexes : les ailes sontun pen obseures, irisées, el ailées sur leurs bords. Cet animal est si pe!it qu'il est diflicile de l'atteindre pour le détruire. Il se confond d'ailleurs dans son état parfait avec nombre d'espèees de la mềne farnille qui lui ressemblent beaucoup.

On se plaint aussi, parlieulièrement dans le département du Var, d'un autre ver, pareil au premier par ses déģâts et sa manière de vivre, un peu plus gros seulement, et d'un genre très différent. Il ressemble assez à la mouche de l'olive dont il sera queslion dans le eliapilre qui traitera de lolivier, et fait partie comme elle du genre oscinis, Latreille. Je dois la eonnaissance oscinis du blé.

de cet inseefe à M. Laure de Toulon, membre de la sociélé d'agrieulture et de commeree du Var, et correspondant de la sociéré aeadémique d'Aix, agrienlteur très distingué par son esprit d'observation et ses nombrenses conniaissanees. Celle mouche, dont je donnerai la figure, est de forme ovale; le dessus du corps est noiratre, le devant de la têle el ses côtés sont jaunes; les eôtés et le dessous du coreelet, le ventue en ressous et les pattes sont jaunes; il y a deux on quatre mies jauras longitndinales sur le corcelet, dont l'éeusson est aussi jaune.

D1. Blot (Némorial encycl. 185', pas. 296) 
rile terrestre s'est apercu que l'iüle terrestre, vulgairement bête ì mille picals, se tient, l'hiver, aux raeines du blé, quil les ronge et fait périr la plante. On ne s'apereoit du mal qu'en mars, et alors l'animal a déjì disparu. Il faut pour s'en défendre, avoir soin de faire passer fréquemment la leerse cu liver dans les blés en lıerlıe; eomme aussi all septembre et oetobre de brîler tous les débris de végélaux qui se trouvent à portée des elımps ensemeneés, paree que c'est là que liiiile se érelıe et trouve son refuge; la herse le dérange et le léeouvre, cà cet animal n'aime que l'obseurité et vir eaché : on peut alors aisément le voir et lextirper. Je dois ajouter que je n'ai pas lieu de croire que cet inseete qui se trouve eependant dans nos contrées méridionales, y devienne trop nuisible au blé.

Le blé, dẹjà en épi, mais encore vert, est quelquefois attaqué par une elıenille assez̀ effilée, d'un jaune paille, parsemée de points noirs épars, qui étant plus rapproehés sur les eôtés du eorps, y forment deux raies entre lesyuelles règne unc bande d'un jaune pur. Elle s'y voit vers le milieu de juin; elle se transforme en noetuelle ou papillon noefurne vers le milieu de juillet. C'est la ochroleura. nocture ochrolcuca, IIubner, (Duponehel, II ist. natar. des Prepillons de France, tom. VI, p. 511 , pl. 92 , fig.5.) noctun planence, falorieius. Cefte noetuelle est d'un jaune pâtle ou blane 
sale avee deux bandes irrégulières d'un roux brun. Elle vole en plein jour, assez conmunément sur les fleurs des chardons. Au reste, elle n'est pas assez ahondante pour faire un déģit marqué, et les agrieulteurs ne s'en plaignent pas, conlondant peut-êtıc aussi ses ravages avec ceux de la grande sauterelle verte qui ronge souvent les épis verts.

Une autre ehenille raiée longitudinalentent de biun et de gris sombre avee quelques points noirs sur chaque anneau, ronge la raciue du blé et de quelques autres plantes. Elle passe l'hiver dans un creux sous terre à deux on trois pones te profondeurs; elle s'y transforme en elurysalisle vers la fin de juin, et linsecke parfait ćelot un unois iprès. C'est eneore une noctuelle, N. segetis, fahr. Dup. N. segetum, hubu. Elle Notua segen. est d'un gris olsseur, et presque uoiràtıe dans la feunclle; ses ailes supérieures sont traversées par deux lighnes flexueuses noìâtres avee quelques autres taches noires. Elle est figurée daus l'IIistoire naturelle des Papillons de Franee, par MM. Godart et Duponchel, tom. V, p. 250', pl. 68, fig. $\tilde{j}$ et 6 . Ses vavages s'ipereoivent peu, soit paree qu'elle attaque aussi dautres plantes que le blé, soit paree qu'on les confond avee eeux qu'oecasionne le ver du blé déerit cilessus.

Une autie chenille beaucoup plus petite, d'un 
jaune terne el pille, arec une mic dorsale blanche, et les cótés verts, les stigmates d'un biun roussitue, est heancoup plus commute ehez nous. Elle ronge la moédle des chaumes sur pied, lor's et avant mème leur unaturilé. Je l'ai vue presque toules les années tomber en quantić sous les mains des moissonnenrs, ì mesnue quils eoupent les blés. Wle se retrouve sur les aires, entame aussi le grain, et ecrtaines années les agrieulteurs se sont plaint heascoup du dommage qu'elle eause même daus les greniers. Il m'a été difficile de suivre ses métamorphoses, paree que l'époque dé la moisson et les commenecments de la récolte étant passés, elle se blottit dans des fentes et des trous, el s'y tient immobile sims perdie la vie, et ne se donnant du mouvement que si l'ou eherehe à linquiéter. L'hiver survenant, clle meurt souvent dans nos domiciles, quand on l'y garde pour l'observer, saus avoir opéré ses mélamorphoses et sans avoir elu en grosseur. d'ai eru longtemps que le papillou anquel elle devait donner maissanee, élait la tinea clutelda, lnbner, paree que celle-ci se trouve a la fin d'août en prand nombre dans les greniers. Mais je me suis assuré depuis peu que ces deux espèees n'ont aueun rapport, puisque una clıcuille esí loin d’èro en chrysalide quand l'elulellu est déja éclose. Dans te fait je ne counais pas jusquici le lépidoptrue que dome la 
petile chenille que je viens de léerure. Je serais porté ì soupconuer que ce pourail cirre la noeluu. ochroleucr citće ci-rlessus, dont la chenille passeriit le femps de l'hiver dans ect élat d'engonrdissement, pour reprendre sa eroissance au printemps stavant. Celte opinion a besoin d'ctre mieux éclaircic. Réanmur (Além. sur les insectes, $10 \mathrm{~m} .5$, p. 272 , pl. 20, fig. 12, 16) décrit nne elıenille de fansse teigne qui lait de prands dégails en réunissant des grains de blé avee la soie quielle file, et se nourrissant à l'aise de la snibstince du grain, mais les caraelères de linsecte parfais différent de la $\boldsymbol{T}$. elutella. Li fiusse teique de Réammor, trop connmune daus la plupart de nos provinees, a les ailes grises, marbées d'oudes plus brunes, et n'i pas les lignes obliques de l'elutella. Wille est inconnue ou pen comue heureusement chez nons, et dans le aord on ne parait pas comaitie les donmages de la nôtre. Ces espèces ne sont done que trop mulliplićes, et chayue climat a les sienues. On peul voir daus Rénumur celie quill déerit ef qui est connue d'aillenes des maturalistes et des agrieulieurs, suns le nom de ver lles blés, alneile les céréules (Nouv. Cours complet dagricult. Hose, règue animal, Lallr., fom. 2, p. 42 f. - Mím. encycl., muće 1851). Jai entendu nommer par nos enlivateurs, cruadelle, l'esjuce de ebenille dout nous nous plaignons daus 
le midi, quoique ee non paraisse plns particulièrement propre à la larve d'un colćoptère que nous désignerons plus bas. Il n’est pas étonnan I que des effets à peu près semblables ayent porté à confondre sons la même dénomination deux espèces d'insectes d'aillcurs très différents par lenr's caractères exléricurs. đe proposerai pour arrêter les dégâts et la propagation de cette fausse teighe, quelques moyens généraux que jindiquerai plus bas, et qui scront en partic applieables anx autres inseetes que je vais sighraler.

Lialueite des grains (Bose, cours compl. li's yrain. daqrienlt. alucitu cerealella, oliv. euc., méthod. neophora, Latr., règne animal, p. 425. - Réaum. , tom. 2, p. ..., pl. 59 , fig. 18.), désiguće encore sons le nom de Teigue, pou valant, papillon des grains (Rosier, Dict. d'ugr., tom. V, pl. 9 et 10, Mémor. eneycl., 1831.) cause, au moins dans les provinees diu nord et du centre du royaume, des dommages inealenlables. Sa clıenille, qroique Irès petile, est si multipliée qu'elle a menacé de rélluire des provinces eutières à la diselle. En 1760, le gouvernement euvoya deux savants acalémiciens, MM. Dulanel et Dutillet, daus l'Angonmois, pour frouver, après avoir reconnu l'ennemi, quelques moyens de remédicr à ses lavages. Un seul grain de blé, phins souvent un ģrain d'orge, qülicureusemeut eneore elle parait choisir de prélérenec, 
quelquefois la senle moitié du grrain suffit à lenIretien de sa vie entière. C'est done par le nombre qu'elle prorluit les plus grands ravages. Elle attaque aussi le maïs dans l'A mérique septentrionale, et elle s'y multiplic tellement qu'elle remplit les greniers. Bose assure qu'elle y vole en telle quantifé, qnill avait de la peine à garder allumée la lampe qu'il portait ponr aller prendre le maïs de ses chevaux. La chenilie de ectte espèee vit cachée dans l’intéricur du grain qu'elle ronge; elle se conserve vivante même dans le blé mis en terre. Elle est blanche, sans poils, sa tête seule est brune. L'alueite est d'un gris pâle tirant sur le eanelle elair; ses ailes sont assez planes; les inférieures sont très frangées sur leurs bords; ses palpes on barbillons sont relevés all devant de sa tête, comme denx petites cornes recourbées. Bose assure que dians les climats un peu cliands, elle doil produire six générations dans une seule année. đe n'ai pas remarqué cetlẹ espèce dans nos eontrées. Il y a lien de eroire que si elle s'y montre, elle y est rare et oceasionne peu de dégâts. Ce papillon, ainsi que les espèces préećdentes, une fois éclos solls sal dernière forme, ne pent plus entamer les grains et ne s'eu nourrit pas; ils ne sont plus dangereux ( et éest bien assez) que par leur poule qui perpélue la aace.

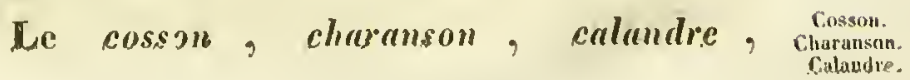


thate-peleuse. challe-peleuse, yond, suivant les licux divers,
cond. calandra calandra granaria, fab. latr., vit sous la forme de larve on de ver dans l'intérienr du girain oì il se loge el quil ronge, eomme la teigne décrite ci-dessus. Cefte larve est blanehe, molle, un peu alongée; sa tête est jaunc, arméc de maudibules on unichoires. Après avoir subi la forme de elurysalide, liusecte troue le graiu, mais il ne le quitte que pour eontinuer à le ronger ì l'extérieur de la mème manière, quoique alors il ne puisse pas oecasionner un grand mál par l'extrème petitesse de ses orgyanes mandueatoires. Dans ee seeond on plutôt troisième élat, il est noir, alongé; sa tète se termine en avant en une trompe on bee long el minee, à l'exlrémité dnquel se trouvent ses mâchoires: ses élytres sont profourlément sillonées, deux antennes eoudées, terminées en masse, partent de la base de la trompe. La durée de lexistence du elaumuson dans le grain depuis l'nenI jusqu"ì sá sortie sous la forme de coléoptère, est d'une furamtane de jours plus on moins suivant la chaleur du pays et de la saison. Les générations de cette espèce se suceètent, en effet, plusicurs fois dans une mème année. On a caleulé qu'une senle paire de charansons peut donner naissanec suceessivement à plıs de six mille indivilus, du milieu d"avril an milieu de septembre; beaueonp plus encore daus nos coutrées méridionales oì la diarée culière de sât 
vie est de moins de trente jours, et oì, conséquemurent, elle se renouvelle phis souvent. Il est donc très important que les précautions qu'on doit prendre pour se débarrasser le cefte espèce iyent lieu avant la poute, et arant l'ćpoque désigonéc pour leur première apparifion.

Enfir, on trouve encore dans les grreniers unc larve beaucoup phus grande que le chamuson, qu'on appelíe aussi et même plus partieulièrement cancilelle ou carlelle : éest sous ce dernier nom vulgaire quielle est dénomméc dans les dietionnaires d'agriculfure de lhosier, tom. 5, pl. 10, lig. 40 et 41 , et de Dosc. Ciest le trogositu caraboides des entomologistes. Elle est blanchâtre, à six patfes qui sont placées immédiatement appòs là têle; eelle-ê est noire, armće de deux fortes mâchoires; la queue est terminće par deux erochets. Elle atlaque les grains à l'extérieur, et ses dégîts sont encore plus consilérables que ceux des autres espèces. A la fin tle lhiver elle quilte le bé pour se blotlir dans quelque tron ou quelque fente. C'est daus eet ałori qu'elle se change en elrysalide, puis en insecte parfint. Ce coléoptère noir, ovale un peu alongé, dlont le corcelet cu deur-ecrele est sćparcé de l'abdonen par un étranglenent asse» manqué, ne vit point de prrains dans son nouvel état; il u'approche des tas de blé que pour y shépnser ses oufs. Il est bon de le connatie sous

Canadelle, Cadelle.

Trogosita caruboides, 
sa dernière forme, aussibien que le charanson, parec que c'est alor's qu'il s'accouple et quil fait sa ponte, et éest lc moment qu'il faut eloisir pour le détruire. Indépendamment de la eourte description ci-dessus, j’en donne la figure.

La larve de la musca lineata, Linn., vit lans les tiges de l'orge; elle en ronge la moëlle ét empèche lis plante de former son épi. Elle a oceasionné souvent de grandes pertes, surtout dans la Beanec. Cetic mouclic est de forme conique, sa eoulcur est janne; clle a une taelic noire sur le front, trois lignes sur le coreclet et quelques taches de la même conleur à la base de Pabdomen. Si longuert est d'une ligne et demie.

Mais peu importerait de connaitre nos ennemis, si nous ne cherehions pas les moyens de les combattre; ils ne sont ni toujours faciles, ni toujours bien connus. Nous allons donner une idée de ce qu'il est possible de tenter.

$1^{\circ}$ Il est impossible de détruire ou d'éloignel le ver qui ronge les jennes tiges du blé; eneore plus impossible de saisir, de détruire et mème Le ver. de hien distingner la monclie qui lui donne naissanee, ì cause de son extrême petilesse et de sa grrande ressemblance avee une infinité d'autres espèecs congéuc̀res. On pourrait arraeher les plantes altaquées lorsqu'elles sont totalement fanées et mortes, parec que ce serait nn moyen 
de prévenir la maissanee de la monche sous sa dernic̀re forme, son accouplement et la ponte qui lui snecede. Mais il faut observer l'épargner les plantes qui n’ont pas encore entièrement péri, puisqu'on a l'espoir de les voir revivre, surtout quand des pluies assez abondantes, et encore micux des gelées un pei fortes font monrir le ver et arrêtent on paralysent ses ravages. Il fant que l'extirpation des plantes ait lieu avant te mois de mars ou même la fin de février, pour prévenir le développement de la petite mouche. On la saisit alors dans sa chrysalide déerite plus liant et facile à reconnaître. Il faudrait enfin (et nous scrons obligés de répéter cette recommandation dans quelyues-uns des chapitres suivants, piree qu elle est essentielle), que tout. un pays s'entendit, que l'autorité obligết les fermicrs et les proprićtaires à user simultanćment de la mème mesure, sans quoi rien ne pourrait empêcher les moucherons éclos clıcz un voisin négligent de déposer leurs ocufs dans le champ du proprićtairc vainement plus soigneux.

On assure que les grains du blé, ainsi que les autres semenees, mêlés avec de la fleur de soufic, dans unc certaine proportion, par exemple d'une onee de soufre sur trois lives de grains, balottés ensuite quelque temps dans un vase couvert, et puis scmés, ne sont pas sujets à être attaupués par les vers après leur germination. 
Les teignes

et alucites.

Oisesur
2. Sur les aires et pendant la moisson, il faut employer des enfants ì ramasser et jeter sur-le-champ au fen tontes les ehenilles qui tombent des épis et qui rodent parmi les grains; et continuer ì leur faire la guerre daus les greniers. Je ferai observer à ee propos, que quelque propreté que l'on désire entretenir dans les greniers, les toiles d'araignées doivent: t̂tre épargnées: elles sont utiles, parce que linsecte yui les tenrl comme des filets, détruit par là une grande quantité de fausses teignes, et mène de eharansons, dont il fait sa proic. A Mloissac, contréc peu éloignée de nons et qui fait un grand commeree de blés, on use, eontre les diverses sortes de teignes et contre les charansous, surtout dans leur état de ehenille on de larve cachée dans les prrains, d'un moyen que nous pourrions aussi pratiquen (Bose, Cours complet d'agrieulure). On enf'erme daus lesgreniers quelques bergeronnelles, oiseaux très-friands de ees vers quils savent dénieher, sans manger le blé lui-même dont ils ue se nourrissent pas. Il suffit de tcuir dans le mème loeal un ou deux plats remplis d'eau. Je pense que lo ronge-gorge (riguou) ponrait rendre ee múme service, d'antant plus que ee petit oiseau qui passe l'hiver dans uos confrées, est très-familier 
et ne eraint pas la présenee de l'lomme. Au reste, l'ime et l'antre espèce est commune dans nos départements, et il est aisé de sien pourvoir.

$5^{\circ}$ MM. Duliamel et Dntillet, qui se sont fort oceupés, comme je l'ai dil plus haut, des moyens d'extirper l'alucita ecrealella, celle qui mine les grains; en ont iudiqué phusienrs. On pent eonsulter le traité du premier de ces académiciens sur la conservation des grains. Le principal procédé est d'éluver les blés avec précantion ì une ehalenr de 60 ilegrés (Licrmomère de IRéaumur). Elle suffit pour faire périr les minenses; mais il faut prendre garde qu'clle ue s'élève pas ì un point plus fort. IBose assure qu'ì 70 degrés, le blé perd la faenlté de germer et devient mème moius bon pour la fabrieation dn pain. Dulnanel indique eucore de laver fortenent les blés ì lican conrante; ce lavage cutraine les anfs, humecte, contraric et fait périr une partie des ehenilles, dı moins eelles qui sont en dehors des prains, emporte les larves de charanson déjìcécloses, et les ordures qui favorisent le travailde ecll e vermine, en lui nénageant nne sorte dialri. Olivier est dans le mème senliment dans mn némoire qu’il a f'iit sur les insectes des grains. Parmentier propose de les exposer ì la chalenr d'un fonr, mais avee de grandes pré 
eautions pour ue pas faire plus de tort au blé que we lini en font les insectes rongeurs. Dulamel indique anssi pour les greniers l'usage d'un ventilateur pareil à eclui dont nous allons parler Lout à l'henre.

4. Les eharansons sont plus diffieiles eneore à détruire, et eependaut ils sont plus communs el plus nuisibles dans nos départements. Renfermés daus le grarin, ì l'état de larve qui est celui oì ils font tout le mal, ils supportent ordinairement saus périr la clıalenr indiquée plus laut de 60 degrés; à moins que l'eau bouillante ne leur soit immédiatement et presque individuellement appliquéc, ec qui est très difficile à espérer; et nous avons vu qu'un deģré supéricur nuirait au blé. On a remarqué qu'ils ne l'atlaquent pas tant qu'il est en meule; e'est sclon M. Teissicr, à eause de l'éloiģnement un peu plus yrand du bâtiment de ferme, et par conséquent des charansons femelles qui ne quittent guère le grenice pour aller pondre plus loin; el paree quon a remarqué qu'ils n'atlaquent jamais le blé sur pied. J'aurais cru que linsecte éfail arrêté par la difliculté quil tronve à pénétrer sous la balle, pour déposer son weuf sur le grrain même, mais il paraît qu'il sait éluder ectle diffieulté; car il sallache au blé en grange on sur l'aire, avant même qu’il soit dégaģé de sa balle. QuoiIjue, d'un autre côlé, eeffe presnière enveloppe 
plus serrée autour dı grain mêne dans lorge el l'avoine, les préserve des atteintes dn charanson, et que par la raison contraice il attaque souvent le seigle et le maïs.

Olivier a remarqué que le blé vanné au eoumeneement de l'hiver eontenail: beatconp moins de charansons que celui auquel on fait subir étte opération immédiatement après la moisson, coumme on est dans l'usage de le faire dans ces pays-ei. Le vannage produit le même cffet que le lavage indiqué plus laut, et qu'Olivier eonscille anssi à la même épơne. Il paunit que le eommeneement de liver est prélérable, parec qu'alors tontes les pontes sout aelievées, les larves plus développées, et les inseetes moins en état de fuir et de résister.

Il est moius diffieile de saisir et d'expulser ce petit auimal dans son état parfait. Mais il est essentiel d'appliquer les moyens que nous allons exposer, avant le milien d'avril pour prévenir la ponte des neuf's, et tarir le mal dans sa souree, ivant l'aceouplentent. Olivier (Enc. méthod. insectes, Char(unson) engage à remuer fortement ef avee eontinuité le prineipal amas de blé eontenu dans un grenier, mais après avoir pris la préeantion d'en établir puelques pelits ì portéc du grand. Lès eharansons eraignent la fraieltenr et le jour : inquiétés par le mourement donné au tas principal, ils s'en ćehappent et vont elıer- 
cher leur trampuillité diuns les phıs petits. Hesı facile alor's, après avoir écrasé ceux quon peut Leau bouillante. saisir au passage, de verser de leat bouillante sup chacun de ees petits las de manière ì la laisser pénélrer. Edes insectes sont étonflés, et lon pent après cela étendre el sécher les gorains : le crible séparera cusuite facilement du blé les charansons morts ou restés lanģuissants. Celle mème manouvre doit se répéter plusieurs fois selon la quantite de grains. BR. Lottinger, avant Olivier, dans un mémoire qui fut jugé digne de l'acecssil an prix proposé en 1768 par l'académie de Limoģe, avait dẹjà indiqué une métlode ì peu près semblable.

Ciest, foudé sur la réprognanee des charansons pour le froid, que IN. goyeuse, dans un mémoire qui remporta ce même prix de l'académie. de Ijimoge, proposa d'adapter aux greniers un

ventilateur. on phusieurs ventilatenrs. Ces ventilatemrs, conscillés aussi par IDulanuel dans l'ouvrage cilé plus laut, doivent aggir pendant toust nn été, ponr entretenir une fraichenr continne de 19 à 20 degrés de Réanmur. M. Joyense a pratiqué ce moyen, et ses essais ont élé comronmés par le succès. Il a rénssi ì faire périr sous ses yenx un tries grand nombre de ees insedes. Je ne puis eependant m’empêelıer dąremarquer que ce degrá me paraîl encore heancoup trop élevé de ne peut suflive que par sa continuté, puisque les cha- 
mansons commencent à saccoupler an milien d'avril où la tempérafure est ordinaitement de 12 i 15 ilegrés dans ees eontrées méridionales. I la fícheux que la cherié de cet apparei, tel que Dulramel l'indique et le déerit, ait dégonté beaucouy de propriétaires; ear on s'en est servi rarement depuis qu'on l'a fiat connaître.

Olivier et Purmentier conseillent encore de metive le lié dans les saes dis le moment quil est batlu ef assez see. Il fint les tenir isolés dans le grenicr, en les posant sur nur chassis élcvé de quelques pouees au-dessns dir sol, et netlant des perches entre leurs rangs. Il est ainsi à l'abri les charansons, pourvu quil aít élé batfu ef mis en sac an moins avant le nois d'avril; paree que les femelles ne penvent déposer lents aufs que dans la minnre dn grain qui est l'endroit le plus lendre, siuns quoi la larve ćclose ne ponrurat pas pénćtrer dans son intérieur et monrait en naissant fate de nourriture. Il y aurait des. milliers d'oufs sur le sac, quaucune larve ne ponrait pénétrer ì travers, quelque liche que fit la toile, parec qu'elles u'ont point de patles pour mareher et quil fiut qu'elles mangent le jour même de lent uaissance. Ce moyen ućeessite mne dépense, une avanee considérable; mais unc fois faile, elle ne doit pas se renonveler de longtentes. C'est an proprićlaire à calcnler. Je fitis observer seulement qu'ou suppose d'apros 
lexpérience, que dans le elimat de Paris, les charansons oceasionnent la perte d'un huitième de la récolte, quand on ne prend aucune précantion contre leurs attagues (nouveru cours compl. $d a g r$.$) Les remèdes que j’ai indiqués sont$ plutôt pour les provinees septentrionales beaucoup plus sujettes aux dommages oceasionnés par les eharansons et les chenilles mineuses, que pour eelles-ei. J"ai dî cependant les fare connaìtre, ces mèmes ravaģes nous menacant quelquefois, tet nous faisant à nol.relour éprouver des pertes qu’il est essentiel de savoir prévenir. Au reste, le blé infesté de cluaransons, que l'on peut porter au moulin, purgé autant que possible de ees insectes par le criblage el le vannage, ne fail aucun mal aux lommes et aux animaux gui s'en nourrissent (nouv. cours complet d'agric.).

Enfin, comme il est prouvé que les charansons ont hesoin d'abri contre le froid et quils fuyent la lumière, qüils se blotissent volontiers en liver dans les trous, les fentes, les grereures des murs, on leur ôtera ees asiles, on tendra à les expulser des greniers, en les tenant dans une graande netteté, et surtout plafonnés, reerépis et soigneusenent carrelés. Si l'on n'y pratique pas des ventilateurs, qu'au moins ils soient bien aćrés, que les ouvertures soient suffisamment multipliées, et ganuies de cannevas qui, en 
arrêtant lintroduetion des inseetes, permettent en même temps à l'air ll'y eireuler. Je llemande senlement grâce pour les araignées que j’ai dẹjà reeommandées à la bienveillance ıles fermiers.

$5^{\circ}$ Les moyens proposés par Olivier et cités ei-dessus, surtout lisolement des saes, s'appliquent encore plus à la destrnetion de la cadelle, qui craint plus le froid que les teignes et les eharansons et qu'il est plus aisé l'extirper. Elle vit non-sculement de grains, mais s'alimente encore de farine et sle pain. On s'en plaint moins il est vrai dans ces deux derniers cas; non plis que de Ia larve du tenebrio molitor, jannître, en forme de serpent qu'on trouve dans la firine et dont ou se sert pour nourrir les rossignols en eage. Si leurs dégâts devenaient 1 rop forts, le vrai moyen serait de tenir les farines dans des saes ou dans des eoffres; ees larves, plus grosses que eelles des eharansons of pue les elienilles, ne penvent pas y pénétrer. Je dois, an reste, ajonter à tout ee que j’ai dit de la cadclle, quelle est plus fineste eneore aux grains dans nos elimats que les tèignes et les charansons, paree que la doneeur de notre température lui est favorable. Dorthez a ćerit son histoire très en létail.

Quant à la multitude des recettes quion a inıliTenebrio motitor

La Cadelle.

(1)

Recettes. quées, dont phlısienrs sont même eonsignées assez légèrement dans des ouvrages imprinés el 
rẻpandus, receltes qui consistent ordinairement en déeoctions, infusions on frietions de diverses drogues, il faut sen méfier, si ee n'est les abandonner totalement. Ou elles sont insufisantes on elles ne unisent aux insectes qu'en laissant sur les grains une odenr et une savenr qui les rend impropres anx usages ćeonomiques, et manquent, par conséquent, le lont qu'on se propose en écartant les animanx malfaisauts. Par exemple, Dulımel a reeonnu par des expérienees exactes, que des elaransons entermés dans une caisse enduite intérienrement de térélıenthine et fermée liermétiquement, ont résisté à eette épreuve sans en ressentir aueun mal. La respiration de ees petits animaux exige si pen d'air, qu'il est diffieile de les asplixier on même de les mettre en fuite par ee moyen. Malheureusement, pour beaneonp d"inseetes, soit ceux qui attaquent nos grains, soit ceux que je serai dans le eas de signaler dans la suite de ee mémoire, le senl moyen est de les reehereher soigneusement, de len. faire la gruerre, d'écraser on brûler impitoyablement tont ce qu'on pent atleindre ; et pow ne pas perdre sa peine en poursuivant limnoeent an lieu du coupable, il faut bien connaître le sigualement de l'ennemi. Je m'y attacherai dans le cours de ces observations, en évitant fontes longueurs imutiles. Car il ne s'agira pas ici proprement d'enionologic, de deseriptions lech. 
niques; cen'est pas un traité d'histoire uaturelle; je m'en tiendrai aux earactères qui sont à la portée de l'aģriculteur, et je pense gu'en aceompagnant ee mémoire de quelques figures, je renplirai mieux mon but, et j'aiderai mienx eneore à reconnaître l'ennesni qu'on doit allaquer.

Veut-on eufin connaître quelques-unes des receltes que des ouvrages estimables indiquent contre ees animanx. En voici d'abord me fort sinuple; c'est de mettue dans les greniers quelques toisons avec le suint. Dans peu de moments elles devieunent, assure-t-on, toutes noireies par la quantité de charansons que leur odeur allire : cmbarrassés dans les poils, ils y périssent, et èest d'ailleurs un moyen de les recueillir plus facilement. Une aufre consiste en une fimmigation de quatre onces de fleur de sonfre quion fait brîler sur un réchaut rempli de eharbons bien embrasćs. Il fant la ménager de mauière à ce qu'elle dure pendaut deux lienres. Elle sullit ansi pour un local de douze pieds carrés. S'il est plus grand, on y proportionne la quantité de soufre; on peut aussi, pour rendre la funcée plus active, ajouler à la dose indiquéc, quatre onees de einaho. Cette fumigation extirpe les teignes et les aheites aussi bien que les charansons. On a indiqué plus nonvellement le procédé de faire sécher sur les tas de blé, des feuilles de tabac, et lon assure que ieur odeur fait disparaitre les charansons. 
Il en est des insectes qui nuisent aux grains, comme de tous les anties, comme de presque tous les êtres qui peuplent notre terre. 'Ious ont leurs ennemis qui cherehent à vivre à leurs déCinips. pens. Plusicurs espèees d'iehneumons, des $e i-$ nips, le céraphron domestique déerit et ainsi dénommé par M. Say, vivent dans l’intéricur des chenilles et des larves dont nous venous de parler, et heureusement pour nous ils en font périr beauconp. đe eonsaererai plus loin quelques lighnes aux ennemis des inseetes, que par là même la providence a rendu uos anis, el qui arrêtent, sans nos sceours, une mulliplication qui serait anssi prodigiense que ruineuse pourl'agrienltenr.

M. Robin, vétéribaire à Chateau-Roux, vient de déconvrir un proeédé qui cungigte à appliquer la vapeur do l'eau bou illante, par un appareil assez simple et l'un emploi faeile, du prix au reste de $180 \mathrm{fr}$, aux grains altaqnés par lalueite. Cot appareil détruit l'ingecte et même ses ceufs, Lauteur a reçu di gouvernement une indemnité pécuniaire ot une médaille d'or; gon proeédé ayant blu approuvé par la société royale d'agriculture, qui le regarde comme supirieur a ceux déjà conuns, Moniteur, Ler. avril 1838. 


\section{CIIAPITRE II.}

DES INSECTES QUI ATTAQUEXT L'OLWHER.

Cet arbre préeicux donné par la providenec pour être la rielıesse de nos contrées méridionales, eet arlore déjà si sonvent menacé par la rigueur des hivers, est eneore sujet aux attaques d'un grand nombre d'insectes.

Un très gros ver ou larve blanche ou d'un Orycles grypus. gris blanchàtre ronge la souche qui, par ses mhinocéros. racines elievelnes, alimente l'arbre. Cie ver s'y trouve caché dans les eavités quiil y pratique sous la surface du sol, et plus ou moins profoudément. Il y est replić sur lui-même en demieerele, il s'y transforme en nymphe qui donne ensuite naissanec à l'oryctes grypus, très grosse espèec de searabé remarquable par la grande corne recourbée que le mâle porte sur sa tête, et yui lui a firit donner les noms vulgaires de 
moine ou de rhinocéros. Le senl moyen de s'en défirire, moyen qui est d'ailleurs de toute manière profitable à l'olivier, est de nettoyer, d'extraire toute la partic cariée de la sonelie, d'autant plus que eet insecle ne s'altaque guè̀re qu'ì eelles qui sont déjà vieiées en partic. Cette opération doit être fate avant le printemps, pour ne pas laisser le temps à linsecte parfait de quilter sa retraite et pour le saisir au nid.

Les branches de l'olivier, le bois de trois on qualre ans recèle un animal plus nuisible quoique bien p'us pelit. Oa teconvait son asile anx tìcles de la longueur et de lis largeur d'un pouce environ, d'abort d'un janne sale, puis violettes et même noirâtres, qu'on apereoil sur l'écolec. Les agriculteur's les counaissent fort bien. Fls saveut retrancher les bianches atlaquées; ils le font ì l'époque ordinaire de la taille de l'olivier, jusques là tout va fort bien. Mais comme daus ee même moment l'insecte n'est pas loiu de sa dernièıe mélamorplose après laquelle il sort de la

Ciron. Taragnon. Hylesinus oleiperda. branche pour faire sa ponte; il fiunt plévenir eet instant, en ne taillaut pas trop tard, et en emportant sur-le-champ, pour les brinler sans aueuu délari, les Is:inches tarées. Le ver ou larve qui oceasionne ee dommage, connu vulgairement sous le nom de ciron on taraguon, est blanc, presque lisse ou sans poils, ì six paltes placées 
près de la tête. Il se loge sous l'écorec et dians l'aubier, où il vit ordiuairement replié sur luimême en demi-ecrele. Il donne naissance à un coléoptère d'une liģne et demie de lonģueur, désigné par Fabricius sous le nom d'hylesinus oleiperda. Cet entomologiste lui assigne les earactères suivants: hyl. villosus, firseus, elytris striatis, griseis, pedibus testace is, fabr. syst. eleuther, tom. II, $\mathrm{n}^{\circ} 23$. Son corps est ovale, très convexe, un peu velu, surtout sur les élytres ou étuis des ailes qui sont marquées de 9 à 10 stries, et plıs ronssâtres que le reste du corps qui est brun. Les antennes, qui sont courtes et en masse, et les pittes, sont rousses.

Le bois mort des branches de l'olivier est habité par un antre colcoptère très semblable au précédent, mais qui ne peut pas êlre dangereux. C'est le bostriehus sex-dentatus, oliv. apate, Latr. siuodendrou muricatmm, fabr. Il diffère Bostrichus scx-dentatus. Sinodendron du précédent par ses antenues à trois feuillets, et les six épines qui terminent ses elytres tronquées. C'est le bostriehe de lolivier et du figuier, de M. Bernard. (Mém. sur l'olivier.) Le feuillage de eet arbre u'est pas non plus épargué. Un ennemi d'une taille remarquable, la chenille du sphinx atroppos on tête de mort, Sphinx utropues. les dévore. Quoique la plns grosse des chenilles, counne elle r'est jamais en grand nombre, ses dégiâts ne réponrlent pas ì ce que sa taille pour- 
rait annoncer. J'ai vu cependant des anuées où elle faisait assez de mal, surtont en mangeant les jeunes pousses. Cette chenille est d'un jaune verdâtre, picotée de blen et de noir; elle a, sui ses derniers anneaux, une corne élevée eomme tous les sphinx, raboteuse et un peu recourbée à son extrémité. Le sphinx ou papillon qui lui sueeède est aisé à distinguer par sa grosseur, ses ailes supérieures brun noirâtres, les inférieures juunes, et surtout par la représentation d'une lête de mort, que l'on voit sur son coreclet. Ce spliux a eela de particulier, qu'il fait entendre surtout quand on le saisit ou qu'on l'effraye, un petit eri très prononeé, produil, à ee que l’on avait eru justu'iei, par le frottement de sa trompe contre les palpes, ou comme il paraît par de réeentes observations, par le rétrécissement ou la dilatation successive de cavités placées à l'origine du ventre et accompagnées de memliranes ćlastiques. Il est aisé de chereher la elıenille, de la trouver, de l'ôter de l'arbre et de l'éeraser. Je puis dire de même de la elıenille d'un autre splinx, sph. ligustri, que j'ai aussi trouvée se nourrissant sur l'olivier. Cette clienille est d'un beau vert avec des bandes bleues ou lilas, obliques, sur les côtés. Son papillon est. tout gris, fort grand aussi, et les côtés de son abdomen sont entrecoupées de gris et de couleur de rose. 
Les oliviers dı Var sont allaqués par un Charansonile qui dévorc les feuilles et même les jeunes pousses. Ses ravages dont les cultivateurs se plaignent hautement, et quils regardent comue un vrai désastre, sont eonmus sous le nom vulgaire de Chaplun, c'est le Paehygaster meridionalis, Déjean. Otiorhyn. chus niger, Germar. Ce coléoptère est de la grosseur d'un gros pois, de la forme orPachygaser méridionalis Otiorliynchus viger.

Cluplun. dinairc aux eharansons, c'est-à-dire, à tête prolougée en bee en avant, mais dont le prolongement dans cette cspèee cst assez court ct un peu évasé, ì eoreclet plus étroit que l'abdomen: qui, reeouvert d'élytres soudées, est presque globuleux. Sa conleur cst très noire, il cst hérissé de quelques poils, et raboteux, ćtant parsemé de points cnfoneés. Il monte la' nuit sur les branclies, et c'est alor's qu'il ronge les feuilles; il passe le jour caché sous la terre, presque à la surface, au pied de l'arbre, surtout dans les sinuosités qu'y forment les inégalités du trone et de lai sonche. Cet inseete n'est done pas très diffieilc à détruire; sa taille et sa couleur le rendent visible; on est assuré de le trouver en quantité cu le clierehant la nuit sur les branehes, à l'aide d'une lauterne; on peut encore le trouver aisément de jour, en f'onillant an pied des arbres quil a dévasté. Je l’ai 
souvent tronvé autour d'Aix, au pied de nos oliviers : seulement il u'y est pas aussi nuisiljle, et l'on ne se plaint pas de ses ravages, comme dans le département du Var. Il attayué anssi les orangers, et parait se nourrir des feuilles de plusicurs arbres qui les conservent l'hiver : je l'ai rencontré très fréquemment an pied des cyprés, il sc tient caché en hiver, pour commenecr ses dégâts dès le commeneement du priutemps. C'est à M. Laure déjà eité avantageusement dans ee mémoire, qué je dois la connaissanec de ect inseete et la plupart de ces détails.

La Cantharide commute Lytla vesicatoria, assez grande et sa couleur d'un beau vert doré, dévore aussi les feuilles de l'olivier, quoique elle soit eneore plus avide du frène, du troësue et du lilas. Comme elle vit eu famille, ses dégâtts peuvent être considérables, peı de jours, peu d'heures même lui sufliraient pour déponiller totalement un arbre; heureusemcut l'appât du gain intéresse à sa destruction; les pliarmaciens les recherehent et les payeut, e'est assez pour engager les femmes et les enfants de la eampagne à les cucillir et a en débarrasser les arlores.

Uu autre eunemi est infiniment plus petit de l'olivier. et ì peiue visible, c'est une ehenille nnincuse 
qui se nourrit du parenelıyme de la feuille l'olivier. Elle pousse ses galeries entre ses deux surfaees. On aperȩoit sa présence, soit paree que la fenille est marquée en dessus d'une petile tache brune, alongée, irrégulière, soit eneore plus sûrement par un petit tas d'cxeréments qu'on apereoit ì sa surfaee inférieure, à lissue que s'est ménagée la ehenille. Elle sorl de cette retraite au eommeneement d'avril, ou même plutôt selon la température ou le elimat, se transforme ell elirysalide entre les feuilles et les bonrgeons, ou du moins dans les gerȩures de l'ćeoree, et donne quelques semaines après, une petite leigne grrise qui u'a qu'me liggne et demie de longueur. Ses ailes supérieures d'un gris eendré, marquées de deux ou trois points noirs quelquefois pen distinets, sont terininées par une assez grande frange, plus lougue eneore aux ailes inférieures. Ses antenines sont épaisses, légèrement dentées en seie; les deux palpes qui aecompagnent la trompe ou langue spirale, sont dirigés en has; ses paltes sont armées d’éperous qui lui permettent de sauter, autant qu'elle vole. La petitesse de eet inseete le rendrait pen unisible; eependant sa multipliention qui est tonjours très-ģrandle y supplée malheureusement. Beaucoup d'oliviers ont presque toutes leurs 
feuilles attaquées; ecs feuilles sont languissantes et tombent, et l'arbre en souffre toujours. Il quitte même les feuilles vers la fin de sa vie pour se nourrir de la substanec des jeunes pousses tendres et des bourgeons entre lesquels elle s'établit, en se cachaut sons des brins de soie qu'elle filc autour d'elle. Dans les conmunes du département du Var qui aroisinent les montaģnes di comté de Nice, on se plaint extrêmement de ses ravages qui miscut beancoup ì ect arbre préeicux. Le seul remède possible serait d'ôter et de brûler en févricr au plus tard toutes les feuilles tarées : mais je le crois pire que lc mal, à moins qu'on ne voulut, en le fesant de loin en loin, diminuer tellement l'espèce qu'on pît arrêter le mal pour les années suivantes; et c'est alors qu'il faudrait que tout un pays s'entendit pour faire simultanément cette opération partout; sans cela le remède serait nul, il n'en resterait que l'ineonvénient. M. Bernard dans son excellent mémoire sur l'olivier, couronné en 1782, par l'académie de Marseille, suppose que cette même ehenille en grossissant quitte la feuille, et cherehant une nourriture plus sueculente, vicut se loger dans l'embryon du fruit, ì mesure ru'il se développe, et quil en sort en papillon en septembre. Il est im- 
possible que ee manége ait lieu, M. Bernard ne l'a pas vu et n'a pas pu le voir; il est contraire aux mours conunes des ehenilies; un si petit inseete ne prolougerait pas autant sa vie et avee des progrès si lents. J'ai observé d'ailleurs très-positivement, et dans le même moment où j'éeris ecei, que la petite teigne mineuse éelot au plus tard les premiers jours d'arril, et qu'elle ne pent eontinuer son espèee que par une nouvelle ponte qu'elle doit opérer à eetle même époqne. Cet observateur a ẻté trompé par la ressemblanee de la teigne et de la ehenille mineuse de la fenille avee eelle du noyau dont je vais parler. En effet, ees denx inseetes se ressemblent dans leurs denx états, ee qui, au reste, arrive somvent à des ehenilles ou des papillons qui vivent sur le même végétal, tels que les Pieris brassice et rapa, les sphinx niccen et euphorbix, au moins dans leur état parfait. Mais nos deux espèees diffèrent par les mours, la taille et même do légères dissemblances dans les couleurs. La chenille qui vit dans le noyau est plus grosse, elle se nourrit de

la eliair de l'amaude; quand son temps est fini vers la fin d'août ou au commeneement le septembre, elle la peree à l'endroit qui joint le pédieule au fruit, elle en sort pour subir ses métamorphoses, et l'olive tombe 
prématurément et se dessèche sur le sol. Il est impossible d'obviè à cet inconvénient ef d'attaquer un ennemi si caché, et qui s'échappe avant que le siége du mal puisse être conıu. Tont ee que pent faire lagrienlteur est de laisser ees olives se conserver dans une demifraîchenr, par les pluies et les rosées, on mienx eneore ì l'abri dans des greniers fruis en les remuant sonvent; et l'on peut encore en tirer quelque pen d'huile, si le hâle du soleil ne les a pas trop desséchées avant que la réeolte des autres olives soit commencéc et que les moulins soient onverts an publice. On pourrait essayer d'attirer et de détruire cette teigne ainsi que celle qui mine la leuille en suivant le mème procédé que je déerirai daus le chapitre suivant, savoir, d'allumer des feux dans les vergers. I'ai lien, en efiet, de croire que ees teignes ne volent que la nuit, ne les ayant jamais reneontré autour des oliviers pendant le jour. L'époque où il faudrait allumer ces feux serait le commeneement l'avril pon' l'une, et le milicn de septembre pour l'autre. V. chapitre III, des inseetes de la vigne.

Il est assez inutile de déerire ees denx sortes de ehenilles, ectte connaissance ne peut servir quà les détruire, si un henreux hasard les fesait rencontrer antour de l'arbre 
La mineuse dont j’ai déjà déerit plus lıaut le papillon, est d'un vert tendre avee une rangée de points noirs quelquefois peu apparente de ehaque eôté du eorps. La ehenille te l'olive est d'un vert gुrisître, marbrće, avee quatre lighnes longitudinales noires sur le dos. La teigne qui lui sueè̀de ne diffère de eelle des feuilles que par sa stature plus grande; les taehes noires des ailes sont ordinairement plus marquées. Elle a aussi la propriété de sauter; aussi M. Couture auteur d'un mémoire sur la eulture de l'olivier, qui renferme au reste de bonnes vues sur l'agrieulture, l'a-t-il prise pour une sauterelle.

Les jeunes et tendres pousses de l'olivier sont bien souvent endommagées par Ie phloioPbloidubins trilus olce on sa larve. Ce très petit inseete se loge dins la partie la plus tendre du jet, it la base des jeunes f'euilles ou des hourgeous. Il les ronge, soit sous la forme de larve, soit sons eelle de coléoptère. La pousse cernée, eoupcée ì son origyine, se flétrit, se dessèehe et fait perdre l'espéranee des amućes suivautes. Cet inseete est souveut un gुrand fléau redonté du propriétaire. Il est "Hucore plus terrible, lorsqu'après une mortalité, la sonche de l'olivier repousse de tous rôtés des rejettous eueore nouveaux et faibles; c'est lí surlout quil étalblit son domicile ef 
nuit à la reproduetion de eet arbre si utile. C'est prineipalement dans eette dernière eirconstanee que je l'ai observé. Le phloiotribus olece, Latr. est brun, presque arrondi, quoique un pell ovale, d'une forme approehant de eelle de l'hylesinus oleiperde : ses antennes sont terminćes par une masse à plusieurs feuillets : il est d'une eouleur brune. On reeonnaît sa plaee sur les jeunes jets d'oliviers, à une sulstanee gyelatineuse, assez semblable à la manne, qui suinte des plaies qu'il fait aux jeunes rameaux.

Le Chermès, pou de l'olivier, est aussi infiniment nuisible ì eet arbre. An eommencement de son existenee, eet insecte est ì peine de la grrosseur d'un pon on d'un trèspetit puecron. Mais après sa féeondation qui a lieu vers la fin de l'hiver, la femelle, scule nuisible, s’aeeroit considérablement, se fixe aux branehes et. mème aux feuilles, s'y trouve tonjours en grand nombre, et souvent plusieurs à la même place serrées les unes contre les autres, semblables à de petites fralles. Elle insère sa trompe acérée dans l'ćeoree ou le bois tendre, elle en suee la sève qui s'extravase d'abord et suinte de son corps sous la forme d'une liquenr miellée, et ensuite, quand eette liqucur s'évapore, en une especce de poussière noire ressemblant is 
la suie. Les rameaux épuisés, perdent leur sue, se flétrissent, périssent partiellement, et la vigueur de l'arbre entier est eonsidéblement altéréc. Les parties les plus elraudes des départements méridionaux sont particulièrement sujettes à ses ravages : le département dı Var est un de eeux qui ont le plus à s'en plaindre. Cet inseete se propage avee une rapidité prodigieuse; il ne se eontente pas d'attaquer l'olivier, quelques-uns de nos arbres d'orangerie, surtout le laurier-rose, lui eonviennent aussi. Je voulus snivie les mœurs de ee ehermès, dans une eontrée où les oliviers sont plus rares et n'en sont pas attaqués. On m'en avait envoyé quelques-uns; je leur livrai un petit olivier isolé dans un vase; je elierehais surlout ì connaitre le mâle qui doit ètre ailé, qu'on ne eonnaît pas eneore et que je ne pus parvenir ì apereevoir. Bientôt je remarquai que les lanriers-rose de mon orangerie alors exposés à l'air libre et assez. à portée de mon petit olivier, en étaient remplis; el peudant plusieurs années eonséculives, j'eus lieu de me repentir de ma nóģiggenee, j’eus bien de la peine à les ehasser de ee nouvel asile. Le elrermès de l'olivier e'st hénisphérique, marqué de deux liģues ílevées, transversales; sa couleur est d'nn yrris un pen eanelle : il est de la gुrossenr 
d'un grain de poivre, quand il a pris tout son accroissement. Coccus olea, Fahr.

La fleur de l'olivicr eneore en bouton ou déjà développée, est piquéc et sucée par une psylle, petit insecte de la famille des ciģales, Soton delolfver qui se eache sous une enveloppe colonneuse, Poỵlla olew. produit d'une secrétion de l'animal, à l'abri de laquelle elle épuise la sève qui nourrit la jeune fleur, la fane, la flétrit et la fait avorter. Son repaire est connu sous le nom de coton de l'olivier. Je ne connais aucun moyen d'en délivrer ect arbre, ì canse de la délicatesse le la partic attaquée. On ponrrait se scrvir cependant des noyens indiqués contre les pucerons dont eet inseete se rapproche beaucoup, mais il ne faut pas trop se fier à ecs receltes souvent au moins fautives. (Voyez plus bas l'article des puecrons.) Cette psylle n'est décrite jusqü ici, à ma connaissanec, par ancun auteur. Ses élytres sont membraucuses, d'unc eonsistanee sèehe, blanchâtreses, marbrées de brun; le devaut de sa tête est avancé et applati; psylla olexe, nob. Il continute de fréfuenter Tolivier dans son état parfail, mais alors il n'est plus caché sous son coton; e'cst dans le courant de juillet qu'on le retrouve sous cette dernic̀re forme.

() ver do livitive.

L'insecte le plus préjudiciable, sans doute, au prorluit de cel arbre, est, le ver qui ronge 
Ia chair de son fruit. Les olives en sout quelquefois si remplies que l'hnile est totalement infectée. Quion la détrite avant ou après la sortic du ver, son sue en est plus on moins altéré; il contracte une odeur, un goût d'onguent désagréalle; il y a plus de erasse que d'huile véritable, et laggrieultenr éprouve des pertes considérables et sur la quantité et sur la qualité de la réeolte. Celle d'une des dernic̀res années, 1834, a subi presque partont ee fléan à uu déģiré que nous avions vu rarement. On peut dire que la réeolte a été à peu près perduc. Ce petit ver on larve est d'un blane jaunâtre, alongé, avec une tête jaune. Il sort des olives à la fin de novembre ou an commencement de déeembre, préeisément à l'époque, ò̀ après les avoir cueillies, on les entasse dans les greniers. Il se transforme en une elirysalide ovale, jaunàtre ou d'un blane sale, semblable à un. petit gorain alongé; et an bont de quelques jours, favorisé par la elıalenr qni règyne dans ces lienx, il se développe en forme de monehe. Celle monche, du gुenre oscinis, latr., est d'un vert gyrisître; son coreelet est bordé de deux liggnes jaunâtres et sa pointe on écusson est jaune. L'abdomen est pieoté de quelques points noirs assez régulièrenent alignés, et terminé en pointe dans les femelles: tont le eorps est 
d'une forme à pen près ovale; ses ailes transparentes sont teintées de brun vers le bout. Il paraît d'aprè̀s les observations de M. Lamre, quelle pond dans la même saison, on sur les olives même, ou sur l'olivier, des $\propto u f$ 's qui préparent un nouvean dommage pour l'année suivante, si quelque influence bienfaisante de l'athmosphìre ne vient pas en arrêter la propagation. Le même savant agriculteur s'est trompé quand il a erir (annales de la soc. d'agrie. et de commeree dil Var, 1835) que le ver sorti de ees oenfs, se réfngiait le mềne hiver, s'abritait et se nourrissait dans les tiges dn blé, et était le même que jai signalé plus hant. Il suffit pour se convaincre du contraire de comparer atteutivenent la mouche sortie de l'olive, et celle que prodnit le ver' du blé. Elles ont quelques rapports, beaueoup de ressemblance, sont toutes les denx dı même genre oscinis (quoique selon moi, la mouche de l'olivier se rapproche davantage dn genre tephritis, et doit pent-être former un gene à part) matis leurs coulenrs dilièrent, et la nature de leurs mours et de lenr nourriture les distingue encore plus. Latreille nomme la mouche de l'olive oscinis olcre.

On al de tout temps indiqué beanconp de recettes contre les insectes de l'olivier, ainsi que des autres végétaux. Mais l'expérience les 
a presque toujours démentis. Ce n'est pas la fante du naturaliste sil a affaire à des cmuemis, qui, par lenr agilité et lenr petitesse, échippent à sa vuc et à ses mains, et dont. le nombre est incalculable. J'ai déjì indiqué quelques moyens bien simples, mais qui vont au but, et qui out au moins le mérite de liminuer la quantité des insectes nuisibles, d'arrêter leur propagation jusqu'à un certaiı degrré, puisqu il n'est pas possible de les anéantir entièrement.

On peut extirper le elicrmès, en y apportant de l'attention, de l'applieation et des soins assidus. Il faut les faire tomber de dessus les rameaux, en les raclant et les détachant avec un contenu de bois plutôt que de fer, ou en frotlant rudement avee un linge grossicr, et les reeneillir soigueusement ponr les ćeraser à mesure. Après cela on imprègne fortement la place oì ils étaient, avec un pinceau trempé. dans du vimaigre, pour achever de tuer les neufs qui seraient restés contre l'écorce. Si l'on se sert du linge grrossier, il est bon qu'il soit aussi imbilsé de vinaigre. On indique contre les cheruès ou cochenilles, la déeoction de feuilles de suream et de noyer, mais elle we fait que pen d'eflet.

Le unoyen snivant doit être bon pour andeles au diminuer considérablement la propagation 
ver de lolive. du ver de lolive; (je vondrais pouvoir dire Précaution. l'anéantir, mais ce serail un espoir inagyinaire) parec que quoique fort simple, il est fondé sur les moeurs et les habitudes de l'inseete. II sera eflicace, sill est pratiqué avec suite et attention. Cette larve quitte les olives i l'époque que jai énoneće; la ehaleur entretenue ordinairement daus les grreniers où on les entasse, hàte sa métamorphose; elle se réfuģic en rampant, ear elle n'a point de pieds, dans les recoins, la poussière, les ordures du grenicr, et surtont sous les tas d'olives. On est sûr de l'y trouver, je l'y ai trouvée moimème, rasscmblée en immenses quanitités, soit en elirysalide, soit déjà en monche, mais n'ilyant pas encore assez de forces pour prendre son essor. Que l'on balaye fréq̨uemment tous ces repaires, qu'on brûle exactement toute cette balayure, sans attendre que la mouclie ait pû s'échapper; on diminuera infailliblement et notablement la gyénération des années suivantes. Mais il funt antant que possible suive ecte unéthode dans tous les grreniers d’une mème contrée; sans cela les mouches dn voisin épargnnées unal ì propos iraient ehereher les oliviers qu'on a voulu préserver. Be sens bien que dans les pays oir la fabrieation de l'huile dure tout lihiver, à eause de la grande quinatité d'olives, tels que le comté de Niee et 
heaucoup de commmnes du Var, mon prow cédé devient bien insuffisant, mais il faut alors le réitérer plus souvent, surtout avant comme après le moment le plus riggourenx de l'hiver, lorsqu'une température plus donce pourrait attirer les mouches au dehors. Je propose eneore pour détruire les vers et les mouelıes, si du moins il est possible de tenir fermé le local où sont entassées les olives, d'y mettre des rouge-gorges, des hergyernonnettes, des mésanģes, dans le mème but. qu'on a indiqué pour les greniers à blé. (V. ect irticle.)

C'est surlont après une mortalité généralc: des oliviers qui n'a lieu que trop souvent, que l'agrieulteur se plaint davantage de la multipliention des insectes, ef des dommiges quils lni causent. En effet il est reeonnu que les insectes s'attachent de préférence anx arbres les phis rabougris, les plus malades, à cenx qui ont sonfert de l'aetion des fortes zyelées. II semble que la sève vigonreuse des arbres sains ne leur convient pas, on mème leur est muisible, et quils sinecommodent mieux des sues noins aloudan is des végétanx

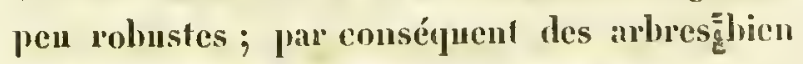
enltivés, bien fumés, soignensement fems, émontés, nefloyés des liehens at des écorces cironnces on cancérenses, sont moins sujels 
ì leurs attaques. Pen de temps après la mor$\underset{\substack{\text { Outil } \\ \text { ieur Julien. }}}{\text { talité de } 1789 \text {, le sicur Julien, maire d'une }}$ commune rurale voisine de S'-Chamas, Bouchesdu-Rhône, présenta aux administrations et à quelques particuliers de la ville d'Aix, un instrument dont il se servait pour débarrasser les oliviers des inseetes parasites. Cet outil en pointe aiģuẹ d'un côté, applati et tranchant de l'autre, était propre ì pénétrer dans les eavités, les interstices de l'éeoree, et ì racler eelles qui étaient mortes ou eariées. Mais que pouvait-on atteindre ou enlever avec un pareil instrument? à peine quelques insectes mal eachés sous la première écoree. Tous les autres, ou profondément enfoncés, ou voltigeant dans l'air, enfin des acufs que le mieroscope ferait à peine apereevoir, éehappent à la destruction à laquelle on prétendait arriver par ce procédé. Aussi je n'ai pas appris qu'on s'en soit servi longtemps, et quill ait fait la fortune de son auteur.

Chanere de lolivier.

Les oliviers sont sujets à une maladic qui rend leurs rameaux canećreux et remplis de bosses irréģnlières. J'ai vil beameoup d'agrieulleurs les altrilbuer à la piquîre d'un insecte. II est difficile de eroire avee Mr. Beruard, que ees ehameres vieunent originairement des morsures par lespinelles la elieuille mineuse eutane les jeunes pousses. Une olser- 
vation assidue et la dissection de ces galles qui du nom provençal boucerle (élevure, protubérance) donnent aux oliviers qui en sont eonverts le surnom de boucerlous, ne m'y ayant jamais fait reconnaître ni traces d'insectes, ni la configuration des nids des espèces qui seraicut au eas de les produire, il est prouvé à mes yeux que e'est plutôt une maladic occasionnée soit par une exubérance de sève, soit par quelque arrêt de transpiration. Sil faut les attribuer à la cause signaléc par M. Bernard, les insectes n'en seraient jamais que la cause originelle, développéc par d'autres cireonstanees.

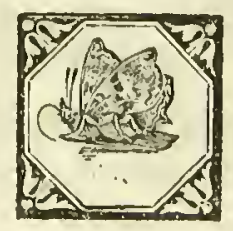





\section{CHAPITRE III.}

DES INSECTES DE LA VIGNE.

Nos viggnes dans les elimats méridionaux ne sont pas sujettes à de grands dommaģes

causés par les inscetes. Le cliermès ne s'attarque guc̀re quaux vignes en treille qui sont pen communes iei, et destinées plutôt à l'agrément qu'ì la production. Comme cet insecte ne s'attache qu'an jenne bois, à celni de l'année précédente, la taille ordinaire de nos vignobles dans ee pays-ci, ne laissant que deux on trois yeux, empêche lo ehermès de s'y propager. La elienille du sphinx de la vigne, sphinx sphinx Fipenor, elpénor, sc reneontre rarement. Elle se tronve beancoup plus souvent sur l'épilobe, plante très-inutile inx agrienltcurs. Le mal qu'elle peut faire ì la vigune est done rarement ì craindre, on pour mienx dire, insensible. C'est par nue prrande errem que Rosier, 
Dict. d'agriculture, attribue à cette chenille le mal qu'une très-petite teiģne fait aux raisins, entre les grains desquels elle se loge, qu'elle ronģe et qu'elle gुâte. Cette petite teigne est infiniment différente de l'clpénor et par sa anbiguclla.
Cochylis petite taille et par ses earaetères génériques. roserana. Ic n'ai pas pu obtenir jusqui ici le lépidoptère qu'clle produit, parec que son apparition n'est pas constante. Bose en parle aussi sans la décrirc. Ses déģî̀ts sont gyrands dans quelques parties de l'Allemagne, surtout dans le Wurtemberg. Ici on a rarement à se plaindre du mal qu'elle fiit, et les procédés pour amener sa destruetion sont les mêmes que ccux qu'ou indique pour l'espèce suivante. Senlement comme c'est en octobre que le papillon doit éclore, c'est alors qu'il faudrait appliquer le remède (1).

La pyralc de la vigne ( $N$. cours complet d'agricult., Bose) se touve rarement chez nous, je n'y ai jamais remarqué ses ravages. Sa chenille se loge dans les feuilles qu'elle roule et dont elle ronģe le pétiole, et même

(1) 1 paratt d'apres l'excellent et savant Mímoire que M. le barun Walckenaër vient de faire paraître dans les annales do la société putomologique, Mrmoire que je n’ai conıu qu'après aroir terminé eslui-ci, unais dont jo me permettrai de profter pour y njouter quelques notes et y faire upuelques coriertions, que celle teigne on elienille tordense donne naissance ù lo timera ambiguella, llulın., cochylis roserana, Dup. Ses ailea superieures sont d'un junue pałm, un pou luştró ou argenté, covpées par une bande brune plus étroite du coté intorno. 
le pédoneule des grappes. Elle ẹause dius le nord du royaume des pertes énormes. Bose assure l'avoir observée dans les viģnes l'Argुenteuil, une année où elle avait empêelıé lit moitié des eeps de porter des raisins. Le même malhenr, ajoute-t-il, a eu licu pendant phusieurs années conséeutives dans les viggnobles de Rheims et de Màeon. On a remarejué que leur nonbre auginentait peu à peu pendant quelques années, el qu'ensuite elles disparaissaient, sans doute parr quelque pluic froide survenue en juin. C'est l'époque oǹ le fort de leurs ravages a licu pour le elimat de Paris. La même cause arrête heurensenent: les progrès de plusieurs autres chenilles dévastatriees; nons aurons oceasion de le faire observer dans les articles suivants. On eroyait ne pouvoir opposer à celles-ei qu'un moyen indiqué par linstinet qui porte le papillon, produit par elles, à s'approcher de la lumière et dı fen, jusqu'à s'y brûler. "On a done essayé d'allumer " des fenx de paille et de fagots dans des lieux " élevés, autour des viģnobles, à l'entrée de la

" nuit, à l'époque oǹ les pyrales sortent de leurs " chrysalides et ehercheut à s'acconpler. "Ce procédé a rénssi : on est parvenu à détruire une immense quantité de? ees petits papillons qui " devant pondre chaeun une ecntaine dicufs et "pcut-être plus, anraicut eansé de nouveaux 
" ravagges l'année suivante. La durée des feư

" doit être d'une lıeure clarjue nuit. Il n'est

* pas même nécessaire qußils soient consilé" dérables. Si on a la préeaution de les faire " dans des lienx élevés, vingt leux dans ehaque " vighoble, elangés d'emplacement chaque jour, " penvent suflire. Il faut que ces feux soient * construits de manière ì oceasionner des tour* billous dans l'air, et que le moment où il eon* vient de les faire soit fixé par une personne " intelligente, pour qu'on n'en perde pas le " fruit: ear les pyrales éelosent à des époques " difrérentes dans ehaque elimat et ehaque an" née, c'est-à-dire qu'elles paraissent plus tard " à Paris qu'à Màcon, et plus tôt daus les " années ehaudes que dans les années froides. " En général, leur passage, si je puis employer " ee lerme; dure une trentaine de jonrs, allant " eu croissant et déeroissant. De sorte quil fau" drait faire des feux ehaque jour pendant tout a ce temps, excepté lorsque le eicl serait froid, "pluvienx ou venteux, paree que les insectes " ehangent alor's diflieilement de place (1)."

(1) Ir. Audoin qui s'ocenpe beaucoup en ce moment (1857) des mours ct de Ia destruction de cette pyrale, est porté h préferer aus fagots, des lampes allumées. Jo pois aussi dans les annales de la société cntomologique que $\mathbf{M}$. Hesjardins, a tile de France, njoute au procedé des lampes ou des fenr, des jattes on cusctles pleines d'ean quon placerait a eote de la lumicre on du fogre. Je crois cette indication excellente, pour remplie le but qu'on se propose. J ai de tout temps éprouvé moi-mine que les papillons aturés par les lumùres. 
J'insiste volontiers sur ce moyen, quoique a[pliqué à un insecte qui ne nous nuit pas ici, paree qu'il est d'une ntilité générale et peut servi à détruire ou diminuer beaueoup d'autres espèees; tous les papillons noeturnes, bombyx, phalénes, teigues, étant toujours attirés par l'éelat de la lumière brillant pendant la nuit. M. Audoin, de l'aeadémie des seienees, eliargé par le gouvernement de ehereher les moyens de préserver les vignobles importants du Míeonnais et des contrées voisines, des déģâts de ee lépidoptère, y a r'éussi avee le plus éelatint suceès, bien dû à la saģacié de ses savantes observations (1). Il a suivi la pyrale et sa eheuille avee une persévérance diflicile ì imaginer dans toutes les pliases de sa vie. Son beau travail aecompagné de planehes aussi parfaites, quant à l'exaetitude du dessin et des délails les plus minutieux, que pour le eoloris, doit paraitte

se jetaient ensuite dans l'eau qquand ils en tronvaient a portée, probablemeut pareo que l'eau réfléchit la clarté du feu ou de la lanpe. Il est singulier que les insectes qui viennent se bruller à Ia damme, y retournent de nouvean a demibrùlés, sans ctro dégontés ni effrayés par une facheuse expérience.

(1) Nous ne conuaissons heureusement pas dans nos contries le procris ampelophaga, dont le meme Mimoire fait mention, comme ravageant les vignobles eu Piénont. Je ne suis nullẹment étonné de ses dégàts, puisqu’on verra dans le chapitre suivant le mal que fait aux amandiers une espèce presque ennginère l'aglaope infausta. J'ose ici a peine exposer un doute. Il me semble diffiejle do supposer, comme paralt lo croire M. Wulckeuser, que ce procris soitlinvolvulus on ronvoloulus qui selon les anciens nuisait beaucoup aux vigues parce que les chenillos du genre procris ne s'enveloppent pas dans les feuilles, et M. Walckenaer lui-meme semblo dire le contuaire. Jatribuerais done plutot ce nom Intin aus pyrales désignées ci-dessus.

Procris ampiclophaga. 
incessamment. Je preuds iei la liberté de donner une idée de ses expérienees, qui rendraient presque inutiles les proećdés que je viens d'indiquer, pnisquil a pu déceonvirir et arrêter le mal dans sa sonree. Le papillon paraît vers la mi-août; il pond alors ses oufs ; la petite elıenille en sort au bout de quelques jours, mais ce n'est que pour se caeher dans les fentes et replis de l'éeoree où elle liverne. En avril, dìs que les jeunes feuilles de la vigne paraissent, son instiuet la réveille, clle va les eherelier, les attayue, les roule; si elle entame même le pédieule de la grappe naissante on même déjà formée, ee n'est pas pour s'en nourrir, c'est en les desséehant, pour se ménager un abri, une ombrelle, qui la mette à convert de l'ardeur du soleil, tandis qu'elle dévore la feuille qu'elle a ronlé en eornet on en eylindre; et eomme tontes les grappes doivent subir cette opération, on peut se faire une idće juste des ravages. L'ćelieuillage u’y fait rien, paree que lá réeolte est déjà perdue, et que favorisant une nouvelle pousse de la f'unille, les ehenilles, après avoir consumé toutes celles des envirous, se jettent avce avidité sur cette nouvelle proie. Meureusement les oufs sont pondus en petits tas à la surface supérieure les feuilles; ees tas sont assez visibles pour quil soit facile de les enlever. C'est. là vaiunent. atlayuer le fléan daus sou origine, el ce pro- 
eédé si simple mais si lieureusement trouvé, et qui fait le plus grand honneur à son auteur et par lui à l'étude des insectes dont il démontre l'utilité positive, a réussi à rendre, dès l’année suivante, une pleine récolte au pays où on la pratiqué. On doit désirer connaître, par une description suceinete, un papillon si funeste. Sa forme est eclle des autres tortriees ou pyrales de Linué; les ailes arrondies à leur base s’élargissent ensuite jusques vers leur extrémité en forme de chappe. Sa lougueur est de 5 à 6 lignes de la tête au bout du ventre, et son envergure, les ailes étendues de 8 à 9 liģnes. Sa couleur est d'un beau jaune très lustré , avee deux bandes obliques rougeâtres qui desecndent en s'arrondissant du bord extérieur jusqu'i linterne; le bord postéricur de l'aile est sonvent de la mênac couleur; mais ees bandes varient beaucoup, étant plus ou moins marquées; quelques-unes manguent souvent presque en entier. M. Dupouchel, Hist. nat. des lepid. de France, en donne la figure coloriće, pl. 239 , fig. 8, tom. 9, p. 91. Il la nomme Tortrix pilleriana. Hubner la donne sous le nom de tortrix luteolana, tab. 21, fig. 136 (1). Je dois déerire aussi en peu de mots les autres insectes que j’ai cités plus haut.

Le chermés on coehenille de la vigne est d'un

(1) Le lecteur s'apercevra ajsément que cet article , écrit postérieurement à la première réduction du Mlémoire, y a été inséré plus tard, lora de l'im-

Tortrix pilloriana.

Chermes ou cochenill de la vigne. pregsion. 
yris tanné, sa pean est rabotense et inégale, sa forme entre la ronde et l'ovale; mais il est surtout remarquable dans l'état adulte de la femelle, la seule que je déeris, par le nid eotonneux plus large que son eorps, sur lequel il repose et qui est rempli de ses $\propto u f$ 's. Ce coton vient d'un sue épais, secrété par l’insecte, qui se forme à l’air en filaments, presque de la même sorte que la ınalière soyense dı ver à soic et de l'araignéc.

La chenille de l'elpénor est brunc, marbrée de grris; la partie antéricure de son corps diminue insensiblement de grosseur vers liı lète qui est petite en proportion dn reste dn corps : il semble que ses premiers anneaux forment une espèce de groing, et cette conformation lui a fait donner le nom de cochonne. Les trois premicrs anneaux on segments sont marqués latéralenent d'une tache à cercles con eentriques bruns et guris-elair, qui représentent assez bien un ail. Une très pelite corne un pen molle sélève sur l'avant-dernier anucan. Le papillon ou sphinx auquel elle donne naissance, ou plutôt dans lequel clle se uétamorpliose, est d'nn vert olive, eonpé sur son abdomen et ses premières ailes rle baudes conleur de rose, les secondes ailes sont anssi roses aree me bande noire. Ses anleunes sont prisualiques et épaisses. Il vole sur le soir antonr des fleurs cu eloche dlont il pompe le miel avee si longue trompe. La chenille est 
grosse et frappe aisément les ycux; il est aisé de la prendre et de l'éeraser.

Les jemes plants de vighne sont sujets à voir leurs raeines attaquées par un gros ver hlane, alan, ture engraisse poule. qui est la larve dn hanneton commun, et par celles de deux ou trois espèces plus petites du même genre. Ces larves, connues des agrienlteurs sous les noms de man, ture, ver blanc, engraisse-poule en Languedoe, sont plus communes et plus nuisibles dans le nord; mais elles ne sont pas ineounues cliez nous.

I'cumolpus vitis cause de gyrands dommages zumolpus vitis, à la viģne dans ces mêmes départements du piquete-brot, nord; on s'en plaint aussi dans le Gard. Sa coupe-bourgeons larve brune, ovale, a six pattes, coupe les jeunes ponsses et même les qyrappes qui se forment. Elle ronge les feuilles dès leur premicr développement, les crible de trons, et par conséquent muit beancoup à la végétation et an produit de la vigne. Oa le connaît dans le nord de la Franec sous Jes noms vulgaires de lisetle, pique-brot, coupe-bourgeons. Lal duréc de sa vic est d'environ trois mois. Linscete parfait qui suecèdc ì la lanve est un colćoptère (on insccte à ailes eachées sons des elytres ou étnis coriacés ) de médiocre grraudeur on même assez pelit. Son coreclet est roud et bomlé ; sa tète est enfoncéc dans le corcelet qui est un peu plus étroil que les elytres et l'abdomen quiclles re- 
couvrent, elles sont d'un roux foneć, tandis que le reste du corps est noir. La tête est ornée de Henx loughues antennes ì articles grenus et distinets. Il s'aceouple et se reproduit à la fin d'avril on au commeneement de mai. C'est le moment le plus favorable pour le reeneillir sur les vighnes et le détunire, parce quil se eache moius alors et qu'on prévient sa ponte. Il faut faire attention qüil se laisse tonber à terre, dès qu'on l'approche, et quil contrefinit le mort. On le voit alors plus difficilement paree quesa couleur est à peu près la même que celle du sol.

Un autre coléoptère assez nuisible à la vigue dans nos contrées, est le rhynchiles betuleti. Ses ravages se bornent ì faire périr les feuilles un les flétrissant et les dessćehınt entièrement. L'insecte est d'un beau vert doré très brillant; son eorps, large en arrière, est eflilé au devant; sa tête se prolouge en un bee aigu aecompagné de deux anteunes en masse semblables à eelles du charanson du blé, mais non condées. Il est comme lui de la famille naturelle des curculionites. Son ćelat le rend remarquable et facile à saisir; d'ailleurs il ne s'échappé pas trop aisément. On le voit, en mai, oeeupé, à l'aide de ses pattes, à contourner les fenilles en cylindre. Pour les rendre phis souples et plins propres à son travail, il entame en partic et affuiblit le pédicule. Il caehe un ou plusienrs aenfs dans les 
replis de eette espèee de eornet. La petite larve qui sort de eet ouf se nourrit de la substance de la feuille demi-dessćchće, et y trouve un aliment qui n'est ni trop lôt see, ni trop humide; jusqu'à ee que sa courte existence terminée, il quitte sa retraite. Les f'euilles dessćeliées, pendent de trons eôtés, donnent à la vigne un triste aspeet, et sa végétation en est quelquefois considérablement affectée. Le rhynchiles bacchus, autre espèee du même genre, de la même forme, mais d'un rouge enivreux et léģèrement velu, use de la même manouvre, mais on le voit bien plıs rarement sur nos vighes.

La taille est le meilleur moyen, comme je l'ai dit plus haut, de se préserver des elıermes ou eochenilles de la vighne. Ils sont très nuisibles aux treilles quand il les infestent; elles languissent, les sarments végétent mal, périssent et le raisin se desséche et ne mûrit pas. Le seul moyen de les en délivrer, est de racler ees inseetes avee un eouteau de bois, on de les détaeher en frottant avee un linge grossier empreint de vinaigre, eomme je l'ai indiqué ci-dessus pour l'olivier.

Le ver blane fait beaueoup de mal au ehevelı des raeines de la vigne. On distingue eelles qu'il altaque par la langueur des tiģes et la flétrissure des feuilles qui se fanent. Il faut alors fouiller an pied de l'arbnste, surtout avant le mois de mai, époque où la larve prend la forme de lanneton

Rhynchites. Baechus.

Précautions le chermès 
et quitte sa retraite. Alors avec nn pen d'attention on surprend le ver. Le labour, an commeneement de l'hiver, au pied de la vigne, le contrarie, le fait périr même en le déuichant, paree qu'il eraint la rignenr din froid. On assure aussi qu'il préfère les raeines des plantes potagères, surtout des fèves, à eelles de la vigne si on en plante dans les vignobles attaqués par le ver blane, il quitte eelles-ei ponr s'attacher ì eelles-là. On reeonnaît bientôt ì leur air languissant eelles qu'il a elıoisies, et alors il est faeile, en les arraehant, de tronver le ver an pied. Gette larve est d'autant plus malfaisante que sa vie est plus lonģne. L̈inseete n'existe, il est vrai, que peu de jours sons la forme de hanneton; mais il vit anparavant trois on quatre ans sous eelle de larve. Nons dirons aillenrs un mot du hauneton lni-même, inseete que tont le monde eonnait et qu'il est facile de ehasser et de détruire dans sa dernière forme.

Le seul remède contre le rhynchiles betuleli cl rhyneh. bnechus, est de eueilir les fenilles eontournćes et de les emporter an loin, on les jeter au fumier ou an fen, pour étonfler l'animal dans son bereeau. On prévient par là une ponte nouvelle, mais on ne remédie pas an mal dẹji fait. Ia senle ressouree contre les ravages de l'cumolpe, est de tîeher de leur donner la clıasse et d'en éeraser le plus possible à l'époque 


\section{que j’ai désiggnée plus haut. C'est assez dire qu'il y a bien peu de remède (1).}

(1) On signale cetto annéo meme 1837, un nourel ennemi des vignes. Ciest Allica oleracua. l'altica bleracca, dont on trouvera la description, chapitre VII : car elle ne borne pas ses ravages à une seule classe de végétaux. Cet insecte, dans sou stat parfait, a causé un dommage considérablo aux vignes des environs de Montpellier. (Atandles de la Soc. entomolog. - 1837 ). 



\title{
CHAPITRE IV.
}

\author{
DE L'amander.
}

Cet arbre, qui ne prospère bien que dans le midi de la Franee, qui est très productif quand ses fruits ne sont pas arrêtés dans leur développement; mais sujet, plus qu'aucun autre, aux retours des froids qui font périr les amandes à peine nouées; est encore-la proic d'un grand nombre d'insectes. Les seules ģelées tardives sont cause qu'on ne peut gauère conpter le produit de l'amandier que sur le pied d'une année sur einq ou six. Les inseetes, en dévastant son feuillage, font quelquefois languir ou desséeher le fruit avant sa maturité, les années même où l'on espère le voir échapper aux derniers froids; Fausse-chenille de l'emandier. et causent souvent la mortalité d'une partie des branehes et quelquefois de tout l'arbre. Depuis quelques années surtout une nouvelle espèec de fausse-chenille, jusques là ineonnue, s'est 
propagée pen ì peu des bords de la Durance jusqu'aux portes d'Aix. J'ai suivi sa marche progressive d'annéc en annéc. A près avoir ravagé les amandiers de la plaine du $P_{u y-S} S^{t e}-R e ́ p a r a d e$ (Bouches-du-Rhône), sur la rive méridionale de Durance, l'annéc suivante, clle commença ì une demi-licue de son premier siége. Un ou deux ans après, clle s'avaneait encore plus loin d'un quart de licue ou d'une demi-licue vers le midi, toujours s'annoncant par ses dévastations. On s'attendait à la voir faire de nouveaux progrès, mais elle n'atteignit pas les hauteurs, clle sembla se fixer dans la plainc. Elle serait cependant sans doutc descendue jusqu'an terroir d' $\Lambda$ ix, mais au lout de denx ou trois ans, clle a disparu presque entièrement. J'en ai retrouvé pourtant eneore quelques-unes isolées, cette mème année 1835; mais depuis l'annéc dernière on ne se plaint plus de ses ravages. Un voyagcur arrivé dernièrement des pays silués sur la rive septentrionale de la Durance in'a assuré avoir vu beaucoup d'arbres dévastés par ce même insecte; l'ennemi serait donc encore bien près de uous. Enveloppée dans ses toiles soyeuses, ectte larve enlace les rameaux et les feuilles; vivant en famille, le nombre des individus est considérable. Quand clle a dévasté complétement un arbre, clle s'émigre, ou en serpeutant le long du 
tronc jusqu'à terre, d'où elle gagnne les arbres voisins, ou mêtme suspendue à ses fils de soie, elle se laisse flotter en l'air, et le moindre vent la transporte bientôt jusqu'au nouveau butin qu'clle veut exploiter. Elle est du même vert que la feuille de l'arbre, sa tête est-noire, luistute, elle n'a que six pattes à ses premiers' anneaux et denx eroes ou épines éeartées à sa queue. Sa première apparition est au commeneement d'avril; elle quitte l'ćlat de larve à da fin de mai ; alors elle se laisse gylisser des arbres jusqu'ì la surfaee du terrain: Elle s'y enfonee si profondément, qu'on la retrouve en hiver sous la forme de elirysalide, anssi bas que les racines des amandiers, quand on est au eas de les arracher. Sa forme et ses caraetères dénotent elairement que e'est la larve d'un Lydus, Fabr. Pamphilins, Latr., genre de la fimille iles tenthrélles ou mouches à seie. Micis, malgré mes efforts, je n'ai pu me proeurer l'insecte parfail qui snecède à cette larve. Il doil être de forme ovale, InI pen alongée, ì quatre ailes eonehcées sur l'abdomen daus le repos, à antennes aussi longues au moins que le eorps. Réamur a connu lis larve, il la décril el la. ligure (Mćm. sur les insectes, tom. 1, p. 183, pl. 15, fig. 2, 3, $4,5,6$ ), matis il u'a pas été plus heureux que moi et u'a polotenir l'inseete parfiit. Il en est de même du baron Deģéer. 
Celui-ei eite eependant Friselı et Bergुman qui paraissent l'avoir eonnue et déerite dans les Mém. de l'académie de Stockholm. Selon eux, il est noir avec quatre anneaux de l'abdomen, bordés d'un peu de jaune sur les eôiés; la tête est variée de jaune, ainsi que le dessous du ventre; les pattes sont jaunes; les antennes longues. C'est sur l'abrieotier que Réaumur et Deggéer ont observé eette fausse chenille. Je donne le dessin d'une espèce approelıante, et l'on peut, d'après elle, prendre une idóe juste de la tenthréde telle qu'elle doit ètre. (Eegéer, Mém. sur les inseetes, tom. 2, p. 102\%, pl. 40). Après plusienrśannées de reeherches vaines, je serais parvenu ì lit connaâtre sans l'heureux événement d'une pluic d'été qui paraît nous en avoir presque débarrassé. Elle avait investi nos amandiers assez subitement; nous sommes lieureux si elle nous quitte de même, et si c'est pour toujours ou pour longtemps. Il paraît que la sécheresse extraordinaire qui a réģné, il y a peu de temps, pendant quelques années eonséeutives, avait amené et favorisé son invasion. Si elle n'a pas eneore paru dans le Gard, il est toujours bon de la signnaler, parce qu'clle peut s'y montrer.

A peine les fertilles de l'amandier eommeneentelles à se développer, que la elienille du p. cratregi, le Gazé de Geoffroy, eommence ì les attaquer : quelquefois même elle s'attache aux 
nleurs. Ces elenilles ont passé tout l'hiver dans les replis d'un petit paquet des anciennes feuilles desséelées, qu'elles lient entre elles, attachent ou suspendent avec de la soie aux rameaux de l'arbre. Dès que l'hiver commenee à s'adoucir, elles en sortent et se répandent sur les fleurs, sur les f'euilles, les dévorent et causent souvent beaucoup de dommagye à l'arbre par leur nombre. La ehenille est alongée, noire sur le dos, avec deux bandes longitudinales jaunes, ses côtés sont grris; elle est assez velue, mais ses poils sont eourts. Elle se change en elurysalide à découvert, sans coque, et pour cela, elle sattache, par un lien de soie en forme de ecinture; sa queue est aussi fortement attaclée contre l'abri qu'elle s'est eloisi, qui est une pierre, une muraille, le trone même de l'arbre où on la voit souvent. Elle est d'un jaune blanehâtre avee des points et quelques raies noires, ovale, uı peı en pointe vers la queuc et vers la tête, et marquée de quelques tubercules on liggnes élevées qui lui donnent une forme assez irrégulière. Au bout de 15 ou 20 jours, vers la fin de mai, le papillon se déģagye de la elirysalide. Il est d'un beau blane avee les neivures noires. On le voit voler en très yrand nombre, surtout sur les seigyles alors en fleurs : il y trouve sans doute la liqueur miellée qui lui convient pour sa nourriture. Il n'est pas rare de le voir se reposer le soir sur les arbres 
et plus eneore sur lamandier. Il est facile de le saisir pendant le sommeil qu'il y va chercher. Au reste, sa chenille dévore également les autres arbres fruitiers et l'aubépine.

Un autre ennemi de cet arbre, qui donne un petit lépidoptère nocturne ou plutôt erépuseulaire de la famille des sphinx, est bien commun

toutes les années. Cette chenille est presque ovale, large, assez courle, un peu applatic, plisséc transversalement. Elle a le dos et le ventre jaune, avee deux bandes longitudinales sur le dos, dont la supéricure brune et l'inf'érieure bleuâtre et beaucoup plus ćtroite. (Hist. natur. Jes Lépid. de Fr., Godard, t. 3, p. 166). Sa marche est assez lente; elle vit à déconvert, il est aisé de l'écheniller; encorc plus aisé peutêtre si on lui a laissé le temps de faire son eocon, de la saisir et de la détruire dans eette dernière retraite. Ce cocon est ovale, légèrement bomlué en dehors, d'un blane sale : il est de pure soie, mais d'un tissu fort serré et très uni. On le voit en quantité, appliqué surtout conlre le trone de l'amandier. L'agriculteur est impardonnable s'il ne le détruit pas. Son ennemi une fois déerit et signalé à ses recherches, il n'y a rien de si facile que de s'en reudre maître. K'instrument imaģiné par M. Julieu, dont j’ai parlé ei-dessus ì l'arfiele de l'olivier, freiliterail beaucoup la besogne. Le papillon qui sort le celte eoque, aglaope 
infausta, se reeonnaît à ses ailes supérieures, noires on couleur de suie, et aux inféricures, rouges avee leur base noirâtre : sa tête est ornée de deux antennes en plumet dans le mâle, filiformes dans la femalle. On le voit auprès des amandiers au milieu de juin; il vole à peine et il serait aisé eneore de lui donner la chasse, et d'en détruire le plus possible, surtout les femelles qui par la ponte perpétuent l'espèce.

Quant à la larve du pamphilius (1), j’ai souffert plus que personne de ses ravages. Je l'ai fait éeheniller, mais quand elle était avaneée en âge, la dépense surpassait le donmage. Les femmes de la campagne se plaignaient de ce que eette opération leur soulevait le cœur; elles aimaient mienx y renoneer. Mes fermiers me disaient que j'y perdais mon argent, sans diminuer sensiblement le mal. Ciest done dans le commeneement de leur vie qüil faut les détruire, dès que les premiers nids paraissent, et alors ils n'oeeupent que pen de feuilles. Ayez des journaliers intelliggents, qu’ils éerasent le nid entre leurs doigts ; ou entre denx pierres plates; alors l'opération

(1) Je croyais les dégàts oecasionnés par le pamphilius auspendus ef même śloignés de nous. Jo viens d'en voir les traces après ce Irémoire achevé, sur les hanteurs de Venelles et Puy-Ricard, d une demi-lieuo en dessus et nu nord d'Aix. Ils ont été trìs seusibles, cette annéo 1850, et jeut-Atre se rapprocherent encore l'anné prochaine du terroir de cette ville. D'un nutre coté ces larves n'ont plus paru du tout, dans le premier local où je les avais observes, au Puy-Ste-lleparade. 
est fieile, on u'endommage que triès peu de fenilles, et le mal est arrêté dans son oriģine avant qu'il ait.pu s'étendre. On peut eneore essayer la méthode usitée en Suissz contre toutes les chenilles qui mangent les feuilles des arbres. Faites une eeintures de poix de 5 à 6 ponees de largeur an tronc de l'arbre : vous avez soin de la renouveler de temps en temps pour que le soleil ne la dessèche pas trop; vous suspendez ensuite aux branches de l'arbre un sae que vous avez rempli de fourmis, ees petits animax (qui au reste, malggré l'opinion répandue, ne nuisent en rien aux arbres) ne trouvant pas à vivre et ne pouvant s'échapper à eause de la bande de poix, se jettent sur les elıenilles et les dévorent. Ce proeédé s'applique surtont à celles qui ne sont pas trop velues; mais serait-il suffisant ici? Je n'oserai l'affirmer, ees elıenilles, se laissant emporter par le vent d'un arbre à l'autre, et éludant ainsi les précautions que l'on essaye de prendie pour les anćantir quand elles sont déjì assez grandes (v. la note ci-dessus).

Je n'ai pas d'autre procédé à indiquer eontre

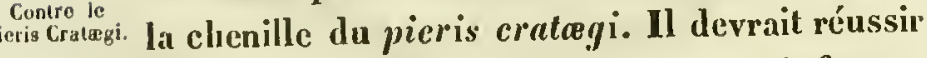
pour cette espèce et pour l'aglaope infausta. Mais il y a un moyen aussi ellicace pour détruire la premièce des deux, comme je l'ai dit: plus laut. Pendant l'hiver leur's nids renfermés dans une ou quelques feuilles sèches, pend en 
paquet anx petits rameaux des arbres fruitier's. Ils sont très visibles dlans cette saison. Un paysan peut pareourir les vergers, un enfant monter sur les arbies, armés l'un et l'autre de ciseaux et d'un panier. Ils penvent détaclier tous ees petits nids, cn rempliv le panier, et les jeter ensuite au feu. Un pen d'attention, et snrtout une direction générale dans tout un pays, aurait lientôt sinon anćauti, an moins diminué considérablement l'espèce.

On assure qu'on pent employer avec suecès necettes. contre ees clienilles, et surtout contre celles qui labitent en finnille des nids de soic, l'eau de savon, le goudron délayé dans l'essence de térébenthine, le lait de eliaux assez coneentré, enfin un mélange de 2 liv. acide sulfurique, étendı dans 12 litres d'ean commune. On imbibe de ees droģues des étoupes on des éponges placées an bout d'une perche, on en hassine fortement les nids, les elıenilles entrent en convulsion et périssent promptement. Il faut clooisit l'époque où clles sont encorc petites, parec qu'alors clles quillent pen leur nid. On pent encore passer rapidement une torche de résiuc alluméc, ou une poignée de paille on de brins de chanvre enflammés, sous ces unêues nirls, mais en évilant de brûler les feuilles, ce qui n'est pas aisé, sans une frrande atleution. 



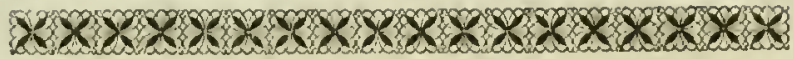

CHAPITRE V.

DES ARBRES FRUTIERS.

Une foule de chenilles et quelques autres insectes font beaucoup de mal aux arlores dont les fiuits eontribaent ì notre nourriture et à l'agrément de nos tables.

La chenille, appelée par Réaumur la commune, cst un fléau terrible dans les provinces du nord.

Elle dévaste tous les arbres fruitiers et s'attache de préférence aux pommicrs, les plus utiles de tous dans ees contrées. L'administration s'est appliquéc plusicurs fois à détruirc cette espèce ou à neutraliser ses ravages. Elle a obligé les propriétaires et les fermiers à écheniller. Ses ordonuanees s'élendirent en général à toutes les clicnilles pernicieuses par leur multiplieation; mais ec n'est proprement qu'à ectte espèce ưion a appllqué le remèle, et eneore ne l'ob- 
serve-t-on qu'aux environs des villes principales. Dans le midi on n'a jan ais tenté sérieusement de pareilles précautions. Elles seraient ecpendant utiles ou nécessaires, si ec n'est contre l'espèce: dont je parle en ec moment, an -moins contre plusicurs autres yue j’ai été an cas de signaler, ou que jindiquerai postéricurement. Je parlerai plus bas de l'instrument nommé échenilloir, up'on devrait mieux connaîlre, employer plus sonvent, et qui est bien pen nsité dans nos départements. Henreuseunent la cherille conmune

bombyx chrysorrhea, n'est guère connuc ici par ses ravages. Il sembleriit qu'elle affectionne plutôt clicz nons d'autres arbres moins précicux qui eroissent spontanément. Elle est trìs répandue dans les montagnes des unures, département lu Var; mais ce ne sont pas les pommiers ni les aulres anbres produclils qu'elle altaque principalement; ce sont les arbousiers qu'clle dévaste. Il est facile de s'en débarrasser en hiver daus sa jeunesse. Elle vit en fimille, et comme alors elle est de tris pelite taille, son nid consiste en quelques feuilles liées en parpuet par de la soie. On peut alors les aperecvoir et les couper facilement. Mnis quand elle est plus grande, les arbres en sont converts, et l'éclienillage est bien plus difficile. Je dois déerire, en peu de unots, ef la ehenille el le bonibyx, pour ponvoir les reconnaître èt s'en délaire les années où elle 
pourrait devenir nuisible. La chenille est noiràtre munic de petits tubereules d'où partent des aigrettes de poils ronx; son dos est marqué d'une liggne rouģe, accompagynée de taches blanches, avee denx petits points vésieuleux, encore plus rougyes, vers l'extrémité. Elle se elıange en ehrysalide dans une coque assez molle, mais d'un tissu serré gris-blanchâtre. Le bombyx qui en éelot est d'un blane éelatant; l'extrémité de son ventre est chargée d'un épais duvet d'un brunjaunître doré; ses ailes sont un peu en toit, et son corps assez épais, comme dans toutes les espèces du même gुenre.

Un autre fléan des arbres fruiticrs du nord, úne elıenille qui fait souvent d'immenses déģâts dans les pommiers à cidre, est celle que Réanmur a appeléc, d'après les jardiniers, la livréce, à canse de la disposition de ses coulenrs. Elle La Livrée. est rayée longitudinalement de roux et de bleu . sur un fond noir, avec une bande dorsale blanche; elle est un peu velue. Son cocon ressemble presque à eclui du ver à soie, mais il est plus petit, plus ovale, d'un tissu moins serré et parsemé d'une poussière janne souffie. Ce encon, se tronve, ainsi que le préeédent, assez à portée des lieux où a vécu la ehenille, ou à l'enfourclure des rameanx serrés, ou dans les fissures des écores. J'ai er'u utile de le déerire, paree quil est quelquefois plus facile et tout aussi im-

B. Neustria. 
portant de le détruire que la ehenille mêmes Celle-ei se voit dins notre climat, mais elle n'y est pas répandue an point de s'y rendre très unisible; je l'ai peu vue sur les arlyres fruitiers, d'ailleurs elle mange aussi les feuilles de l'orme, du eharme, du ehêne, et de presque tous les arbres. Le bomby.x neustria, c'est le nom du papillou, est d'un jaune biche, avec deux liģnes blanehîtres un peu obliques sur les premières ailes. Il est fiteile d'apereevoir ses anfs; la femelle les dépose à côté les uns des antres, autour d'un pelit ramean, serrés et enfoncés dans une enveloppe gilutineuse qui se dureit extrémement, eette agrégation a la forme d'un auneau on d'un petit bracelet. Ils doivent être arrachés soignensement et détruits. On prévient par lì, d'uu seul coup, la naissauce et les dégâts l'une fimille entière. Les jeunes ehenilies se tienneut ensemble sous des toiles soyenses : il est encore facile alors de s'en rendre maître; plus tard, elles se séparent et sout plus dilliciles à rechereher.

La ehenille de la phalena brumala dévore les jeunes feuilles dès le moment qu'elles sortent du bourgeon. Ldes pommiers en sont quelquefois tout ehargés dius le nord où ses ravages sont très grands. Je ne l'ii pas reueontré daus uos vergers, et si elle y parait, elle n'y doit fiure que peu de naal. C'est une arpenteuse it dix paltes, verte, rayée longitudinalement de blane. 
Elle vil sur les arbres frniliers, mais aussi sur lorme ê le chêne. Un eoup de bìton qui ébranle subitement l'arbre; un coup de fusil, en ippuyant le eanon sur l'enfourchure des branches, les fait tomber par milliers, suspendues chacune à un long fil. En faisant alors le moulinet avec le même bâton, on arrête, on brise les fils; les elienilles, préeipitées à terre, périssent par l'ardeur du soleil, ear il fut choisir pour celte chasse le moment oì il brille, et répéler pendant phusienrs jonrs ectle manxuvre, jnsqu ì ec qu il ne tombe plus de elienilles. Il fiut entonrer en mème temps le bas de larbre d'une bande de goudron, ou de vienx oing yui les empéche de remonter. On obtient le même effé en le eciguimut de deux on trois tours d'une eorde fiule de erin de eheval, dont les petites pointes arrètent les chenilles anssi hien que les limaçons, les piquent. même et les tuent. La phalène qui naît de eelte ehenille a dix lignes environ d'envergure, ses ailes sont étendnes el horizontales comme ehez toutes les espèees de ee genro de lépidoptères. Les premières ailes sont d'une coulcur terrense on fenille-morte avee des handes brunes, les inférieures, fenille-morte sans bande. La femelle n'a point d'ailes, mais senlement des moignons. Elle éclot en aulonne on même en liver, quelquefois lorsque la terre est converte de neige (Bose, N. C. compl. d'ugre) Un suédois, 
M. Cronstet (cité dans les Mémoires de l'aead: roy. de Stoels.s.) a imaginé un procédé qui lui a réussi ì détruire une énorme quantité de ees chenilles et surtout de leurs plaalénes, ainsi que de l'espèee dont je parlerai immédiatement après. Il revêtait les trones des arbres d'une large ceinture composéc de paquets d'éeoree; on les liait à l'arbre avee du gros fil à coudre les voiles, on tâchait de les adapter le micux possible à l'écorce de l'arbre fruitier; les interstices étaient bouelıés avec de la mousse ou semblable matière : on recouvrait le tout d'un enduit épais de cambouis qu'on a soin d'entretenir dans un état de fraîcheur. Les chenilles, les femelles parfaites qui sont aptères, les mâles mêmes s'y prenaient en immense quantité. Il en détruisit, par ce moyen, plus de six mille dans l'espace de moins de six semaines depuis le 23 septembre jusqu'au 6 novembre.

Une autre phı̀lène, phal. defoliaria, est aussi pernicieuse anx arbres fruitiers que eelle que nous venons de déerire. On peut lui opposer les mêmes procédés que ei-dessus. L'enduit de goudron ou de eambonis a eet avantage contre ces deux espèees, que leurs f'emelles étant aptères, ne penvent pas franelir eet obstaele en volant, et suffit quion le pratique, pour la première à la fin de l'automne et même en hiver, ruand on la voit paraitre autour des arbres; et 
pour la seconde gui éelot deux fois l'année, au commeneement de l'automne et au printemps; elles meurent empétrées daus eette glue, en voulant grimper à l'arbre, et leur propagation est lıeureusement arrêtée. La phalène defoliaria mâle est d'un jaune d'oere plus ou moins foneé, pointillé d'atomes bruns, coupé, vers l'extrémité de l'aile par une bande plus foneée; les ailes inférieures sont beaneoup plıs pîles et sans bande.

La chenille de la noetue psi nuit aussi quel- Noctua pri. quefois aux pommiers, aux poiriers et aux pruniers. Elle est reeonnaissable par un long tubereule en forme de bosse qui s'élève an milien de son eorps : son dos est jaune-blanehâtre; ses côtés un peu velıs sont variés de roux et de brun et eneore bordés de blanc. Sa ehrysalide est renfermée dans un eoeon de soic blanche assez irrégulier dans sa forme; clle le file ou entre les feuilles on dans quelque retraite à portée de l'arbre. Le papillon noeturne, la noetue qui en sort, est d'un gyris elair avec plusieurs traits noirs sur ses ailes, dont quelques-uns ont la forme de la lettre preeque $p s i$.

La ehenille à orcilles ne borne pas ses ravages aux arbres finitiers, elle se nourrit aussi des feuilles de clıêne. Ie n'ai jamais olsservé que ehez Chenille
ì oreilles. B. Dispar. nous elle fut très nuisil)le. Elle est remarquable par denx assez grandes tonfles de poils qui aceompaģnent sa tête et qui lui ont fait donner 
le nom quielle porle; le reste de son corps a des touffes plus petites, implantées comne les premières sur de petites verues ou fubereules, sa couleurest brune avee quelgues taches bleues. Son cocon est ì peu près semblable à ceux des eśpèces précédentes; sa clirysalide, comme celle de lai conmune et de la liviée, est ornéc de touffes de poils roux. Le bombyx dispar. qui en sort est gris ou blane, suivant le sexe, avee des raies noires en ziģzag. Il n'existe d'autre remède contre ees deux dernières espèces ef la suivante que l'éehenillage qu'on doit employer lorsque leur multiplication devient trop forte. Hes aufs du B. dispar. sont très faciles ì apereevoir. Ils sont agflomérés en paquet irrégulier, recouverts d'un eoton roux : la mère les place ordinairement sur l'écorce des arbres, il fiut culever et éeraser tous ceux qu'on aperȩoit.

Une autre ehenille, eclle ru papilio polychloros

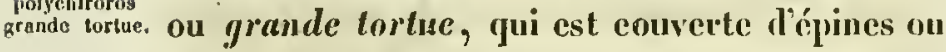
pointes élevées, l'une couleur f́auve avec quelques taches noires, llévore souvent les feuilles du cerisier et s'y trouve quelquefois en asse\% grand nombre. Elle est ecpendant polyphage et vit aussi sur l'ormẹau, le peuplier et d'autres arbres. Je l'ai frouvée quelquefois sur le caprier. Il fant choisir, pour s'en défaire, l'époque oì elle est eneore jenne, paree que, vivant alor's en famille, on saisit d'un seul eoup tous les indi- 
vidus. Sa elirysalide est nue, éest-ì-dire sans eoque, suspendue par sa quene qu'clle attache contre un arbre ou un mir. Elle est couleur de feuille unorte, arméc de pointes et ornée de quelques taches argentées. Le papillon est d'un roux vil avec de grandes taches noires et une bordure de points bleus.

C'est le cas de parler de l'échenilloir. Celui Échenilloir. que décrit Rosicr, eour's d'ugrieulure, t. VH, et Buchoz (IIistoire des insectes nuisibles, ete.), dont le premier donue la figure, consiste en une pairc de grimds cisean $x$, lont la première lame a le hout un peu plus recourbé qu'une serpette, et le minche creux; on $y$ introduit nne perehe de la hauteur convenable pour atteindre le repaire des chenilles; on l'y fixe avec une cheville qui passe dans les trons pratiqués à ec même manehe afin de rendre les eiserux plus solides. La seeoude branche dout la lame est un peu plus laige que la queue, s'ouve et tombe perpendieulairemeul; ì la queue de ectle lame on althehe une corde ou fil qui la tive avec foree et la fait jouer contre la lame erochue, pour. eouper net des bruches plus grosses que le ponee, et an inoins retranclier les fenilles et les bramehes où se trouvent les eheuilles et les piaquets qui renforment lenrs mids. Cet instrument est conmu depuis louglemps des jardiniers d'Amieus qui s'en serveut avee sucès. 
Pyrale holmiana, Les pyrales holmiana, gnomanu, oporana, gnomana, oporana.' espèces de lépidoptères noeturnes, nuisent aux pommiers par lenrs elıenilles qui plient les fenilles en paquet pour y vivre caelıées. Quclquelois, par leur multiplieation, elles détruisent le fenillage et arrêtent la eroissance du fruit. On peul. se servir, contre ces espèces, dı proeédé décrit plus haut à l'oecasion de la phal. brumata. Des feux allumés, eomme je l'ai indiqué dans non chapitre de la Vigue, peuvent contriluer à faire périr en assez grand nombre les papillons de ees diverses espèces. Mais il faut répéter qu'il est indispensable pour que la mesure réussisse, de la mettre simultanément à exéention dans tous les vergers, et d'oloserver l'époque où les papillons doivent être éclos. En général, eelle mesinre est bonne contre tous les lépidoplères noeturnes, et nous ne la répéterons plus. C'est anx agrienlteurs à chereher à l'appliquer dans l'ocension. Il est peu nécessairc de dépeindre les pyrales que je viens de nommer. Leur deseription se trouve dans les auteurs entomologiques; elles sont figurées dans Hubner. Les ravages de leur's eheuilles ne sont pas connus dans nos départements, ou bien ils y sont rares; et d'ailleurs l'inseele parfait. est difficile ì alleindre. Les procédiés que j’ai iudiqués suffisent pour en diminuer la propagalion, si elle devenail trop rapide.

Mais notre allention doit se porter prin- 
cipalement sur une espèce qui a été ut vrai fléau pendant nombre d'années, soit dans le nord, soit ici. Je veux parler de l'hyponomeuta padella. Son apparition et son existence ont eu quelque ehose d'extraordinaire. Je l'ai vue, en 1793, investir les mahaleb; je ne l'avais pas remarquéc jusIn'alors; les années suivantes elle s'attacha aux pommiers, et pendant longtentps clle les a dévoré annucllement au point de ne leur laisser aueme feuille. J'ai vu ees arbres u'avoir plus que les rameaux et les grosses nervures des feuilles et présenter un aspeet phus triste que eclui de l'hiver. Ises chenilles de cette espèce, vivant tonjours sous les foiles soyeuses quielles filent, les couvraicut d'mu réseau grisître. Quand l'arbre était totalement dévoré, clles desecndicient le long du trouc, pour passer à d'autres pommiers; ees trones restaient revêlus totalement d'mue cuveloppe soyeuse et continue quon pouvait enlever par lambcaux d'un ou deux ponces de largeur. Après s'être longtemps nourries sur le pommier, elles commeueèrent ì attaquer les prumiers qu'clles n'éparguèrent pas davantage, saus tontefois abandouner les premiers arbres. J'ai fait écheniller plusienrs fois; cela proeluisait quelque lien, an moins quelque diminutiou; je parvenais à sanver les fruits; 
mais mes voisins n'en fesaient pas autant, et mon procédé restait insuffisant. D'aillenrs, a cause des toiles qui renferment les elienilles et enveloppent les feuilles, on ne peut les extirper sans arraeher une quantité de fenilles eneore tendres, car c'est dans l'origine qu'il faut attaquer lc mal, ([uand la elienille est jeune, et que les nirls sont moins étendus; le remède n'est done pas sans inconvénient. J'ai vu essayer, mais bien en vain, la fumée du soufre; elle ne chasse pas les chenilles et peut nuire au feuillage autant qu'clles le font elles-mêmes. Bose indique de brûler sous les arbres, tant pour cette espèce que plus eneore pour les autres qui ne sont pas protégées par l'abri de leurs toiles, de la paille mouillée on dn fumier de litière eneore frais. Ce proećlé que je n'ai pas essayé pent être bon pour d'autres espèees, je erains quil ne soit bien insuffisant pour celle-ei; mais au moins il n'a pas lineonvénient du soufre. Il faut éviter de faire ces fumigations, les jours on le vent souflle, paree qu'alors la fuméc dévie et n'atteint pas son but. On peut encore essayer ec que j’ai indingé ei-dessus, chap. de l'amandier; eomme anssi imbiber les uids des drogues citées an nême endroit. On peut eneore faire tomber les chenilles en ébranlant l'arbre 
par un coup de bâton, comme je viens de le dive fout à l'lıeure. Il y a 8 à 10 aus que ees chenilles ont presque disparu; je les retrouve fréquemment, il est vrai, sur le fusain, et bien eette même espèce, non pas l'evonymella qui sen rapproche, eomme je l'ai bien vérifié; mais clles n'ont presque plus attagaé nos arbres fruitiers. Bose fait la mème remarque pour le nord; leurs ravages y ont eessé eomme elıez uous assez. subitement, de la nû̀me manière que je l'ai fait observer pour les fausses elıenilles de l'amaıdier. Il l'attribue à une pluie froide survenue au moment deleur métamorphose ou à la famine qu'elles éprouvent, ì raison même de leur grand nombre, quand après avoir dévasté tous les arbres qui leur servent de pâture, elles sont réluites, facte de subsistance, ì mourir lle faim. Cette elıenille est d'un jaune livide avee deux rangées de points noirs; ses mouvements, dès qu'on la touche, sout d'une grande vivacité. Elle fait son cocon dans les toiles qu'elle habitait dans sou premier état. Le papillou qui en sort est alongé, de $\mathbf{5}$ à 6 liģnes de long; ses ailes, d'un blane lustré, un peu gaist̂tre, sont parsemées de points noirs et roulées en eyliudre autour de son eorps. On le voil. ou posé on voltigeant autour des arbres qui ont nourri sa elıenille, il cherche à y dléposer ses oufs, ferine d'une nouvelle fénération; le 
enltivatcur doit le comnâtre pour ne pas l'épargner.

Recettrs

Pnisque nous avons déerit bcaneoup de ehenilles et indiøué plusieurs moyens de s'en dél'endre, nons devons ajonter iei en peu de mots les reecttes indiquées par un agrienltenr, entomologiste en même temps, par Bose d'Antie (nouv. cours eompl. d'aggr.), son nom les recommande, et on peut y avoir un ecrtain deģré de confianee. Il eonseille la dissolution de potasse, l'ean de savon, les décoetions de tabae, de suream, de fenilles de noyer, de jusquiame, ou mélangécs ou séparément. Voici la préparation, indiquée par Rosier, pour nne de ces déeoetions, eelle qui se compose de feuilles de surcau, de noyer et d'aulne. On entasse les f'cuilles dans une barricjue jusqu'au tiers de sa eapaeité, et l'on aehìve de la remplir d'eau. On remue souvent le tout, et on eliange l'eam de temps en temps pour prévenir la eorruption. On en arrose les plantes atlaynées, les branclies des arbres. Je n'ose ajouter que ces proeédés me paraissent bien insuffisants, et souvent bien diflieiles à pratiquer.

teurg défauts. En ģénćral, il est impossible que l'agriculture obtienne du naturaliste, des proećdés sîrs et infaillibles pour détruire tout ì fait les ehenilles et les autres insectes malfaisants. On pent espérer tout au plus des cssais plus ou moins incomplets pour arrêter et diminucr leur trop grande inulti- 
plieation. Assurer le contraire ne serait qu'un pur clarlalanisme démenti par l'expérience ef opposé aux lois de la nature. Contentons-nous done (et ce Mémoire ne peut raisonnablement avoir d'autre but) de ehercher les moyens de combattre plutôt que d'extirper le mal; ec sera toujours par des soins et un travail continu, dirigé et éelairé par la connaissance des mours des inseetes, plıtôt qu'à l'aide des recettes fautives des empyriques.

Les fruits eux-mêmes, et nous ne nous cn Pyralis pomana. apereevons que trop, sont gâtís par une inultitude d'inseetes de toutes les classes. Le ver ou plutôt la chenille, de l'intéricur des pommes et des poires est produit par la pyralis pomana, qui est d'un gris sombre, rayée transversalement de noir, avee une tache bronzée à l'extrémité des ailes. Elle nuit chez nous à une récolte agréable, productive même, mais dans le nord elle attaque les pommes à cidre et devient un fléau. Les feux de fagots, dont je parlais plus haut, sont superflus contre eette espèce, paree que son apparition varie et se répète sans règle depuis le commeneement de l'été jusqu'à la fin del'automne. L'amande dı noyau de la pêehe est souvent rongée par une chenille. Je n'ai jamais pu eonnaitrc le lépidoptère qui la produit, ct qui doit être du même genre que ceux que je viens de déerire, ou une espèce de teigne. Blle expose ec fruit ì 
tomber avant sa parfaite maturité, mais elle l'attacue pas la pulpe. Bose cite eneore une Des Prunes. pyrale qui vit dans l'intérieur des prunes, il ne l'a déerit pas; je n'ai pas remarqué qu'elle fit heaueoup de dégât cliez nous, et je n'ai pas observé ses métamorphoses.

Des Chataignes. Ce qu'on appelle vulgairement le ver des chitPyralis pllugiana taignes est eneore une ehenille. Son papillon est connu des entomologistes sous le nom de pyralis pfugiana, fabr. Réaumur en parle, tom. 2 de ses Mémoires, pl. 40, fig. 19.

Les fruits sees, les poires, les prunes, les des nois. raisins, dans cet état, les noix, sont très sujets, dans nos pays où l'on en f'ait un grrand usage et même une branche de commeree, alx attaques d'une petite ehenille ou teigne qni les salit et les défigure, autant, et plıs qu'elle ne les dévore, car ses ravages ont lieu en hiver et sont fort lents. Il m'a été impossible, quoique ayant souvent gardé la ehenille, d'obtenir l'insecte parfait; mais la teigne ressemble beaueoup ì eclle qui ronge le blé, soit dans les épis, soit dans les grreniers.

Quelques larves de monehes et de eharansons se logent aussi dans les fruits, et se nourrissent de leur pulpe. Les cerises, surtont les espèces à chair ferme et louee, connues génćralement sous le nom de bigrarraux ou en provençal gruffirens, sont souvent verreuses. Ces vess sont les larves du balaninus cerasorum, fab. oliv., cue. 
metl. et de la mouche du ecrisier tephritis cerasi. Thephritis cerasi Lat. Le eliaranson a sa tète terminée en avant. par un bee fin et alongré, ses jambes sont armées d'une petite épine, sa couleur est brune avec l'éeusson gris, et des liggnes transverses de la même eouleur sur les élytres : sa longueur est d'une lighe et demie. La taille de la mouelie est la même. Elle est noire, avee le tour du coreelet et l'éeusson blane, ses ailes sont tachetées de noir (Réaum. Mém. sur les Insect. , tom. 2, pl. 38 , fig. 22 et 25 ). D'autres larves de eliaranson, d'autres larves de mouches ou de diptères se rencontrent aussi dins les poires, les pommes, les prunes. Ce sont les eliaransons du prunier, curculio pruni, fab., oliv. Geoffr. 49: curculio pruni. l'altclabc blcu, inseete de liı même famille; le stelabe bleı. charanson des pommes, rhynchicnus pomorum, Mhynchinus fabr. éclui du poirier, polydrusus pyri, Dejean Polydresus pyri. Catal., oliv. fahr. Nou-senlement ees deux derniers miuent les fruits dans leur premier ćtat, mais devenus eoléoptères, ils rongent les feuilles et les fleurs. Deux ou trois espèces de mouehes attaquent ces mêmes fruits. Lianthonomus pomorum qui parâit dès le printemps reeoqueville même les pétales de la lleur du pommier qui se déforme et devient épaisse sans se développer et semblable ì un clou de gérofle.

- Le charanson gris, qui parait aussi de bonne Charanson gris. heure au priatemps, mange les bourgeons les 
Charanson pommiers et des poiriers. Te eharanson du Curculio mali. pommier, eureulio mali, oliv., autre eureulionite, dévore cenx dı pomnier. Le premier est cntièrement ggris cendré, de la longueur de deux lignes ou deux lignes et demie; son bec est très eourt, épais et obtus ou tronqué à son extrémité antéricure; ses cuisses ne sont pas épineuses, eomme celles du second, dont la coulcur est brune avee les pattes et les antennes testaećes ou roussâtres. Le rhyneh. pomarum, fal)., eité pumorum. plus hant, a les cuisses antérieures armées d'épines, son corps est d'un gris nébuleux ou 111 peu marbré.

Je ne me suis jamais aperenn que les dommages que peuvent causer ees espèees, soient très remarquables dans nos vergers. Le eharanson du prunier n'est pas conuu daus le midi ; mais en Suède sa grande abondanee est très nuisible. Si larve vit dans de petits tuberules ou vésieules qu'elle produit sur les feuilles de eet arbre, et qui les flétrissent et les font tomber. Liatlelabe apion cyaneum. bler, apion eyancum, déjà nommé plus haut, n'est long que d'une ligne et demic, d'un blen foneé, ses pattes sont noires, ses antennes non coudées mais en masse.

Il n'en est pas de même de la fausse ehenille de la tenthréde du eerisier. Elle dévore les feuilles de eet arbre et eneore plus celles dn poirier, au point de n'en laisser que le réseau, 
uprès avoir eonsumé tout le parenehyme. Ces arbres présentent ilors un aspeet hicleux, et le dommagre eausé aux feuilles est toujours nuisible à l'arbre même. Cette fausse chenille est ellemême désagréable à l'neil : elle est visqueuse, son corps est comme gélatineux, d'une eouleur de poix on vert-roussître. La partie antérieure est ordinairement plus grosse que le reste de son eorps, ear l'animal peut la dilater à sa volonté. La mouehe à seie, à laquelle elle donne naissanee, est noire, de $\mathbf{3}$ lignes de longueur, l'éeusson et les pattes sont jaunes, et les antennes sétaećes. Cet insecte est facile à apereevoir dans l'état de larve. Il faut lui faire une eliasse assidne partont où on le trouve; Il n'y a pas d'autre remède.

Plusicurs espèecs de hannctons, surtout le uelolontha mulgaris; plusieurs cétoines, les Hannetons melolontha vulgaris. unes remarquables par leur brillante robe d'un vert doré, les autres par les poils roussîtres on gris qui reeouvrent leur eorps de coulenr noire; une autre espèce du même genre qui est noire taehetée de blane, mangent les fleurs et les feuilles de divers arbres fruitiers. Les deax dernières; cetonia hirta, cetonia stictica, paraissent dès le commeneement du printemps. Leurs ra- Celonia tirta. vages, en sićtendant ì toutes les fleurs, devienuent moins nuisibles, et celles des arbres fruitiers en souffreut moins : eependant on doit les regarder comme des inseetes qưil est utile de 
détruirc. On pourrait facilemcut les faire ramasser par des enfants; elles sont de grande taille et très visibles. On les tronve en abondanee sur les roses. Le hanneton vulgaire et les autres hannetons, ne nous eausent pas les déģâts qu'elles oeensionnent dans les provinees du nord.

Un inseete très malfaisant et qui dégrade le du puirier.
Tingit pyri.

feuillagye du poirier pendant tout l'été, est celui quc les jardiniers ont appelé le tigre, à cause de sa robe bigarrée, autrement lc puceron du poirier, il cst de la famille des punaises, Latreille l'appellc tingis pyri. Sa forme cst extrémement remarquable. Son eoreelet, ses élytres, tout son corps est entouré d'un large rebord applati, diapliane, festouné sur ses côtés; sa couleur est grris-cendréc, marquée de bandes ou taches noires. Sa taille est très petile, une liggne $1 / 3$ an plus; mais sa multiplication est extrême. Il finit plusieurs pontes sueeessives dans le courant de l'été; le revers des feuilles du poirier en est convert; la trompe aeérćedont sa bonehe est munic pompe leur suc; elles se fanent, preunent une couleur livide et se dessèchent. Cet insecte préfère en grénéral les espaliers. On peut essayer eontre lui les recettes que nous indiquerons pour les pucerons; mais clles paraissent devoir être insuflisantes. Si le jardin est isolé, on pent eueillir toutes les f'euilles attarucées l'année oì eet inscete est le plus abondant, et en saerifiant ainsi dcux 
ans de réeolte, on peut espérer de se défendre dù même mal pour les années suivantes.

La larve d'un très petit insecte, cecidomyia Cecidomyia pyri. pyri, Blot (Jomrnal Aeadém. d’Industric , 1832, p. 197.) se loge sous les bords des feuilles du même arbre; par l'effet de ses piqûres, ils se ronlent en spirale et se reeoquevillent; la feuille devient galeuse, se noireit, se fane et tombe; alors les vers se laissent glisser ì terre, ils s'y changent en ehrysalides et donnent naissance à des moucherons qui s'approchent, par leur figure ef lenrs earactères, de eehi que jạ dessiné comme provenant du ver du blé. Leur existenee, sous la forme de ver ou de larve, est d'environ trois semaines. Cet inseete donne trois générations par annéc: une an printemps, une en été qui n'a pas lien avant la S'-Jean, et une dernière en automne. En profitant de eette observation, si l'on ébonrgeonne soigneusement les poiriers ittilynés un peu avant la S'-abean, on les préservera néeessaitrement des alteintes de ee diptère. il ne s'agit que de faire 15 jours plutôt, ee que l'on fait 15 jonrs plus tard. Voilà ee qu'en dit M. IBlot dans le journal eitć. Je n'ai pas vu cet insecte daus nos contrées du midi.

Le pêeher est sujet à être infesté par ıme espèce de cochenille ou chermès, ovale, alongé, d'une couleur brum-tanuéc : il est très musible ì eet arbre. Comme le pêcher est ordinarement 
plus petit que l'olivier, qu'on ne le plante que dans des jardins ou des enclos, il est beaueoup plus facile d'appliquer à ectte cochenille le remède que j'ai indiqué au sujet de eclle de l'olivier. Un jardinier d'Aix, le sieur Miehel, est parvenu à se débarrasser des clicrmès du pêeher, en arrosant d'un lait de eliaux toutes les branches attaquées ou du moins les places oecupées par ees inseetes. Le même proeédé peut s'appliquer aux

Du prubier. elıcrmès des autres arbres. Les pruniers sont aussi sujets aux cochenilles d'une autre espèec. J'ai déjà dit, dans mon chapitre de l'olivier et dans celui de la vigne, combien ees animaux étaient nuisibles aux arbres auxquels ils s'attaDu घguier. ehent. Ils font beancoup de mal aux figuiers dans les parties de nos départements où la ehaleur est plusforte, particulièrement dans le Var; ils s'attachent mêmes aux figues, et les fout tomber sans les laisser mûrir. M. Bernard, dans son execllent Mémoire sur le Fiģuier, a siggnalé cette espèce et ses dommages.

Les puecrons sont le fléau de presque tous les arbres et toutes les plantes. Je n'en parle pas iei; je renvoie au chapitre où je traiterai des inseetes nuisibles à plusieurs sortes de véggétaux en géénéral.

Lucane

Le bois même, l'intérieur des branches du pommier, du prunier et de quelques autres arbres rucane
paraltelipipidc. fruiticrs, devient la proie de plusieurs larves 
d'insectes. Celle du lucane cerf-volant, du lucanc parallélipipède, du sinodendron cylindrique, $\begin{gathered}\text { Synodendron } \\ \text { cylindrique. }\end{gathered}$ s'attachent au pommier. La saperde cylindrique attaque le poirier, le prunier; elle ronge la moëlle des rameaux. Le coléoptère qui naît de cylindrique. lia larve est de la fimille des capricornes ou longieornes. Ses antennes sont aussi longues que le corps qui est alongé ct cylindrique; ses élytres sout d'un noir ardoisé, et ses pattes antérieures jaunâtres. Il est très-difficile de déloger cette larve de sa retraite. On conseille dintroluire dans cette cavité, après en avoir remarqué lissne, un fil de fer assoupli an feu, et rendn propre à s'insinuer dans les replis, jusqu'à ce qu'il ait alteint et pereé l'animal. L'issue se reconnait ordinairement par les excréments qui l'eutourent; mais on ne peut pas se promettre d'atteindre toujours la larve par ce moyen. Il devient inntile si la galerie qu'elle a crensée est trop prolongée, si l'insecte est logé à l'extrémité sıpéricure, et surtout si les détours de sa retraite sout trop multipliés : on pent dn moins en tenter l'usage.

Les fruits dans leur maturité, ou avant même

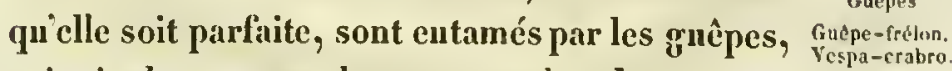
prineipalement par la grosse espèce de ee genre conuue sous le nom de guêpe-frclon, vcspa crabro, en provenęal cabridan. Il n'est pas trèsaisé de chasser ces animaux redoutables par leur 
terribles piqûres. J'ai vu pratiquer un moyen qui a réussi à mon propre jardinier. Il suspendait aux branehes de l'arbre de petites plioles à embonehure un peu large, qu'il remplissait à moitié d'eau fortement miellée ou suerće; sa donceur attirait les frelons, qui, ne pouvant IIus en sortir, s'y noyaient: proeédé qui an reste est eonnu. La gruêpe-frelon fait ordinairement son nid sous la terre. Il est peuplé d'un grand nombre d'individus; on les $y$ voit entrer et en sortir par l'issue qưils ont ménagée. Si l'agrienlteur les apereoit, il doit saisir loceasion et introduire par le trou une gnantité d'eau bouillante suffisante pour étouffer tous los habitants.

Capricornes. II amaticherus heros, miles. Lamia tristis Mange-père.

Plusieurs sortes de grands capricornes on de lamies, tels que hamaticherus heros, hamaticherus miles, lamia tristis, rongent anssi quelquefois les poires. On leur donne en notre langrage vulgaire le nom de mange-pére. Mais les déģats quils peuvent faire eomptent peu : la grosseur de ees inseetes les rend aussi faeiles à aperecvoir qu’à saisir, et leur nombre n'est jamais assez eonsidérable pour les rendre dangerenx.

(1) Le Rhynchrtes Bacchus que nous avons indiqué plus haut, comme nujsible aux feuilles des vignes, a fait des dégàts considérables anx pommiers, tant dar. la Bric, en 1833 ou 34, qu’en Normandie, dans l'été de 1836 . Il s'y était multiplié d'une maniere extraordinaire. (Annales de la soc. entomol. 5 e trimestre 1837.) 


\section{CHAPITRE VI.}

DES ARRRES UTILES OU D'AGRÉMENT.

Le mûrier est avant tout au nombre des premicrs. La racine des jeuncs arbres de cette espèce si précieuse au commerce ct à l'agriculture, est quelquefois sujette aux attaques du ver blanc, larve du hanneton, dout il a déjà été question, cluapitre de la vignc. Rosier preserit pour l'extirper, dans le cas actucl, de faire un trou au pied de l'arbre, et de le remplir de plusieurs sceaux d'can simple ou micux encorc dans laquelle on fait étcindre et détremper de la chaux vive.

La chenille du bombyx proecssionnaire vit en familles très-nombreuses sur le eliêne. Elle processionnaire. file un nid de soie très-volumincux qu'elle applique an tronc on aux grosses branehes de l'arbre. Les ehenilles en sortent, surtout Ia 
nuit, pour aller butiner, et leur marehe imite alors eelle diune procession, n'allant qu'une ì une, à la suite l'une de l'autre, et formant ainsi des files extrêmement longües. Elles dépouillent totalement les ehênes de leurs feuilles, s'attiachant de préférenee à eeux qui sont ì la lisière des bois. Cette ehenille a le dos noirâtre, elle est assez velue, ses poils sont plus longss sur les cûtés qui sont d'un gris assez clair. La chenille elle-nême, et eneore plus ses nids, sont redontables, parec que les poils qui s'en détachent eausent à la peau, surtout anx endroits plus délieats, tels que les lèvres, le palais, le gosier, les paupières, une cuisson insupportable ; ils lorment en se brisant facilement, une poussière que la respiration et le soufle font pénétrer partout. La chenille se elange en ehrysalide dans le nid même, après avoir vécu sur les arbres toute la dernière moitić d'avril et le mois suivant. Le bombyx éelot au hout de trois on quatre senraines. Il est d'un gris obseur : le derrière de la femelle est chargé d'une épaisse conche de poils on écailles noires, dont elle se sert pour recouvrir ses oenfs qu'elle pond par paguets; eette couverture les préserve de la pluie et. lent fait passer ehandement l'hiver. Heurenx l'amateur des bois et des arbres sil pent trouver ees nils et les anéantir. Je ne vois pas d'autre moyen de combattre ectte espèce; celui que 
jindiquerai eontre la suivante pourrait peut-ìtre réussir jusquı à un eertain point.

La proeessionnaire du pin ou ehenille dn procrssionnaire bombyx pillyocampa est encore plus dommageable à eet arbre, que celle dont nous venons dul pin. de parler, l'est au elêne. Ses mœur's sont les mêmes : son nid est placé en quenouille autour des branches; sa marche est aussi processionnelle, mais le plus sonvent eommenȩant par un seul individu, tandis que le rangr suivant est de deux, quelquefois le troisième de trois; après eela la progression s'arrête ordinairement et les rangs suivants sont assez constamment de deux ou trois de front. Ses poils, entremèlés sur ehaque anneau du eorps d'espèees d'éeailles dorées, sont d'un roux vif. Ils sont aussi sujets ì oceasionner de violentes démangeaisons quion guuérit ainsi que eelles de la proeessionnaire dn chêne, en frottant avee du vinaigre étendu dans de l'eau fraîhe les parties qui en sont affeetées. Ces elıenilles qui paraissent sur les arbres dès le mois d'octohre, sortent de leur nid pour se métanorploser en terre à la fin d'avril. Elles la quittent au bont de trois semaines ou un mois en état de bombyx. Sa forme est la mème que eelle du B. processionca; ses eouleur's difficrent; ses premières ailes sont d'un gris eendré avec des raies ondées noires; les seeondes sont 
blanehes : l'abdomen de la femelle est eouvert à son extrémité d'un paquet de petites écailles brun-dlorées. Elle pond ses oufs autour d'une feuille de pin, en spirale; leur assemblage forme un eylindre alongé; elle le recouvre eutièrement avec les ćeailles de son ventre, sur lesfuelles la pluie golisse aisément sans pénétrer. Cette ehenille dévaste totalement les bois de pins. Elle est très-multiplice "dans nos provinees; les froils extraordinaires arrètent seuls sa propagation. Elle est ì peu près aussi difficile à combattre que celle du chène. W'ai vu cependant détruire les nids et anéantir les chenilles, (qui n'ont plus de vie et de force quand elles sont préeipitées, abattues et isolées ) par un coup de fusil chargé de petit plomb, et tiré au milieu du nid. L'eau de elıaux, l'eau de savon, le goudron dissout dans l'essenee de térébenthine, peurent s'essayer contre ces ehenilles ainsi que je l'ai indiqué dans un préeédent elıapitre. Les deux premiers proeélés m'ont rénssi contre les processionnaires du pin. Mais ils sont bien diffieiles ì employer, quand les nids sont plaeés fort hautsur l'arbre. Le dépôt de leurs oufs, qui est beaucoup plus faeile ì apereevoir que celui de la proeessionnaire du chêne, oflre eneore un moyen facile et sûr d'arrêter leur multiplieation. Mais il faut les cherecher sur les pins pour les jetter au feu, 
avant septembre, les petites chenilles devant quitter les oufs vers cette époque.

Le elhêne, sitôt après le développement de ses premières feuilles, et tant qu'elles sont encore un peu tendres, est la proie d'une infinité de clienilles. Il est inutile de les déerire, mème de les signaler toutes. Leurs ravages sur cet arbre de haute futaie, n'approchent jamais de ceux des proeessionnaires. Sils devenaient plus considérables, l'échenillagge serait à peine praticable, ì cause de la hauteur des branehes. On ne pourrait pas même avoir recours aux feux indiqués plus haut pour attirer les papillons nocturnes qui suceèdent ì ces elicnilles et les reproduisent à leur tour, parce que ces diverses espèces éclosent à des époques très varićes, quelque-unes même l'automne ou l'hiver suivant sculement. Les chenilles à livrée et à oreilles, sheniltes déerites dans le chapitre préeédent, sont dı. at areilies: nombre de eelles qui font le plus de mal aux chènes.

Les glands recèlent presque toujours un ver ver des plands: ou larve qui donne ensuite naissance à un chades nois. ranson balanimes nucum. Il se distingue par sa des noisettes trompe au moins deux fois plus longue que le reste du corps. Sa couleur est roux-tannée avec quelques ondes plus foncées. La larve ronge les gylands, les noisettes, les noix. Elle est blanesale, sans pattes, assez courte et un peu renfléc, 
repliée en demi-cerele sur elle-mềme dans sa retraite. Elle hâte on force la matırité des glands et les fait tomber prématurément. Elle les rend impropres à la germination, mais les bestiaux peuvent se nourrir sans aucun ineonvénient de ceux qui en sont attaqués. Il n'y a d'aillemrs aucun remède possible. Il cst bon seulement de connaitre le charanson dans son état parfait, et de prévenic sa reproduction en le tuant quand on le reneontre.

La larve du lucanc cerf-volant, celle des grands copricornes, vivent dans l'intévicur des rameaux du chêne et de plusieurs autres arbres; elles sont assez semblables au ver-blanc dn lanneton. Je crois que la première vit dans les raeines du clıêne comme dans ses branches. Les raneaux morts que l'on voit fréquemment ì la cime des arbres les plus vigoureux viennent eertainement de ces diverses larves. Mais quel remèle peut-on indiquer? Il faut faire la guerre anx colécptères qui reproduisent ces larves. Tout le monde connaît le eerf-volant remarquable par ses énormes mandibules qui se prolongent en forme de cornes en avant de sa tête. La fenclle n'est pas armée du même instrument. Les capricornes se font reconnaître par leur ģrande stature, leur conleur noirâtre, et leurs antennes à gros articles noucux, aussi longues ou phis longues que leur corps. 
Les promenades publiques de nos villes, les bosquets de nos eampagunes, sont salis une partie de l'été par la larve de la galleruca calmariensis. Elle tombe des ormes où elle se trouve en si grande quantité, qu'après avoir rongé toutes leurs feuilles dont elle mange le parenehyme en laissant les nervures et la membrane, ees arbres restent dépouillés, ne présentant pour feuillaģe que de sales et livides dentelles. Il niest pis d'anuée wù elle n'exeree ses ravages, et de temps ì autre ils deviennent exeessifs. Cette larve est brune sur le dos avee quelques petits points jaunâtres; ses eôtés et son ventre sont jaunes. Elle u'a que six pattes à la partie antérieure de son eorps, et e'est à tort qu'on lui donne vulgairement le nom de ehenille qui ne doit s'appliquer qu'aux larves produisant des papillons. J'ai quelque regret d'ajouter, qu'iei eneore, les remèdes sont nuls. Le coléoptère auquel la larve donne naissance est d'un vert un peu jaunâtre; ses élytres ont une bande latérale noire, et une autre sur le milieu de ehaeune qui ne va pas jusqu'au bout. Elle pond ses oufs sur les feuilles de l'orme, serrés les uns à 'eòtés des autres; ils sont petits, jaunes, ovales, un peu pointus à leur extrénité supérieure.

La elienille commune, bombyx chysorrher, dont jai parlé à l'artiele du poumier, vit anssi sur les orne's. 
Mais la peste la plus terrible de ce bel arbre est la ehenille du cossus ligniperda ou gâte-bois. Cette très-grrosse espèce vit dans lintéricur de l'arbre et se nourrit de l'aubier. Les arbres épuisés languissent et périssent. Le mal se répaud rapidement. On a vu les bords des grraudes routes complantés en ormes se dégarnir entièrement; les promenades publiques, les bosquets des partieuliers ne laissent voir elıaque année que des trones morts et dessécliés. Il faut faire connaître et la ehenille et le papillon. La première est d'un rouge sombre et salc sur le dos, ses eôtés et son ventre sont d'un jaune blauehâtre. Elle est rase et sans poils distinets; elle exhale une odeur fétide. Je l'ai souvent rencontrée rampant sur le sol, soit elierehant un asile pour se métamorphoser; soit pour aller d'un arbe ì l'autre. Fille passe son état de chrysalide dans l'intérieur même du bois où elle a véeu. Quant au papillon, il est de la elasse des noeturnes, à gros ventre, à antennes épaisses et légèrement dentelées : il est d'un gris eendré un peu perlé et varié d'un grand nombre de raies transverses, irréğlières, noires; ses ailes inféricures sont noirâtres. Sa démarelse et sou vol sont lourds. Lauimal est pesant et ne peut aller loin. On gaguerait done ì eouper ou arracher les arbres morts sans les remplacer d'un an ou denx. Si on les remplaee, le papillon de 
larbre voisin trouvant les nouveaux à sa portée, peut y déposer ses oufs. Mais si l'intervalle est considérable, il ne peut le franchir, et le mal est interrompu. Le cossus éclot et sort des arbres pendant une quinzaine de jours environ en juin, plus tôt ou plus tard, suivant la préeoeité des claleurs. Sa sortie a toujours lieu, dit Bose ( $N$. cours complet d'agric.), depuis neul'heures du matin jusqu'à trois heures du soir. Il ne bouge pas du lieu où il est éelos et du tronc de l'arbre jusqu'à ee que la nuit commence; alor's seulement il peut prendre son vol. Il faut done profiter de ces heures pour lui donner la cliasse : on peut y employer des femmes et des enfints. Bose caleule qu'en payant un ou deux sols par papillon, moyennant un déboursé qui ne dépasserait pas $150 \mathrm{fr}$, on épargneruit aux environs de Paris un dommage quil évalue à $\$ 0,000$ f:. par au. Le fil de fer, dont j’ai parlé dans le chitpitre ei-dessus, ne rénssirait pas toujours poụ" alteindre la ehenille dans sa retraite. Il faut diabord counaitre le trou extérienr, et pour cela on est quelquefois obligé d'enlever l'ćcorce : souvent la galerie qu'a ereuséc linseete est tortucuse et savance vers le cour de larbre, comment alor's sera-t-ou sûr de l'atteindre? Cette chenille vit anssi dans lintérieur du saule.

Celle du zeuzera resenli cause le mêue dlommagye en vivant de la mène manière dans lés 
rameaux du maronnier, du saule, du peuplier, de l'érable, du frêne, de laulne. Elle muit heancoup aux pépinières dont les sujets sont moins ell état de lui résister. Elle pénètre aı eentre "lu jeune arbre et remontc la tige en suivant le canal médullaire. On peut tout au plus dans certains eas essayer le fil de fer. Le papillon qui est aussi de la tribu des bombyeites a le coreelet un peu laineux, les antennes très-eourtes; il est blane, parsemé de gros points d'un noir bleuâtre, ses ailes sont étroites et oblongues, les inférienres sont noirâtres.

Sisir.

Les ehenilles de plusieurs espèces de sésie, genre de lépidoptère erépusculaire à ailes ordinairement vitrées et étroites, vivent aussi dans lintérieur des arbres, surtont des différentes espèees de peupliers.

Les ehenilles des hépiales rongent les racines des plantes et des arbustes. Une espèee de ee genre habite dans eelles du houblon, plante qu'on cultive dans plusieurs localités pour servir à faire la bière. Elle se transforme sous terre, et lorsque le papillon doit éelore vers la fin du printemps, la elıysalide sort à moitié du sol et reste ainsi exposéc à l'air pendant quelques jours. La forme du papillon ressemble betuleoup ì eelle du zeuzera resculi. Sa couleur est trèsdifférente dans les deux sexes. Ise mîle a les ailes supérieures blanehes, et la femelle les a 
jaunes avec des raies rougeâtres: leurs antennes sont aussi fort eourtes.

La larve de la cigale eommune vit sous terre; La Cigale elle reste deux on trois ans sous cette forme. Elle sattache anx diverses racines, à celles des arbres et des plantes utiles, eomme aux autres. Elle les suce senlement avee sa trompe, et ne fait par eonséquent qu'assez peu de dommage. La eigale n'est pas plus dangereuse dans son état parfait, malgré la grande nultitude de ees inseetes.

Les larves de diverses sortes de saperiles, ģenre de eoléoptères dont nous avons déjà parlé à l'artiele des pruniers, attaqueut aussi l'intérieur das bianehes des peupliers, des saules et des autres arbres. La saperda eareharias, la plus grosse de toutes, la saperda oeulata, saperda populuea, s'attaeltent ì ees premiers arbres : la saperda linearis, aux noisettiers, la saperda sealaris, au peuplier, à l'érable à feuille de syeomore. Elles produisent des nodosités assez. remarquables sur les rameaux; la larve $\mathrm{y}$ vit, s.y transforme et en sort dans son état de perfeetion. La saperda tremula a fait périr ì Toulouse, il y a déjà plusieurs années, une grande quantité de peupliers blanes et de trembles (Bosc ibid.) Je l'ai trouvée souvent iei, dans sou dernier état, dons le premier de ees arbres. Elle est d'un vert tendre, parsemée de points noirs.

Saperda carcharias, oculata , populnea, calaris, linearis, tremule. 
Chrysomela popoli, tremulis.

Chrysomile à 10 points.

Les larves de la chysomela populi et de la chrysomcla tremuloe nuisent très-souvent aussi aux feuilles du peuplier commun, du tremble et dı saule. Le premier coléoptère est ronge-vif, quand il est en vie, avec un point noir à l'extrémité des élytres et le corcelet noir-bleuâtre. Celui du second est bronzé ou cuivreux, et ses élytres du même ronge; mais sa taille est plus petite du double. Leurs larves assez semblables sont de la même forme que celle de la galleruca calmaricnsis, brunes avec quelques nnanees ou points jaunâtres. Les inseetes parfaits se trouvent sur les mênes arbres que les larves. Ces deux espèees sont très eommunes, mais je ne sais aueun remède pour s'en défendre, qu'une reeherehe assidue. La chrysumc̀lc is 10 points dévaste le saule mareeau. Elle est jaune avee 10 points noirs : elle est pen commune ehez nous. Les antennes des chrysomèles sont assez longues et composées d'artieles un peu nouenx : leur eorps est ovale, un peu bombé.

Gialleruea a ani. Ia gallerieca alni ronge les feuilles de l'aulne, et les réduit au mème état que la galleruca calmariensis produit sur les fenilles de l'orme. La gall. alni dans son état de coléoptère est d'un bean bleu lustré. Sa forme est la même que eelle de la calmariensis, mais elle est trois ou quatre fois plus grande et son corps est proportionnellement un pen plus large. 
Une chenille arpenteuse à $\mathbf{1 0}$ pattes, rayée de noir, de jaune et de bleu, dévore les feuilles des frênes. Ces arbres en sont quelquefois tont couverts. Un gुrand coup d'un fort bâton appliqué see, comme je l'ai déjà dit, les fiut tomber en grand nombre et dounc le moyen de s'en défaire. Elle vit en automne ou sur la fin de l'été, se transforme près de la surface de la terre, et donne la phaloena ulmaria dont les ailes sont blanches avee quelques ondes et taches conleur de rouille : son eorps est jaune pointillé de noir; ses anteunes sétacées dans les denx sexes.

Eneore une chenille, celle de la pyjralis chlo- ${ }^{\text {Pyralis entorana }}$ raua, lie en paquet les fenilles des osiers. Comme elle se tient au sounmet des tiges, elle unit à leur longueur, et c'est eette longuenr qui fait leur prix dans le commeree. On ne remédierait point au mal en arrachant lene nid; il faut done convenir qu'il n'y a anemn moyen de se soustraire ì ce dlominagye qui leureusement n'est pas toujours très-fréquent. En observant le temps où elle éelot, que je ne pris indiquer iei, n'ayant pas assez observé cette chenille, on ponurait essayer le procédé des feux de fagots, dont on a déjà parlé. Cette pyrale d'assez petite taille est d'un vert tendre; ses ailes arrondies ì leur base s'élargissent carrément sur les eôtés et imitent la forme d'une cliappe.

L'oranger dans nos serres, comme en pleine $\begin{gathered}\text { Chermis } \\ \text { de l'oranger. }\end{gathered}$ 
terre dans les pays où il peut supporter l'hiver", est sujet aux atteintes d'un ehermès semblable ì eelui du pêcher, plus petit, mais qui n'est pas moins nuisible à ees arbres dont il altère et flétrit les feuilles. On peut lui appliquer les procédés déjà désignnés pour les autres espèees de coehenilles ou même contre les puecrons. Il 'est connu sous le nom mal appliqué de puncise de l'oranger.

Fourmis. Les fourmis ne font pas de mal réel à cet arbre, non plus qu'aux autres, malgré l'opinion trop répandue parmi les agyricul teurs. Mais quand les orangers sont dans des eaisses ou des vases, elles peuvent seulement déeouvrir et fatiguter les raeines en fouillant et labourant la terre. On y obvie en mettant, sous elaque pied des eaisses, des terrines, en pratiquant aux vases une gorge qui en fait tout le tour; en remplissaut d'eau les unes et les autres; en entouraut le pied de l'arbre d'une eeinture d'épis de blé barbu dirigésen en bas qui empêehe les fourmis d'y grimper. Au reste cet inseete n'a d'autre rapport avee les chermès et les puecrons que d'être attiré par la liqueur miellée quilis distillent, ou par la sève dont ils causent l'épanehement extérient. C'est une grande erreur de croire que les fourmis apportent les pueerons sur les arbees. 


\title{
CHAPITRE VII.
}

\author{
DES INSECTES QUi NUISENT AU JARDINAGE, AUX

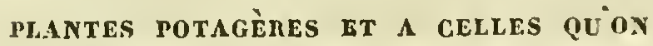 \\ CULTIVE DANS LES CHAMPS.
}

C'est iei que les dégầts sont très-multipliés, soit par le nombre des espèees nuisibles, soit paree que les véşétaux étant moins gyrands supportent moins leurs ravages, qui souvent les détruisent depuis la racine jusqu'aux dernières feuilles.

La elienille de la plusia gamma, Duponelıel, Phusia ganma. est extrèmement eommune; quoique presque toutes les plantes lui soient bonnes, elle n'épargne pas davantage eelles'qui nous sont utiles. On la trouve sur la jacobée, la renouée, les ehardons, la sauge, l'absinthe, ete.; mais elle dévaste souvent les plantations de chou, de chicorée, de laitue, de pois, de 
fèves, le trèlle, le chanvre, les haricots. Elle a cecasionné de grandes pertes sur ees deux dernières espèees, ainsi qu'en Alsace sur les plantations de talne. Ce fut surtont en 1735, que les ravages de eette chenille furent immenses dans une grande partie du royaume; ils sétendirent depuis Paris où les jardins s'en ressentirent prodigieusenent, jusqu“à 'Tonrs, jusques en Anverghe et en Bonrgogne; ì Chartres elle attagua même les avoines. Ces ehenilles durèrent depuis lit fin de juin jusqu’à celle de juillet. Elles étrient si nonibreuses qu'on les reneontrait en troupes traversant les chemins. Une mallieureuse influence de l'itmosphère et de la saison oecasionna cette funeste multiplication dont on aurait de la peine à assignner la cause préeise; mais qui heureusement ne se renouvelle pas souvent. Cette chenille parait deux fois chaque année, à l'épơque que je viens de désiģner et alu mois d'avril. Si rien n'arrêtait sa propagation, dans les années ordinaires, elle serait telle d'après le calenl de Réanmur que 20 papillons senlement dont la moitié sernient femelles devraient donner dans un an 800,000 chenilles, un jardinier qui en tuerait deux pourrait se flatter d'avoir empêelcé la production le 80,000. Cette chenille est d'un vert pâle avec quelques poils blanchâtres, parsemés et 
rares, sur le eorps; elle n'a que 12 pattes. Réaumur en eite une variété, qui est d'un vert foné avee trois raies jaunes. L'une et l'autre font leur cocon entre des feuilles ou de petites branehes, ou dans quelque retraite à leur portée; j’en ai trouvé sous des écorees oll sous des pierres. Il en sort au bout de 16 à 17 jours un papillon nocturne, le même pour les deux varietés de ehenilles, qui est d'un brun lustré avee un reflet métallique et quelques nuanees plus elaires, ses premières àiles sont surtout remarquables par une tache d'uu blane arģenté qui représente axaetement un $\mathbf{Y}$ our la lettre greeque gamma. Son eoreclet est orné de houppes de poils qui forment une espèee de erĉte. Réaumur engage les jardiniers à s'armer d'un filet fait pour ehasser les papillons, et ì en prendre pour les détruire autant qu’it leur sera possible. D'après le ealeul ei-dessus, on gagnerait beareoup à se livrer à ect exereiee, an moins dans les moments de repos des journaliers. Il en serait de même de la elıase aux deux espèees de papillous blanes du ehou dont nous parlerons tout à l'heure. Pour en revenir à la ehenille de plusia gamma, on erut dans le temps qu'elle avait eausé des maladies, la mort uncue, à eenx que l'on supposait en avoir avalé avee des léguines, des laitues. Celte 
opinion n'est fondée sur aueun fait avéré, ne parait nullement vraissemblable, et n'était die quà des terreurs exagérées ou plntôt sans aueun fondement. La ehenille et le papillon sont très communs ici l'un et l'autre; quoique heureusement il ne s'y fassent pas ordinairement remarquer par de grands dégâts. Le papillon contre l'habitude des noeturnes vole continuellement pendant le jour sur les fleurs. C'est peut-être son apparition aux heures oì le soleil nous éelaire, qui en la rapprochant davantage de nos regards nous fait eroire quielle abonde plus que d'antres espèces aussi communes, mais qui éehappent la nuit ì nos yeir.

Plusia chalcites.

Une autre chenille, fort ressemblante, mais

Tomates. bien plus rare, dévore les feuilles des tomates; solanum lycopersicon, son papilion, du même genre que le précédent, est d'une couleur encore plus lustrée, presque entièrement dorée avee quelques nuanees plus brunes, plusia chalcites; elle se trouve prineipalenent dans nos contrées méridionales.

Ninctes pronula.

Les noctua pronuba, brassica, pisi donnent naissanee à des ehenilles qui passent une partic Nortua pisi. de leur vie, eachées dans la terre. Elles en sortent ì l'entrée de la nuit, pour se nourrir des feuilles de diverses plantes. Elles s'y caclient de nouveau des que le jonr reparait. Les deux, 
prenières dévorent les feuilles des elioux, des navets, des raves, des autres plantes de eette famille. La pronuba se nourrit de beaueoup d'autres végètaux; mais elle ravage aussi quelque fois totalement les semés de elionx. La elienille de la noctua pisi attaque les pois, les gesses, et divers léģumes. On m’a parlé de grands dommages eausés dans le département du Var sur les harieots noirs, dolichos ungui culatus, réeolte importante dans ees quartiers; je soupconne quils sont dus ì cette dernière elienille, quoique au reste je ne l'aie jamais reneontrée, et quieu général ses dégầts soient plus eommins dans le nord quiei. La noctua pronulia est grande, ses premières ailes sont brunes ou d'un gris terreux; les seeondes d'un beau jaune avee une large bordure noire. Sa elienille est d'un vert jaunâtre ou d'une eouleur obseure à deux rangs de taehes noires le long du dos. Celle de la noctua brassicre ronge. les raeines même du ehou et les feuilles du tabae. Elle est d'un gris jaunâtre marbré, de brun avee eing raies longitudinales pâles; ou bien d'un vert foncé également marbré de noir avee les mêmes lighnes. Il est plus aisé de la trouver dans sa jeunesse; plus ģrande, clle se loge souvent dins le exur même de la plante, et alors on ne l'aperȩoit pas, et ses ravges ne paraissent que quand on ne peut plus gunère y remédier. On la trouve sur les 
plantes depuis le eommencement de juillet, jusqu à la fin de septembre; le papillon neéelot qu'au printemps suivant; il est nocturue, hadena brassica; il est noirâtre avec des ondes ou des nuances plus claires, parmi lesquelles on remarque une petite tache en crochet, plus noirc que le fond. La noctua pisi est roussâtre, ses premières ailes sont coupées par trois liģnes jaunâtres, ondées ou en ziggzag; la dernière de ees lignnes se termine en une tache blanche au eoin inférieur de l'aile. La ehenille est vert-noirâtre ou brun-violet avec deux raies longitudinales citron de ehaque côté du corps. Parvenuc en septembre ì toute sal croissance, ellc se métanorphose en terre, d'où le papillon sort an retour du beau temps.

Che autre ehenille ronge aussi les diverses plantes potagyères, surtout les laitnes; les jardiniers la connaissent bien sous le non de ver gris. ver-yris. Elle s'attache surtout au cocur des plantes et mème à leur raeine, sans eependant épargner les feuilles. Elle est grrise, ponetuée de noir, avec nne ligne dorsale brune et une

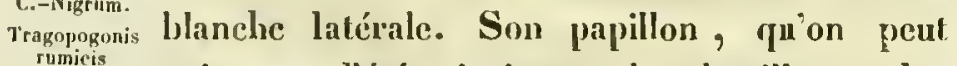
on del'oseille. voir tout l'été ainsi que la elhenille, a les Exoleta. ailes antéricures d'un brun coulenr de rouille avec un croissant jaane et une ligne blanelıe, tridentéc, transverse: ses ailes sont en foit et son eoreelet orné d'une huppe en erète, nocha oleracea. Les noctues de la laituc, $C$. 
Nigrum, Tragopogonis, Rumieis ou de l'oseille, exoleta, vivent aussi sur les ilivers légumes de nos jardins.

C'est à la lueur diune lanterne quil fiut chereher, la nuit on le soir, ces sortes de chenilles quanıl les plantes rongées font soupȩonner leur existence. D'antres espìees restent toujours eaehées sous terre où elles ne vivent actua segetio
aquilina. que de raeines, telles que les ehenilles iles noctua segetis, aquilina, ruris, erassa, ete. Quand on s'aperęoit par la lanģueur des plantes que leurs racines souffrent, il fant fouir et lithourer la terre à leur pied : on déeouvre aisément les ehenilles. J'en ai reeneilli quelquefois un granil nombre de eette manière llans les elıamps, sous les racines de la petite gesse, lathyrus eicera, vulgairement grroutte, geissette. J'en ai trouvé l'antres sons des toufles de plantes saurages.

Partont nous avons à nous plaindre ile la larve des haunetons. Les pommes ile terre se Larve
des hanmetons. ressentent de ses attaques, comme en général tontes les raeines. Il faut défendre contre elle, soit les plate-baniles en terre de bruyère où l'on élève des plantes ilélieates, soit les conches dans les pays ılı nord. Le procédé qü indique Bose, eonsiste à asseoir ces eonehes sur un lit de sable ıle upuatre pouees d'épaisseur, il empêehe cette larve, qui s'enfonec pendant l'hiver 
quelquefois à six pieds de profondeur, de remonter au printemps jusqu’à la plate-bande, paree qu'elle n'aime pas le sable où elle ne peut trouver sa subsistanee. Le sable a Yavantage d'éearter en même temps et les lombries ou vers de terre et les courtilières.

L.3 Courtiliere.

Taupe-grillon.

C'est ee dernier insecte qui mérite plus pentêtre qu'aueun autre, toute notre attention, et sur lequel nous devons nons étendre davintage. Lc dégâât quil eause dans les jardins est inmense : il faut souvent alsandonner le loeal et changer la eulture. Le proverbe allemand sur eet inseete est eonnu, et donne la mesure du dommage qu'on en redonte. Un voiturier, dit-il, doit arrêter sa voiture ehargée, füt-ee à la rampe d'une montagne, lorsquil reneontre une courtilière; et ne pas poursuive sa route qu'il ne l'ait tuée. On a eru longtemps que eet animal rongeait les raeines pour s'en nourrir. Féburier, dans le nouveau eours complet dagriculture, assure quil ne vit que d'inseetes, de lombries, de substances animales; et que sil coupe les racines des plantes, e'est pour frayer le passagye aux lougues galeries quil se ereuse sous terre. Ses pattes antéricures larges et dentelées en seie lui servent ì trancher avee une grande promptitude ce qui s'oppose à son travail. La foree de ees pattes est extraordinaire, on le ressent quand on saisit linseete entre les doigts; 
e est par eet organe seul quil résiste: il ue peut d'ailleurs faire aueun mal à la personne qui le tient. La durće de sa vie est fort longue, ce n'est qu'après la troisic̀me année qu'il peut se reproduire. C'est en juillet et août qu'il pond ses aufs au nombre de 200 environ. La taupegrillon, ( ear on lui donne également ee nom qui exprime à la fois ses habitudes et ses earaetères extérieurs ) boubiou dans notre patois méridional, ereuse un nid pour ses petits, il l'entoure d'une galerie eireulaire qui empêehe l'eau d'y pénétrer. En effet le nid lui-même, dont la terre est bien pressée et comme battue, est plus bas que la galerie et à un, deux ou trois pouees de profondeur au-dessous du terrain, suivant que la ehaleur est moins ou plus forte. Il est aisé à reeonnaître dans les prés, paree que le grazon soulevé en eet endroit et bientôt fané, forme nue petite motte. La mère, plus soigneuse que tous les autres inseetes, réside dans le nid quand les petits sont ćelos, les eouve en quelque sorte et les soigne jusqu'à leur première mue. Ce nid eommunique anx autres galeries que l'animal ereuse dans le terrain et qui ont quelquefois plus de 60 pieds de long, sans eompter les ramifications. Elles sont orlinairement plus profondes que le sul de $7,8,10$ pouees, selon le terrain et la température. Au eommeneement de la belle saison, les anciennes étant souvent 
rompues et oblitérées, les nouvelles ne sont pas encore aussi prolongées. C'est le moment dont. il fant profiter pour leur donucr la eliasse avee plus de sueeès. Le terreau des eouches les attire; il paraît qu'ils préfèrent le funier de eheval, taudis que celui de eoelıon leur déplait selon Linné.

Quand oll s'aperȩoit de la préseuce des courtilières, il fuut enlever d'abord le funier; on applanit eusnite la terre sans la battre, on voit alors les onvertures des galeries. On fait 11 rebord tout autonr de l'espace; on y verse un ou deux arrosoirs d'eau mêlée avee quelque peı d'huile, un verre à boire sur deux ou trois arrosoirs. L'eau pénètre dans les galeries, elle amène avee elle l'huile qui, bouehaut les organes respiratoires des courtilières, ou du uoins les inquiétant et les fatiģuant, les oblige ì quitter leur trou. On les saisit à leur sortic, si l'hnile ne les a pas tuées tont à fait; l'autenr cité assure que par ee moyeu il en a détruit jusqu'ì 1200 dans un quart d'heure.

Dans les terrains serrés, eeux oì le fumiel n'est pas entassé, quand on a aperçu on deviné une galerie de taupes-grillons, il fant la déeonvir et la suivre jusqu'à ee quion trouve le trou vertieal ou la galerie inelinée qui suceède ordinairement all chemin horizontal de l'inseete. Ce tron vertieal rend facile et ellieace l'infusion de 
l'eau huilée. On verse alors un demi-verre d'eau avee quelques gouttes d'huile, il périt par l'eflet de l'huile, s'il n’a pas pû parvenir ì s"éehapper.

Si la terre n'est pas compacte, si elle est nouvellement remuće ou sablonneuse, elle risque de s'ébouler dans l'opération, et l'animal s'éehapperait plus aisément. Pour obvier à ees ineonvénients, dit l'auteur de lartiele qu”iei je laisserai parler lui-même. "J'employai un moyen quui me mit à même d'en détruire une quantité prodiggieuse. Je suivais tous les détours des galeries des courtilières, jusqu à ee que je fusse parvenı au trou vertical. J'y plaẹais alors l'index de la unain gyanehe, et au moyen d'un ontil long diun pied aree le manehe, et se terminant pirr une plaque de fer aeérée largge de 4 à :̋ pouees, dont les eôtés étaient relevés en forme de levoir, je ereusais avee la main droite, jusqu’à ce que je fusse arrivé an fond du trou où je trouvais la courtilière. Cette marehe est la senle sûre dans tes terres nonvellement labourées. Si en suivant la galerie avee le doigt, je m'apereevais qu' elle faisait un petit eerele, $j$ 'avais la ecrtitude d'un nid plaeé an eentre de ee eerele, et que la mère était à quelque pas. Si je nanquais linseete, je redressais bien la terre, je la foulais un peu, et le lendemain j’y apereevais une légère élévation qui m'indiquait sa retraite. Je fouillais sur-le-ehamp, et le trou étant vertical et unique, 
paree que la eourtilière navait pas eu le temps d'en faire d'autre, $\ddot{j} y$ versais un peu d'ean avec une goutte d'huile, et elle ne pouvait m'éehapper. Comme il se tronvait quelquefois des plantes qui auraient pu souffrir de la fouille, je me eontentais alors de l'huile, après avoir bien découvert le trou vertieal et eonsolidé ses parois, jont enpêcher l'éboulement des terres. Je mis mes onvriers an fait de eette ebasse, et je lenr domnai une gratilieation par inseete et par nil, pour les eneonrager à eette reeherehe, pendant les lieures des repas. J'employai un autre moyen pour avoir des elassenrs de nuit, moment anquel les eourtilières se promènent quelqgnefois sur la terre, et sont, dans le temps de lenrs amour's, à l'entrée de leur trou. Je eommeneai par jetter des eourtilières vivantes à mes elıats; ils les mangeaient avec avidité. Ensuite jen plaeais sur la terre et j'empèchais les elıats d'y toneher, jusquà ee qu'elles se fussent enterrées. Jelìeliais alors les ehats, qui, avee leurs griffes, avaient bientôt déterré la eourtilière. "

Rosier, (Dict. dagric.) indigne deux autres moyens, répétés après lui, dans l'onvrage que je viens de eiter. Il faut avoir une caisse que lon remplit de fumier de eheval bien serré et bien battu. "Elle doit être pereée de deux eôtés d'ın trou earré de huit lignes ou d'un pouee d'ouverture. On l'enfouit dans une fosse en laissant un 
vide de quatie pouces environ entre les parois de la fosse et eeux de la eaisse. Ce vide se garni de fumier menu see et pailleux, dans lequel la courtilière tourne et retourne jusqu“ì ce qu'elle ait trouvé l'ouverture. Il est à propos que eette onverture soit plaeće à un pouce ou deux du niveau de la terre. Les autres eourfilières suivent la même route et se rendent dans lintérieur de la eaisse. Il est évident que le dessus de la eaisse doit être reeouvert de terre. A l'aide des eordes ou d'un levier, ou micux encore de deux mains de fer qui doivent ètre adaptées ì la eaisse, on l'enlève rapidement, et l'on se rend maitre des inseetes qu'elle eontient. On répète la mème manœuvre tous les quatre ì einq jours.

Un moyen plus simple et qui a servi seul à Autie chasse. Rosier à ell détruire un grand nombre dans les jardins, "c'est de placer deux balles de funier de litière à la tête de elraque petit ehemin tracé entre deux planelies de jardinage; on le piétine et on le laisse peudant einq à six jours ainsi amoncelé, et mêıne enterré. Avant le lever du soleil, un ou deux liommes armés d'une fourehe à trident, viennent doueement vers ehaque monceau et d'un seul coup l'éventrent et l'éparpillent. Ils voyent alors les taupes-grillous, et les tuent. Il est boi d'observer qn'il ne faut pas déranger l'ouverture des galeries qui eorrespondaient an 
fumier; après l'opération, le jardinier amoneelle à la même place le même fumier. Sil est devenu trop see, il l'arrose un peu et le piétine. Le lendemain ou le surlendemain au plus tard, il reeommenee sa ehasse de la même manière que la première fois, et ainsi de suite pendant toute la saison. " Elle est parfois infruetueuse, mais il ne faut pas se dégronter et renouveler le fumier de temps à autre, paree que l'odeur de eelui qui est plus frais attire davantage ees inseetes.

Voiei eneore un proećdé qui parât assez eflicaee, quioique d'une très simple exéeution. Plaeez des pots un peu ventrus, vernissés, de einq à six pouees, le long des murs et dans les sentiers qui séparent les earrés des jardins; remplissez-les d'eau jusqu'aux deux tiers, enfoncez-les ì un pouee ou deux an-dessous dn niveau dn sol. Les taupes-yrillons les reneontreront dans leur passage, ils y tomberont et s'y noyeront. Diantres inseetes même des rats, des mulots, y périront aussi.

L'auteur de l'artiele eité du N. Cours compl. d'Agric., Féburier, dit avoir détruit, par les divers moyens indiqués ei-dessus, jusqu’à $\mathbf{1 5 , 0 0 0}$ courtilières dans l'espaee d'un an, et dans un seul jardin, à Versailles. Ce seul fait pent faire jugger de limmense multiplieation d'un inseete si destrueteur. Il conseille de faire attention à naeheter que des fumiers ou des terraux dans 
lesquels on soit assuré quil n'existe pas de ces inseetes, du moins, si le termain dans lequel on loit les employer, est clos de murs, il ne pourra pas en venir de delıors, la courtilière ne pouvant pas grimper à cause de la pesantenr de son corps, et fesant rarement usage de ses ailes qui ne peuvent pas la porter loin.

On défend les melons de l'atteinte de ees inseetes en enfonçant en terre aulour de la plante ì une distanee de sept à huit ponees de son pied, des bâtons ou eannes très rapproehées, qui forment une enceinte quils ne peuvent franehir. II faut que ces bâtons soient enfoneés au moins de six à huit pouees.

Rosier dit que dans le Béarn on donne le nom de laire, à un colćoptère qui ronge les raeines du maïs ou blé de Turquie. Je ne connais pas cet inseete dont je n'ai vu nulle part la description. Je pense que ee doit être le scarabrus punctalus, ou quelque charanson, ou enfin la larve du lanneton.

Les cloportes, qui se multiplient très-rapidement, dévorent les semis, les graines qui gierment, surtout lorsqu'on les élève sous des chàssis ou sur eouehes. Ils vivent cependant aussi d'autres insectes dont ils font lenr proie. On s'en rend maitre en appliquant contre et raz de la couehe une planelie et sur la planelie un paillasson mouillé soulevé par de petites pierres,

Laire.

Scaraheus junctatus.

Mass. 
placées d'espace en espace. Les eloportes qui aiment l'olsscurité et l'linmidité, y choisissent leur asile; on peut les $\mathrm{y}$ prendre tous les matins.

Deux ou trois espèces de criocéres, genre de Criocéres. eoléoptères à corcelet étroit, élytres assez carrées, antennes longues et noucuses, vivent sur les asperges. La plus grosse cst rouge avec 6 points noirs sur ehaque élytre; deux autres plus petites sont un peu plus alongées. L'une est pîle avec une eroix noire, l'autre noire avec 6 taches et la bordure des élytres pâle. Ces inseetes causent souvent beaucoup de mal. On peut, d'après Rosiev, se scrvir contre eux de la décoction dont j’ai parlé dans le ehapitre des arbres fruitiers.

Une autre espèce du même genre dévore entièrement les lys, et les salit en même temps, puisque daus l'état de larve qui est celui oú elle est le plus nuisible, clle se recouvre de ses cxcréments et sien fait un manteau qui la garantit des ardeur's du soleil. Le coléoptère dans lequel elle se transforme est du plus beau vermillon. Il vit anssi sur le lys, et dans eet ćtat il est encore plus facile à apereevoir; car il n'est pas très petit et sa couleur qui fait contraste avec la blancheur de la fleur quiil fréquente est très apparente; c'est le moment de s'en défaire.

La cassidc vertc, colćoptère assez applati, Casside verte. d'un vert assez clair, dont les élytres sont extrèmement rebordées, les antennes grenues et 
grossissant vers le bout et dout la forme représente un peu eelle d'une tortue, vit sur les feuilles de l'artichaud et quelquefois s'y multiplic beaucoup. Sa larve y vit également; elle est aussi applatic que l'insecte parfiit; sa queue épincuse et recourbée sur le dos, soutient ses exeréments desséehés et lui en fait un parasol; les eôtés de son corps sont gyarnis d'épines frangóes placées liorizontalement; sa eouleur est à peu près la même que celle du coléoptère, mais plus pâle. La chasse est le seul moyen de les détruire. C'est dans les mois de mai et de juin qu'il faut s'y prendre pour prévenir leur propagation.

La loetterave, dont la culture est si répandue aujourd'hui, qui est devenue un objet imporBetterave tant pourl'agrieulteur, et un article de eoumerce, est attaquée daus sou premicr développement par la larve d'un petit eoléoptère que MM. Maequart et Latreille ont rapporté au genrè cryptophagus, et nomment cryptophagus Bctoe. Cryplaphagus Elle fut si multiplice en 1819 dans les environs de Bétlune, que les semailles de ectte plante furent entièremeut perdues. On eroit que les champs employés sept à huit ans de suile à la mềme eulture, favorisent leur propagation. " quelques eultivateurs, pour se préserver de leurs déprédations, convienneut entre voisins de senter le mène jour, de sorte que ses in. 
seetes disséminés sir des espaces considérables, ne font qu'un effet insensible, tandis que les semailles faites isolément sont souvent détruites. " Le coléoptère est un peu luisant, sa tête et son corcelet sont noir, lisses et très finement ponetués ainsi que les élytres qui sont d'un Irun, tantôt rougeàtre, tantôt noir. Sa longuenr n'est que de $2 / 5$ de ligne. (Ann. des sciences nat. inai $1831, p .253$.

Lo chov. Le elou est la proie d'une grande quantité d'insectes malfaisants. J'ai déjà parlé de quelques espèces de chenilles au commeneement de ce chapitre, ehenilles qui vivent sur ectte plante et gui passent le jour sous terre. Dewx autres espèces séjournent jour et muit sur ses fenilles, et leur graud nombre, surtont quant ì la première qui y vit en famille, devieut très-nuisible : les choux en sont quelquefois tout dévorés. Ce sonit les pieris brassicre, et pieris rapo. La chenille de la $p$. brassice est plus grosse, d'un vert grlauque on un peu bleuâtre, marbréc de jaune, et de points noirs; elle a quelques poils. Sa chrysalide de la même forıne et attachéc de la même manière que eelle du $\boldsymbol{p}$. cratogi dont jai p̧arlé, clıapitre de lamandier, est d'un vert - Ģrisître ou jaunâtre, tachetée de noir. Lá ehenille de la $p$. rapae est verte, velonlée avee trois p. Rapæe raies jaunatres. Sa clirysalide parcille à la précédente est d'un gris verdâtre presque sans 
taches. Cette dernière espèce mange aussi les feuilles du réséda des jardins. La première se Rúséda. trouve eneore sur la plupart des plantes erueif'̈res, entr'autres sur le pastel, isatis tinctoria. Le Pastel. Les deux papillons se ressemblent entièrement et ne diffèrent que par la taille : l'un et l'autre extrêmement communs dans les jardins, les prés, partout, sont d'un beau blane, avee des taches noires dans l'un des deux sexes, et le dessous des seeondes, teint de jaune-soufre. Il faut faire une chasse assidue tant à ees chenilles qu'aux papillons. La chenille de la $\boldsymbol{p}$. brassice se eache souvent pendant le jour; on l'atteindra mieux en la eherehant le soir à la lumière. Le pastel, quielle dévore comme le ehou, est un objet important de culture, à eause de la teinture qu'on en tire à Toulouse, ì Avignon, probablement dans le Gard. Cette ehenille mérite done une surveillanee particulière.

Trois ou quatre espèces de punaises infestent. encore les feuilles de eette plante potagère, sueent leur substance avec leur trompe aigue, les flétrissent et les rendent impropres à notre nourriture. Les jardiniers s'en plaignent beaneoup, il n'y a eependant que le soin continuel de les ehereher pour s'en défaire qui puisse en diminuer l'espèce. L'une est le lygæus apterus Lggaus apterus qui n'a point d'ailes; il est rouge avee lc milieu du coreelet et l'écnsson noir, et deux points de 
la mème eonleur, dont linférieur est beaneonp plus gros, sur ses élytres un pen écourtées.

(imex ornatus. Les antres sont le eimcx ornatus qui est rouge avec des liggnes et des taches noires dont les principales forment une espèee de croix : le

Festivus. cimex festivus qui est jaunâtre et présente les mèmes taelıes et quelques nuanees d'un rouge

D'eraccus. píle; enfin le eimex oleraceus qui est blell ou vert bronzé, bordé de blane avee quelques taches blanches. Nos jardiniers les confondent quelquefois avee d'autres inseetes sous la dénomination vulgaire et générale de babarotle. Les mèmes inseetes attaquent aussi la navelte et le colza.

Un autre inseete bien plus petit, aleyrodes chelidonii, mais remarquable par son extrème féeondité, tapisse en grand nombre le dessous des fenilles de eette même plante, et surtout des Chous đeurs. choux-fleurs. Il ressemble à une petite plialène, mais il est de la mème classe que les punaises et les pueerous. Il a ì peine une ligne de longueur; ses ailes sont étalées, mais un pen en toit, d'un beau blane avee un petit point noir au milieu. Sa larve est jannitre et ressemble ì un petit puecron. L'un et l'autre ont la bouehe armée d'une trompe qui suce les feuilles eomme les punaises dont nous venons de parler. Plusieurs générations se sueè̀dent rapidemeut daus le cours d'une année. Je ne vois pas que les jardiniers 
se plaignent beaueoup de ee petit inseete. $J^{\prime}$ ai peine à eroire eependant, vu leur multiplieité et la quautité immense que jen ai toujours trouvé sur les elioux quils ne soient pas trèsnuisibles. Il est probable que l'on confond le mal yu ils causent avee eelui prodnit par les punaises, et qu'on I'altribue ì eelles-ei.

L'altise bleue, allica oleracea (vulgairement dans le nord, pueeron, pueerolle, liquet) et l'altise du' ehou, dévorent et détruisent les semis Altise hleve, Alica oleracea.

leuceron,

Puecrolle.

Tiquet. de choux, de navets et de eolza. Quand les Alzise du chou. plantes sont adultes, elles les pereent de mille nasets, colzn. trous, Ies fanent et les dégradent. On indique eontre ces insectes la déeoetion dont jai dẹjà parlé; les eendres, la suie et l'urine ont aussi produit de bons eflets. W'après des expérienees multipliées faites en Belgique et rapportées par M. Poiteau (Mém. encyel. 1834, 1 . 296.) par M. Brullé, dans un des derniers Yos des Ann. de la soeiété entomologique de Franee ( $\$$ février 1854) et par l'hortie. Belge, tom. 1 ${ }^{\mathrm{er}}$. Il est prouvé que leurs aufs ne sont pondus ni dans la terre, ni dans l'eau d'arrosage comme vélieule, ui enfin sur les firaines après le moment de liı semenee, mais sur ees mèmes graines quand elles sont eneore sur la plante. On les y a distingué au nombre d'un à cinq sur elatgue graine. MIM. Brullé et Poitcau ont pris le parti de tremper ces semenees pendant vingt-quatre lieures, et 
mème moins de temps, daus une forte saumure, avant de les confier à la terre. Dès lors les jeunes plantes levèrent et se développèrent parfaitement, sans qu'auenne altise parut. La première espèec est toute diun bleu lnstré : la seeonde est noire avee les élytres conleur de rouille pâle, bordées de noir, avee une bande noire. Lune et l'autre sont de forts petits inseetes de deux tiers de ligne de long, ovales, ì antennes grennes, à euisses postérieures très-renflées, ce qui leur donne la faculté de sauter vivement. Isa larve et l'inseete parfait vivent sur les mêmes plantes.

Le baris chloris, l'altelabus cuprirostris, Fab., ou du moins leurs larves font beaneonp de mal anx ehoux, perforent leurs tiges, les rendent eassantes, arrêtent la sève et font lanģnir les plantes. Le mal est eneore plus gुrand dans les ehamps de eolza : ees inseetes se trouvent surtout au collet de la raeine, les eorneilles avides les larves, se jettent en liver sur les plantes, eherchent à eonp de bee à saisir les inseetes, brisent, coupent les tigges, et la plante périt. Comme ils n'altaquent jamais que le eolza, qui, planté ì la eharrue, est reeouvert de terre et plaeé horizontalement; il faut laisser sur place ou planter au piquet le colza galeux, ou si l'on est obligé de le planter à la eharruc, faire en sorte quili soit reeouvert de terre jusqu’à l'oil. (Journ. acad. d'Ind.fév.1852.p. 133.) Ces deux inseetes 
sont de la famille des eureulionites. Le premier est plus alongé d'un vert obseur en dessus, noir en dessous. Le seeond quoique plus petit que le rhyuchitcs bacchus ( $\mathbf{V}$. eliap. de la vigne), est de la même forme : il est d'un vert bronzé, sa trompe est euivreuse. On pent en mai lorsque ces inseetes s'aceouplent les secouer sur des serviettes pour les enlever. Pour arrêter leur multipliention, il faut arracher les plantes tarées avant le mois d'aon̂t, époque où ees inseetes sont $\mathrm{cn}$ état de larve : les choux peuvent encore alors ît ré lons pour les bestiaux.

La mouche brassicrirc, citéc par Bosc, Mrauche produit aussi au collet des racines des ehoux, hrassicair des tuhereules rahoteux où sa larve vit. Là sève s'extravase, el quand elles sont en grand nombre, la tige devient eassante. La mouche musca brussicaria, Fabr., a le eorps noir hérissé de poils. L'aldomen eylindrique, alonģé, avee le second et troisième segment rouges; elle est longue d'environ quatre lignes. Le seul moyen d'arrèter sa propagation est d'arracher la plantation de clioux avant la fin de l'été, en se privant ainsi d'une récolte, pour supprimer la génération qui se serait préparée pour l'annće suivante.

La tenthrède de la rave dévore les fenilles de cette plante; elle s'y trouve quelquefois en très grand nombre et détruit les plantations. Il ny a d'autre parti que de eueillir et détruire la larve 
qui fait le mal. Iinseete parfait auquel elle lonne naissanee et quil faudrait aussi elısser, est noir, avee le ventre, l'éeusson et les pattes blanehàtres.

Perce-orrille. OFillet. Taille-sébe.
Tipule des pres. Oleracea.
Le perec-oreille, forficula aurieularia, outre quill ronge les fruits, gâte aussi beaueoup de planles, mange les feuilles, les bourgyeons, les pétales des aillets. On l'appelle en patlois, taille-sćbe, nom que d'autres eultivateurs donnent aussi au taupe-grillon. On plante pour s'en défaire, ì eôté des weillets, des cannes ereuses, ou des bâtons, avee des eartes plićes en entonnoir, à leur bout, la pointe de l'entonnoil en haut. Ils se réfugieut pendaut le jour dans ces retraites, et on les y saisit.

Les larves d'une grande tipule très commune, la tipule des prés, Bosc, tipula oleracea, Linné; ne vit, il est vrai, que de raeines pourries qu'elle ne ronge pas, qu'elle ne peut que sucer. Mais comme elle habite les terraux ou les terrains humides, et qu'elle y est quelquefois en très frande quantilé, elle laboure la terre, fatigue el déeouvre les bonnes raeines, et quelquefois a fait périr par là une grande quantité de semis. Fouiller la terre, la labourer est le seul moyen de fiure mourir eette larve en la mettant à nud. Elle est eilindrique, légèrement en pointe ì ses deux cxtrémités; sa tête cst rétraclile, l’inseele 
lui fait ehanger de forme à volonté; la couleur de tout son eorps est gris-foneé.

Nous n'avons pas encore parlé des vers, disons plutôt des ehenilles qui vivent dans les cosses des haricots et des pois. Ce sont en effet et des pois. des ehenilles dans le genre des teignes, assez semblables à eelles des fruits sees. Je n'y eonnais aueun remède, et je nai pas encore pu connaitre le papillon auquel elles donnent naissanec.

Ces mềmes pois, les lentilles les ers, les fèves, dans leur état de maturité, sont presque toujours babités par un insecte connu sous le nom vulgaire de courcouçon et dans le nord de puceron, puccttc. C'est le Bruchus pisi, Bryabre à crour mylabre ì croix blanche de Geoffroi. il est d'un gris sombre unaneé de đquelques poils fauves ct blanes : sa forme est presque earrée et l'extrémité de son abdomen tronquée et marquée d'une tache blanche en forme de eroix. Sa liarve se nourrit de la substanee de ces légumes, et c'est dans le ģrain même, qu'elle devient coléoptère. On l'y tronve lors de leur maturité, si auparavaut elle ne l'a pas perece par un trou par lequel elle en sort. Elle se multiplie avee une grande rapidité. Les grains perdent par là une pártic de leur substanec farincuses, indépendamment de la saleté que linsecte y produit, surtout arant sa sortic. On se sert de plusieurs moyeus pour en préserver les légumes. Le prin- 
cipal, le meilleur sans aueun doute, est de les tremper dans l'eau bouillante, en les plaẹant dans un panier que l'on y plonge pendant quelques moments, ou de les exposer à la chaleur d'un four, sans dépasser 40 ou $4 \$ 3$ degrés de Réaumur. Ce procédé a l'inconvénient de les rendre impropres à la germination que n'empêehent pas les inseetes eux-mêmes, parce qu'ils n'attacuent pas le germe. Les lentilles et les pois, qui nous viennent de l'Aurerģne, paraissent avoir subi une autre épreuve. On assure qu'on les expose à l'humidité dans deś eaves, et que cette fraieheur éloignne ces inseefes dans le moment où its devraient faire leur ponie. Quoiqüil en soil, les légumes qui nous viennent de ce pays nont jamais de bruehe, et germent quand on les sème. On indique encore de mêler les pois avee de la sciure de bois, du sable fin, même des eendres, qui en se tassant autour des grains, empêehent les insectes d'y entrer. La cendre surtout, dit Bose, est exeellente et a de plus la propriélé de conserver les pois dans un état de fraicheur qui les rend plus tendres à la cuisson et plus savoureux. On enlève ensuite les eendres par des frottements et des lotions répétées, on les nettoie; et un peu de vinaigre suivi d'une nonvelle lotion enlève les dernières pareelles. 


\section{CHAPITRE VIII.}

DES INSECTES QŨ NUISENT AUX PRAIRIES.

Lues luzernes sont attaquées par pius diun inseetes; une larve verte avee une ligne blanche le long du dos, se trouve souvent at sommet Hyperavariatili: des tiges, en mai. Nlle y vit aux dépens de lá plante: mais je dois ajouter que ses dégits ne mont j'amais paru bien considérables. Le chamanson qui suceède à la larve est gris ou diu jaune sale avec une bande dorsale qui se termine avant lextrémité des élytres : hypera variabilis.

Les larves de eereopis, inseele sucenr de la Cercupss. f'amille des eigales, d'un genre nombreux en espèees qui vivent presque toutes de la nème manière, nuit beaneonp aux luzernes, comme anx autres plantes des prés. On reconnaît leur gite à l'éeume dont elles se couvrent. Il semble à voir eette matière, que l'on a craché sur les 
plantes; si on l'éearte, on voit la petite eigale. Il ny a d'autre parti, quand eet animal est trop abondant, que de faueher avant la floraison des luzernes, paree que linsecte parfait n'est pass eneore formé.

Colaspis barbara

Deux antres espèees, deux eoléoptères de la Eumolpus ubseurus. famille des ehrysomélines sont infiniment plus Museas pointu.
Mourrepounchu. dommageables à ectte plante. Ce sont, le colaspis bubara et l'cumolpus olscurus. Le premier se trouve eertainement dans le département dı Gard, et par conséquent y fait beaueoup de mal. Je ne puis en douter, paree quion me l'a envoyé de Montpellier, département très-voisin. Je crois que le seeond s'y reneontre aussi, puisqu'on s y plaint d'un inseete qu'on appelle muscau pointu, mourrc pounchu, en patois, dénomination qui convient mienx à l'eunnolpc. Ce nom désignerait ecpendant encore mieux le charanson dont je viens de parler au commencement de ee elıapitre, et je sais positivement qu'on lui donne aussi ce nom. An reste; il n'est pas étonnant de voir confondre ensemble par les agriculteurs, des animaux réellement différents par lenr extéricur, ou qui nont que des traits éloignés de ressemblanee, nuais dont les mœurs et surtout les dégàts offrent une similitude réclle. Quoiquil en soit nous les décrirons l'un et l'autre, et les moyens indiqués pour les détruire, s'appliquent également à tous les deux. 
La larve dn eolaspis barbara est noire, hérissée de petites pointes surmontées de quelques poils rares. Elle n'a que six pattes; elle ravage les luzernes au point de n'y rien laisser, traitant leurs fenilles absolument comme la galleruca calmariensis traite eelles de l'orme. J'ai vu dans le département du Var, dans le beau terroir de Solliès, les dommages terribles qu'elle oceasionne. On ne peut plus compter sur le fourrage quion a droil d'attendre de cette plante. On appelle à Arles du nom de bubarolle une larve noire, assez vive, à six pattes. Elle altaque surtont la seconde conpe presque an moment de la fanchaison et la dévaste en pen de jours. En vingtquatre heures, m'éerit-on, elle pent ruiner un pauvre homme. Si elle est retardée, elle n'éparggne pas non plus la troisième eoupe : quand on fauche les luzernes, la terre en est converte. La babarolte me parait être le eolaspis barbara. L'insecte parfait que produit la larve, se tient aussi sur la luzerne. Il est d'un noir très-prononcé; ses antennes ressemblent ì celles de tons les genres de cette famille d'inseetes; son corps de la longueur de denx lignes est fort bombé, le veutre daus les femelles, dépasse les élytres.

M. Léon Dufour (annales de la soe. eutomol. 1836), a remarqué les déģâts immenses oceasionıés par ect insecte, soit aux trè̀les, soit surtout aux luzernes dans les plaines du royaume 
de Valenee en Espagne. Il dit que la larve est flabre; je erois eependant pouvoir assurer l'exaetitude de ma deseription faite d'après l'animal plongé dans l'ean do vie: Il l'a anssi reneontré dans lés Landes près de St-Sever.

Négril.

La larve de l'eumolpus obscurus est connue vulgairement sous le nom de negril ou ver du trèfle. Elle doit ressembler à la précédente et par la forme et par la couleur. "Sa multiplication est si grande que elaque plante renferme quelquefois plus d'une eentaine de ees insectes. Nonseulenent ils détruisent les fenilles, mais ils laissent sur leur passage une liqueur corrosive qui aehève le mal quills ont commeneć. Ils rongent la plante, même au collet de la raeine. » Il paraît qu'aux environs d'A rles et dans le Gard, on a lieu de se plaindre beaueoup de ses dégàts, confondus peut-être avec ecux de l'inseete préeélent, le coluspis. Cette larve, dit-on, attaque la première coupe et fait des ravages terribles sur les nouvelles pousses qu'elle arrête longtemps. Elle pereille les fenilles et rabougrit les jeunes hourgeons. La coupe du fourrage, en réduisant linseete ì une nourriture moins abondante, ne le détruit pas, et il est rare quil n'en reste pas assez pour faire ile nonvean le désespoir du cultivateur. Licumolpus obscurus, dans son état de eoléoptère, a la mèmé forme et est de la même grandeur que celni de la vigue. Sa couleur 
est différente ćtant uniformément brune. La larve altaque aussi les trèfles.

M. Duplan fait connaître un instrument qui paraît proeurer un moyen de destruction tout à fait effieace. C'est un petit eaisson de bois de trois pieds de long sur huit pouees de largeur et de hauteur, fermé aux deux bouts ot ayant un petit côté extérieur incliné, et un grand, aussi iucliné beaueoup plus élevé, et sur lequel est eloué un manche formant un angle de trente degrés avee la caisse. On promène eet instrument, par un temps see, à quelques pouees aurdessus de la terie en mancurrant eomme aree une faulx, et le bord extérieur dı eaisson venant à frapper contre les tiges de la luzerne, fait tomber au fond ou renvoie sur le gुrand eôté toutes les chenilles. De léģers eoups donnés de temps en temps, les amoneèlent dans la caisse que l'on vide dans un panier, au fur et à mesure. Un certain nombre de ehenilles (larves) éehappent à la première opération, mais elles remontent sur les tiges, et on peut recommeneer le lendemain. A la troisième tournée, il est rare que presque toutes ne soient pas ramassées, et un journalier peut en einq heures pareourir un arpent. (Jourual des propr. vuruux, 1832, p. 231.)

M. L. Dufour, dans le même article cité cidessus, parle d'un procédé par lequel les paysans du royaume de Valenee, parviennent ì se 
Celospis barbara débarrasser des colaspis barbara. Il se rapproche de eclui que je viens de déerire : il est plus simple et pent-être presque aussi ellieace. Ils se servent d'une large poelie de toile adaptéc an bout d'un bâton, à peu près comme le filet dont les entomologistes se servent pour prendre les insectes, et la promènent sur les luzernes comme en fauchant. M. Daube assure (anuales de la soc. entom. 1837) que les poules sont très friandes de eet inseete, et qu'en leur donnant une libre entrée dans les prés, elles en détruisent une très grande quantité.

On voit souvent dans les luzernières des espaces à peu près cireulaires, où la plante est Tonsures. uorte et desséehiće : on les appelle tonsures. Cet Itanneton. effet est produit par les larves du hauneton vulgaire et du scarabć rhinoccros, oryetes nasicornis on plutôt dans le midi oryctes yrypus. Ces larves rongent les racines. Elles s'avaneent eirenlairement ì luit ou dix pouces sous la surface de la terre. Leurs ravages ne sont bien sensibles que la seconde aunée de leur existenee; la larve dı hanneton vivant en effet trois aus dans ect état. Celle du rhiuocéros ressemble entièrement ì celle du hanıeton; elle est seulement plus gुrise avec des points élevés plus noirs sur les anneaux. Il faut, pour les détruire, fouiller au picd des luzerues quand on les voit se séelıer; et avoit soin de ne pas laisser séjouruer 
dans les luzernières les eroltins et le fumier des chevaux qui entretiennent la terre plus humide; les hannetons surtont eherehant eette humidité pour y pondre leurs oufs, paree qu'ils crensent des trous pour les déposer, opération qui leur devient phus difficile dans une terre sèehe.

La chenille de la pyralis uneana se eache dans les sommités de la luzerne et y vit aux dépens de eette plante. Mais ses dégàts ne paraissent pas eonsidérables. Le papillon est d'un gris sombre avee deux graudes taehes arrondies d'unc coulemr plus elaire.

" M. Blot a observé que parmi les bontons ì fleurs qui eouronnent les plus liautes têtes de sainfoin, il en est de bien plus volumineuses qui renferment un eertain nombre de petites larves blanehes. Jusqu'à la floraison, ees boutons eontinuent à se développer plus rapidement que les autres. A l'époque où la graine se forme, les petits vers sortent de leurs galles pour subir en terre leurs métamorphoses de nymphes. "Au bont de huit jours, il en sort un diptère du genre ceeidomyia, Meiggen, assez semblable par eonséquent à eelui que j’ai $\begin{gathered}\text { Cecidomyin } \\ \text { du sainfoin. }\end{gathered}$ déerit eomme attaquant les jeınes plantes de blé. M. Blot conseille de faire manger sur pied le sainfoin qui en est altaqué, ou de le récolter avant qu'il soit entièrement fleuri, et de Tenlever de suite dı champ. On prévient par là le seeond 
état de linseete, eelui où il quitte la plante, on l'arrête nu grîte, et la deuxième coupe n'en aura rien à craindre. Ses ravages sont très-considérables, sans doute paree qu'il s'oppose à l'entier développement de la plante et de la graine. (Journal aead. dind. 1852. p. 166). 


\title{
CHAPITRE IX.
}

\author{
DES INSECTES NUISIBLES EN GÉNÉRAL OU QUI \\ ATtaquent tous ou pRESQUe tous \\ LES VÉGÉTAIX.
}

Les inseetes dont je vais traiter sont aussi malfaisants que tróp connus. Je les ai jusqu'ici à peine nommés, les réservant pour un chapitre partieuliev, parce que leurs dégâts s'appliquent à plusicurs des végétaux dont nous avons parlé, et quil aurait fallu les signaler et les déerire en quelque sorte plusieurs fois. Ils trouveront done tous iei leur place.

Les sautere!les et les eriquets sont redoutables par leur taille, quelquefois très grande et par leurs ravages listoriquement conuus, qui dans certaines contrées sont un fléau presque égal à la peste et à la famine, qu'elles arhènent souvent à leur suite. 'Yout le monde silit quion a vu, 
surtout dans l'Orient et en Af rique, leur nombre immense former des nuages de plusieurs licues d'étendue qui obseureissent le soleil. Quand ces troupes aftamées, qui n'ont quitté une provinec que pour chercher dans une autre une nourriture qui leur a manqué, s'abattent sur la terre, elle en est couverte à la lettre comme le eiel l'était. Dans peu d'instants toute verdure, toute végéles détruire. tation est anćantic. Elles sont entassées sur le sol dans une épaisseur de deux ou trois pouees. Le bruissement de leurs ailes et de leurs maclioires est semblable à celui d'une forte grêle. Leurenvahissement produit un effet pire, et tout espoir de récolte queleonque est anéanti. Nous sommes moins maltraités dans notre zône tempérée; cependant on eite des faits et des années où l'Europe a souffert des invasions de sauterelles. Elles iuondèrent tellement en 1787 le terroir de Saint-Gilles, localité qui se rattache au but principal de eet opuseule, puisqu'clle fait partic du département du Gard, que la eommunauté paya un sol la livre des sauterelles qu'on lui apportait. On en détruisit de eette manière onze à douze cents quintaux. Plus aneiennement, en 1613, la Provenec et les parties du Languedoc, qui l'avoisinent, avaient subi le même fléau. On rapporte, dans les relations de ectte époque, que daus peu d'leures plus de quinze mille arpents de terre (\$533 heetares) furent ravagés. 
Les administrations municipales d'Arles, Tilraseon et Beaneaire firent ramasser les oufs de sauterelles pour les détruire. Dans l'espace de douze ou quinze jours on en amassa plus de six cents quintaux à Arles, plus de douze cents à 'Tarascon et autant à Beancaire; ce qui suppose an moins cing milliards d'oufs dans ces trois communes. On payait deux sols par livre d'œufs. On fit aussi la clıasse aux sauterelles elles-mêmes. Le procédé le plus sûr parut ennsister à tendre, eomme des filets, des lineueils monillés eontre les haies et les buissons. En effet, les santerelles venant s'y réfugier le soir, pour s'abriter contre la fraichcur des muits, s'y trouvaient arrêtées et lumeetées, quand le matin elles eherehaient ì quitter eette retraite. Elles s'y prenaient en grrand nombre, et souvent d'un seul eoup on en remplissait un sae de demi-ehargye. On évalue à plus de trente mille livres eelles qu'on détruisit dans le seul terroir d'Arles.

En l'an donze les sauterelles firent de grands dégâts dans les campaģnes qui entourent Marseille. L'académic de eette ville s'oceupa des moyens de les faire périr. Les sieurs de Sinéty, Casimir Rostan et Delyle de Saint-Martin, proposèrent, dans un rapport imprimé par ordre de ectte société, de renouveler des moyens semblables à ceux qui avaient réussi à un ecrtain point en 1613 et en 1787. Un arrêté du préfet 
des Bouches-dn-Rhône promit, en eonséquenee de ee rapport, une prime de deux sols par livre de santerelles et quatre sols par livre d'œuf', qui seraient apportées aux commissaires lésiģnés. 1 invitait en même temps à défrielıer antant que possible, dı moins à écobuer les terrains qui contenaient des oufs en grande quautité. Le nême fléau s'est renouvelé plusieurs fois ces dernières années dans les mêmes loealités. Feu le lieutenant-général Miollis, dans son donaine connu sous le nom de Château d'Avignon, domaine très voisin du département du Gard, avait employé, il y a une douzaine d'années, un moyen à peu près semblable à ecux indiqués ei-dessus. C'était à l'époque où les santerelles étaient encore très jeunes, de la lonģueur de quatre à einq lignes au plus. Une einquantaine de journaliers, lommes et femmes, armés de fourelies et de gaules, battirent les buissons en formant un eerele qüils resserraient insensiblement. An centre de l'espace eireonserit étaient étendu de grrands lineenils : les sauterelles poussées et ne ponvant pas eneore, par leur âge, fiure des sants trop élevés, ni user de leurs ailes, s'y trouvaient rassemblées en foule. Alors on soulevait vivement le drap, on les enveloppait, on les serrait; elles étaient meurtries et étouffées : on en remplissait des saes que l'on enterrait dans des fosses profondes pour prévenir la putréfaetion en pleiı 
air. Il fallait renouveler fréquemment eette ehasse à eette époque de leur vic. Je tiens de lui-mèıne ces détails; et il se louait du suceès de eette mesure, appuyée d'ailleurs par l'autorité et les recommandations des eommunes des envirous d'Arles. Car on a eu grand soin dans tous les temps de suivre eette pratique dans ces mềmes quartiers. Le moment favorable pour faire la eliasse aux sauterelles est vers le commeneement de juin. Leurs ailes ne sont pas encore développées, du moins dans la plupart des espèees. Leurs sauts dépourvus de eette aide sont moins vifs. Ce n'est pas eneore le tenıs de leur aceouplement. Il faut aussi saisir l'heure convenable. C'est, comme nous l'avons indiqué phus haut, lorsque la frâeheur du matin ou du soir les engrourdit eneore ou bien immédiatement après unc pluie. Leurs œufs éclosent dès la fin de mars ou au eommenecment d'avril. C'est done en antomne et en hiver qu'il faut en faire la recherelte. La mère les pond en enfonȩant en terre la partie postérieure de son eorps qui est armée d'une espèce de eoutelas dans les sauterelles proprement dites, et de quatre pointes éeaillenses très fortes dans les eriquets. On les apereoit aisément dans eet aete, les années et dans les quartiers où clles sont extrêmement eommunes. Chaque ponte est. de vingt-eing à trente neufs, collés ensemble par une espèce de gluten que la mère y ajoute et 
qu'elle tire de son intéricur. Leur réunion forme un eylindre membraneux, recouvert et enerouté de partieules terreuses, et enfoneć en terre à la profondeur d'un pouee environ. C'est surtont dans les terres ineultes et dans les jachères qu'elles aiment ì pondre. Il n'est pas aisé au premier abord de tronver ees xufs; mais une fois eonnus on les reeueille facilement et par eentaines. Les années ò̀ les sauterelles, et les oufs par conséquent ont été très abondants, on voit éclore au printemps les petites sauterelles; elles sont alors d'une couleur pàle. On peut avee des arrosoirs les faire périr en les inondant d'eau bouillante. Les oiseaux, surtout l'alouctte lupée, les ainent beaucoup et en détruiraient une grande quantitć, si, comme le mème rapport de l'acadénie de Marseille, que je viens de eiter, l'insinue, la lieenee de la ehasse était réprimée, et son droit limité aux seuls propriétaires de chaque terrain.

Les inseetes, que nous appelons vulgairement sauterelles, appartiennent à deux genres bien distincts. Les uns, les viaies sauterelles locusta, ont le corps plus mol, ainsi que leurs élytres; leurs antennes sont longues et sétacées, et l'anus de la femelle, terminé par une espèec de sabre ou de coutelas, formé de deux lames rapproehées, qui lui sert à percer la terre et à y déposer ses eufs. Lalocusta viridissima, commune 
dans ces pays-ei et dans toute la Franee, nuit beaueoup aux blés eneore vert. C'est une très grosse santerelle qui a au moins deux pouces de long. Lues antres espèces sont fort multiplićes. Plusieurs, semblables à celle dont je viens de parler, ont des ailes qui leur permettent un vol très étendu, favorisé encore par le renflement de leur's euisses postéricures, munies de museles qui les rendent très propres à sauter. D'autres sont aptères, telles que la locusta ephippiger. Celle-ci est verte ou brune avee des raies jaunâtres

qui ecignent son ventre. Elle se fait remarquer par des moignons d'élytres arrondis en forme de bosse jaunâtre, placés sur son dos comme une selle. Cetle espèce est commune et fort nuisible aux produits de la terre. Cette ınême annéc, $183 \%$, on s'en est plaint extrémement dans le Gard. Elle dévorait les bourgeons d'un des arbres les plus préeieux de ee département, des mûriers qui en font la richesse. Elle ronģe aussi les fruits, poires, pommes, ete., avant leur maturité. Une autre très grande sauterelle aptère locusta $g^{i \text { - Locusta gigantea }}$ ganter serait aussi très nuisible, et par sa grosseur et parce que les tiges des blés et leurs grains sont sa prineipale nourriture, si elle n’était beaucoup plus rare que les préeédentes. Elle se distingue par la longueur de son abdomen et par les fortes épines qui garnissent toutes ses euisses et ses jambes. 
Le genre criqucl, acrydinm, est encore plus nombrenx en espèces. Il diffère des locusta par ses antenaes courtes, épaisses, son corps peu alougé, ses cuisses postérieures plus fermes, plus dures que dans le genre précédent et beaucoup phus élastiques. Aussi l'on peut dire que leurs ailes, dont ils se servent pourtant très bien, ne sont presque qu'un organe secondaire lorsquils prenuent leur essort. Tout leur corps est plus fortement cuirassé que celui des locusla; leurs ailes, caehées dans le repos sous des élytres inembranenses ordinairement de couleurs sombres ou grisittres, sont presque toujours aygréablement colorées et ressemblent, quand le vol les épanouit, à celles des papillous. C'est dans ce dernier genre que se trouvent les espèees les plus connues par leurs mavages en balaille rangzée, si l'on me permet cette expression. C'est d'abord l'acrydium tataricum ou lineola, remarguable par sa grandeur; il a trois pouces de longueur de la tête au bout des ailes lorsqu'elles sont repliées sur le corps. Il est gris, rétieulé sur les élytres de traits plus noirs: ses ailes sont assez enfumées, avec une grrande bande noire circulaire. Celte espèce n'est ici, en temps ordinaire, ni très commune ni très rare. On la voil assez souvent l'hiver s'abriter entre les raneaux des oliviers. L'autre crifuet, connu 
nom indique ses mours. Il est un peu moins gros que le tutaricum. Sa couleur est verte, mêlée d'un pen de jaune; l'extrémité de ses élytres tachetće de noir : ses ailes sont d'une teinte verdâtre surtont du eôté qui approclıe du corps. It est plus rare iei que le précédent. Je n'ai pas pu savoir s’il faut attribuer à ces deux mêmes espèces les ravages antérieurs faits en Provenee ì diverses reprises. La rapport de l'aeadénie de Marseille, déjà eité, indique encore avee les deux espèees dont je viens de parler, comme ayant fait le plus de ravages en l'an douze, l'acr'ydium italicum ctlacrydium stridulnm. Ils sont beaueoup moins gros que les préećdents, mais plus communs et an moins aussi voraees. Le premier a ses ailes d'un rose tendre; le mâle de cette espèee, que loon reneontre souvent aceouplée, et qui alors est plaeé sur le dos de sa femelle, est trois fois phis petit qu'elle. Les ailes de l'acrydiun stridulum sont d'un rouge foné avee une bande noire eireulaire : ees eouleurs, dans l'un comme dans l'autre, ne paraissent que dans le inoment dit vol: la eoulenr du corps et des élytres de tous les deux est grise avee des points et des taehes noirs. Ce dernier acr. striInlum est un de ecux dont on se plaignait le plus à Arles il y a quelques années, ainsi que de la grande sauterelle à queue en sabre qui venait pár nuilliers dévorer les grains sur l'aire après avoir 
Locusti

verrucivora, viridissima.

Fphippiger.

Le's Pucerens. détruit les épis. Celle-ci parait être la locusta verrucivora. Ida locusta viridissima et ec mème acrydium stridulum joignaient leurs ravages ì Ùsez, à eeux de la locusla ephippiger, et rongeaient nou-seulement les bourgeons, mais aussi les feuilles de mûrier, surtout la seeonde feuille, de manière à rendre ees arlores fort malades. Dans eette localité ees diverses espèees de sauterelles ocenpaient une zône de plusienrs lienes de long sur une largeur denviron deni-lieue. Elles commencent à peine à en disparaître.

Les puecrons plus tranquilles agissant plus paisiblement, devienneut cependant une peste par leur étonnante multiplicité. C'est là que le nombre des espèees est grand, eliaque plante, presque elıaque arbre nourrit le sien. Leurs organes nutritifs sont très simples, il est vrai; c'est une trompe pointue, eoucliée le long de la poitrine de l'animal qüil redresse et enfonee très profondénıent dans l'écoree des jeuues branelies et le pareneliyme des feuilles. Mais on a observé depuis longtemps leur singulière féeondité, faite pour favoriser une immense propagation. Une f'emelle aecouplée et féeondée une fois à la fin de l'été ou en automne, pond des auf's qui passent l'hiver et donnent naissanee au printemps à des petits tous femelles et vivipares. Cenx-ei, sans avoir besoin d'aecouplement pendant neuf générations sucessives au moins, et tout le temps 
de la belle saison, mettent au jour des pueerons vivants. Les mâles ne paraissent que lors de la dernière portée pour perpétuer les espèees pour l'année suivante. Il est inutile de déerire en détail de petits animaux qui se font aisément aperecvoir par leurs défâts et qui sont plus distingués entre enx par les plantes qu"ils habitent, que par leurs caraetères partieuliers ordinairement peu saillants. On voit partout des pueerons; et en tout temps, exeepté en hiver, leur existence se prolonge ou se renouvelle. Les plantes lanģuissent et sèehent sur pied, les feuilles des arbres se contournent sous leurs piquires, deviennent galeuses, elıangent de couleur et tombent. Presque toutes les plantes potagères, eelles qui ornent nos jardins, y sont très sujettes. Les fèves surtout ne sont presque jamais éparginées, et la récolte de ce légume manquant souvent en totilité, on est réduit à les enterrer en retirant à peine la semenec. Parmi les arbres sujets aux pueerons on remarque les pêelıers, les poiriers, les pommiers. Il en résulte ordinairement aux prenier's la maladic eonnue sous le nom de eloque, lorsque les feuilles se eontournent et se tortillent.

Du moins on l'a eru longtemps : Rosier et Bose s'aceordent au eontraire à penser que la eloque vient d'un viee de végétation de l'arbre, probablement d'une transpiration arrêtée; et que si l'on y trouve fréquemment des pueerons en fimille, 
ils y ont été attirés par les sues plus extravasés et plus propres à leur nourriture par suite de la maladie. Je ne puis douter que la cloque ait lieu

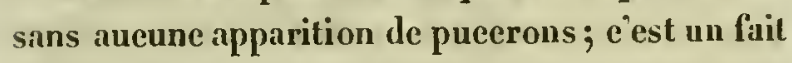
quej'ai vérifié plus d'une fois ; mais sonvent aussi ils habitent ces feuilles recoquevillées en telle quantité, qu'il-me serait difficile de ne pas eroire anx deux eauses réunies on suceessives, savoir : la sève arrêtée sans linntermédiaire des pucerons, et la eloque produite d'autres fois par les piqûres même de ees inseetes.

Non-seulement les pueerons vivent ì déeonver:t sur les végétaux, mais souvent ils s'enferment dans des espèees de galles. Celui du térébinthe y produit les exeroissanees les plus bizarres, peintes des plus belles eouleurs. Les pétioles et les feuilles du peuplier sont remplies de nouures, de bosses qui renferment une autre espèce des mèmes inseetes. Les ormes sont déformés par d'énormes vessies eausées par les pueerons et qui en sont remplies; elles sont vertes avant la sortic de la famille qui les habite, et deviennent ensuite d'un noir fuliggineux et hidenses à voir.

Nos pays méridionaux connaissent une multitude d'espèees de ees petits inseetes. Mais il en est une qui fait beaueoup de mal aux pommiers dans les provinees dn nord, et que nous avons le bouheur de ne pas eonnaitre iei; du moins je ne ly ai jamais observé. Elle est connue sous 
le nom de puccron lanigère ou du pommier. $\mathbf{M}$.

Blot a eru lui trouver des caractères partienliers,

et l'a distinguće sous le nom de misoxylus mali.

Il sattache aux jemes pousses, se loge dans nne fente ou sillon qu’il oceasionne par sa piquure à la surfaee inféricure du jeune ramean, parce que là il se trouve à l'abri. Cne noulosité sucè̀le ì ece sillon, elle eroît d'année en annéc, et d'at’ord fort petite, devient la septième ou huitième année de la grosseur du poingt et nuit à la vigueur de l'arlsue. (Annales de la Soc. Entomol. de.France, lom. $4,1855,1^{\circ r}$ trim.). Ce puceron a longteinos dévasté les ponmiers de Normandie, principalement les espèees propres à la fabrication du cidre. Il y a cinq ans environ quil s'est répandu daus les environs de Paris." Après de nombrenx essais, lougrtemps provoqués par diverses sociétés, il est résulté de ceux tentés en 1850 , dans l'école des arbres fruitiers du jardin des plantes, que l'essence de clarbon de terre, liqueur noire, lmileuse, d'une odcur pénétrante et forte, mêlée à dix on quinze parties dlune décoction de tabac détruit les misoxyles ainsi que les autres insectes. Cefte essence de eharbon de terre est fonrnie à bon marelié par les faloricants de Grenelle. Les prommiers et les abricotiers, soumis ì ees expéricuces, sont daus un bel état le végétation et ne paraissent pas avoir souffert, après avoir été enduits à plusicurs reprises, avee 
la liqueur au moyen d'un pineeau. ") (Annal. de l"Institut de Fromont, Mém. Eneyel. 1853, pag. 262.) Telle est la reette que je eopic; jai fait venir exprès eette essenee de eliarbon de pierre: on mavertit que beaueoup de jardiniers sen étaient mal trouvés, quil fallait létendre dans beareoup d'eau, ee qui n'est pas aisé, attendı que e est une substanee épaisse et huileuse. Je l'ai essayée sur des fèves, sur des pêchers; je niai pu réussir à tuer les pneerons, qu'en faisant périr la plante ou la branche elle-même, peut-être n'ai-je pas détrempé l'essenec dans assez d'eau, peut-ètre y a-t-il moins de risques sur unc branehe de pommier où lespueerons sont réunis dans un sillon. J'ai été obligé par l'hiver d'interrompre mes expérienees; je me promets eependant de les renouveler encore, et j'espère, par une note avant de terminer ce Mémoire, ponvoir rendre couple du résultat. (1)

(1) Ce Mémoire terminé, jai eu la facilité de rectifier par moi-même, J"s expériences qui, l'anoéc dernière, n'avaicot pas été assez bien laites, sur Irs pucerons: $1^{0}$ l'essence de charbon de terre mêlée avec douze parties d'infusion de tabac el appliquéc avec un pinceau sur des fèves, a tué les mucerons sans nuire a la plante; il faut observer seulement de ue pas toucher ies feuilles ou oc sent pas les pucerons, parce qu'il est difficile qu'clles D'en soient pas détries. Cette même essence n'a pount fait de mal, à plus furte raison à de jeunes rejetons d'arbustes et à des branches fortes et de plusieurs années. Aussi suis-je dériclé a en user dorénavant; $2^{\circ}$ Ylutuile commune, également employéc avec un pioceau ou une rlume a détruit les puccrons sans ouire a la plante, si ec o'est aux feuilles tendres qui en oot été frottécs; $3^{\circ}$ les cendrcs aspergécs furtcuent sur les pucerons, 
On propose plusieurs autres proeédés pour détruire les pueerons, et je erois qu'on peut s'y fier assez; mais ils deviennent presque impossibles à émployer dans les eultures ell grand, verggers, pépinières, etc. Pour les plantes que l'ọn peut soiģner de près, et qui par leur prix compensent la peine que l'on se donne, quelques pineées de tabac en pondre bien see, l'essenee de térébenthine délaycé avee de la terre jusqu'à consistanee d'une bouillie claire dont on enduit les bouts des bramelies attaquées, peuvent servir (Rosier, Dietionn. d'Agrie.) Mais Bose remarque que l'emploi des drogyues luileuses est loug; qu'clles sont chères si on les emploie en grand; et qu'elles penvent muire anx arlores. La vapeur du soufre, la fumée de tabae ue nuisent pas aux arbres (je doutcrais fort qu'clles ne fussent pas unisibles aux plantes plus tendres et plus faibles), mais elles n'atteignent pas toujou's tous les pucerons. Elles rénssissent mienx aux espaliers qu'aux arbres en plein vent. Il funt diriger eette vapeur par le moycu d'un soufllet eombiné à eet eflet; anquel on ajuste une boitte de tôle ou de euivre. Cette boîte doit être de la grrossenr d'un neuf'; clle s'onvre daus son milien; elle est ter-

suit cu arrosant la plaute après ou auparavant, n!ont pas nui a la végétatwou, mais noo plus aux pucrrons. Ce dernier procédé qu'on m'dvail vanté et qui venail de honoc source, ne peut donc s'appliquer qu'ans chermè tutut in pliss. 
minée d'in cốté par un tuyau de sept ì huit pouces de longy de la grosseur d'un tuyau de pipe, et de l'autre par un seeond tube plus gros et plus eourt destiné à adapter la boîte au bout d'un soufflet ordinaire de chemince. On remplit la boîte de tabac à fumer, on y met un petit morceau d'amadou allumé : alor's on dirige, par le jeu du souflet et l'intermédiaire du prenier tuyau, la fumée du tabae suv la partic de la plante habitée par les puccrons; ils périssent au bout de deux on trois minutes. Il fant seulement prendre garde que la fumée, trop chande trop rapprochée, ne lrûlc pas les feuilles.

Les dissolutions de sel marin, les infusions de plantes âcres, de tabac, de surcau, de noyer, de jusquiame, l'eau des lessives, des fumiers, réussissent souvent, injeetées par le moyen des pompes, des arrosoirs, de la seringue dont je vais parler. Le moyen le plus eflieace peut-être est la chaux réeente, en poudre, scmée à diverses reprises sur les plantes infestées de pucerons. Ils sont anéantis cn peu d'iustants; la pluie, l'arrosage, survenant ensuite, lavent les feuilles, et la chaux tombant à terre avec les pucerons morts, forme par la combinaison, une espèce de savon qui fume le sol (Bose, $\mathbf{Y}$. Cours complet d'Agric.) Je connais, à Aix, un bou jardinier pépinériste, le sieur Michel, qui se contente 
d'arroser les pueerons et les saupondrer ensuite de eendres : ils périssent aussitôt.

'Indépendamment de l'essenee bitunineuse, on a indiqné dans divers ouvrages d'autres rceettes pour eombattre le puceron lanigère dn pommicr. La suivante est indiquée dans le journal d'horticulture. Dans une livre lunile de colza, mettez. demi-onee de sulfate de euivre (vitriol), demionee d'ahn, demi-onee d'hydrochlorate d'ammoniaque (sel ammoniae) le tont broyé le plus fin possible; et avee un pineeau gyrossier imprégné de eette eomposition, graissez les branches ou parties de branelies attaquées et surtout faites-la pénétrer dans les fentes, gerẹures et chaneres. Une antre plus simple est de frotter d'une huile queleonque, toujours avee un pineeau bien imbibé, toutes les parties ligneuses attaquées par les pueerons; ils périssent ( l'on sait en effet que l'huile en bouehant les stigymates des inseetes, les asphixie) et les pucerons ne reparaissent plus les années suivantes sur les endroits que l'huile a impréģné. On pourrait mềne enduire tonte l'écorce, puisque e'est un moyen de les ćearter pour l'avenir des endroits non eneore attaqués. Les feuilles ne doivent pas être frottées d'huile paree qu'elles périraicnt, tandis que eette liquenr ne nuit en rien au bois. Cette expérienee est due à MM. Prévôt et Poitcan (revue horticole, 1855).

Puisque jen suis à citer des receltes, on ne 
me permettrait pas d'en omettre une assez compliquée, mais qui paraît fort recommandée. On peut l'appliquer tant aux pueerons qu'aux altises dont jai parlé au elhapitre préeédent, et en général à beaueoup d'autres inseetes. Elle est tirée du dietionnaire d'agrieulture, article artichaud. Nous la devons à M. Tatin. Voici sa eomposition. "Savon noir de la meilleure qualité, lenx livres et demie; Fleur de soufre mềne quantité; Clampignous de bois, de couche on antres, deux livres; Lau, 60 pintes.

“Versez 30 pintes de l'eau partagée en deux parties dans un tonneau qui ne servira qu'à eet usage. Délayez le savon noir et ajoutez-y les elampignons après les avoir éerasé légèrement.

"Faites bouillir dans une ehaudière le reste de l'eau; mettez tout le soufie dans un torehon de toile elaire, en en formant un nouet ou paquet, et ajoutez-y un poids pour le faire descendre au fond. Pendant vingt minutes, temps que doit durer l'ébullition, remuez avec un bâton, soit. pour fouler le paquet de soufre et le faire tamiser, soit pour en faire prendre à l'eau la foree et la couleur. Si on double la dose des ingrédients, lés effets n'en seront que plus forts et plus marqués.

"On versera l'eau sortant du f'eu dans le tonnean, on la remuera un instant avee un bâton. Chaque jour on l'agitera jusqu'à ee qu'clle 
acquière le plus grand degrré de fétidité. L'expérienee pronve que plus elle est fétide et ancienne, plus son aetion est prompte. Il faut avoir la précaution de bien boueher le tonneau chaque fois qu'on remuera l'eau.

"La meilleure manière de s'en servir, est par le moyen d'me seringue ordinaire à laquelle on adapte une canule qui doit avoir à son extrémité une tête d'un pouee et demi de diamètre percée sur la partie horizontale de petits trons enmme des trous d'épingles pour les plantes délieates et un peu plus grands pour les arbres. Si eclte eau, ajoute-t-on, ne détruit pas entièrement les insectes, elle en diminue le nombre de telle manière qu'ils unisent très-peu aux plantes. "

On a proposé pour gunérir les pêehers de la tacloque. cloque, d'arraeher les fenilles reeoquevillées, mais le remède serait pire que le mal.

Les fourmis ont une manvaise réputation. Les Fourmis. Leir rapaeité reconnuc, leur avarice prétendue, n'ont pu être compensées par l'admiration que doit leur attirer la patiente et eonstante assiduité de leurs travaux, leur intelligente industrie. Il est très vrai cependant que nous avons à nous en déf'endre. Elles nous disputent nos grains, s'établissent daus nos greniers, dans nos ménages, à la porte de nos maisons. Presque toutes nos provisions, surtout eelles qui sont donees et suerées, sont sujettes à leurs déģâts. Mais il est cepen- 
dant vrai de clire que les fourmis n'apportent ni n'attirent les pueerons sur les arbres; si elles sont toujours ầ leur suite et à eclle des co'chenilles, e'est, attirées par la liqueur miellée que distilleut ees petits animaux et dont elles sont friandes. Elles ne font auem mal aux arbres sains; si elles rongent le bois mort, ee n'est que dans les brauches sèches ou pourries qu'elles le elierelient et le trouvent.

L'eau bouillante versée à flots par l'ouverture de la fourmilière est le moyen le plus sinple et le plus eourt ; mais pénétre-t-elle toujours dans les sinuosités quelquefois très eompliquées de cette habitation souterraine, et n'est-elle pas refiooidie et de nul effet quand elle arrive au fond? Elle est très utilo dans les moments où les fourmis sont en plus grand nombre en deliors et à portée de la fourmilière, exposant leurs nymplies à l'air, paree qu'alors on en atteint un plus grand nombre, et l'espérance même de leur aveuir. Une solution de sublimé-corrosif ou d'aeide sulfureux, de gyaz lydroggène sulfuré, dirigéé daus les trous, à l'aide d'un tube, serait eneore plus effieace. Il faut eloisir pour cela l'heure du soir. Rosier propose de placer à leur portée quelques feuilles de papier reeouvertes de miel; elles y sont attirées en quantité : quand elles en sont couvertes on jette la feuille dans un baquet d'eatu placé auprès, sur laquelle on fait couler un pen d'huile pour 
les empècher de s'échapper. On renouvelle fréquemment le même manège, et on vient à bout de se débarrasser du moins en partie des fourmis dévastatrices.

Dans les îles Antilles où certaines fourmis sont de très grande taille, et oì lenr nombre se multipliant prodigieusement, donne licu de leur part à des émigrations dans le genre de celles des sauterelles, les moyens ordinaires sont insuffisants. Une immense armée de ces animaux menace de tout dévaster en rongeant tout, principalement les camniers à sucre. On ne sait com. ment arrêter ce torrent. On fait des traînées de charbons embrasés pour barrer lcur passage, mais limpulsion est donnée au bataillon, il est trop nombreux pour s'arrêter; les premières tombent sur le feu et s'y brûlent, elles ne sont pas consumées, que les suivantes se pressent, meurcnt à leur tour et à force de calavres font un passage aux autres : le f'eu est éteint par leur nombre, ct elles continuent lenr course. Une autre espèce est bienfaisante; les créoles les voient arıiver avec plaisir à certaines époques périodiqucs. On serre les grrains et les sucreries, il est vrai ; mais elles furètent partout dans les maisons, arrêtent, fortes par leur nombre, saisissent tous les animaux malfaisants, rats, lézards, serpents, etc. Dans pen de moments tout est dévoré, anéanti, et elles laissent au 
propriétaire son habitation purgée pour long tempis ile ees parasites dangerenx ou ineommodes. On les appelle fourmis de visite.

Si l'on eroit avoir à se défendre dn mal que les fourmis peuvent eauser aux arbres, on les arrête par une eeinture de laine et de crin dont on entoure le trone, par une bande de euir larğe de quelques poniees enduite de gylu, par un cerele de suie de four délayée dans de l'huile de ehenevis. On assure aussi que l'lumile de poisson, soit en barbonillant le trone, les branehes on quelques feuilles, soit seulement en en remplissant un petit vase suspendu à l'arbre, les ehasse anssitôt.

Ver blanc.

Melolontha vulgaris.

Hanneton.

Si le ver blane fait un mal eonsidórable anx raeines, le hanneton qui hui sueeède melolontha vulgaris est souvent, dans le nord et le eentre du royaume, un fléau redoutable pour le fenillage de tous les arbres queleonques. Le midi de la Franee y est peu sujet. Comme cet animal est gros et loruyant, et eonuiu de tout le monde, il est facile de le mettre ì prix, et de le faire raunsser par des enfints. C'est dans le moment de li plus gyrande ehaleur dn jour, on au contraire avaut que la rosée soit évaporée, qu'on les saisit plus aisément, parce qu'alors ils sont presque engondis. Liafluence de ces insectes est quelquefois si grande, qu'on eite daus les annales de la soce. entonn., la diliggence de Gisors arrectée 
le 18 mai 1852, par un nuage de ees animanx. Se précipitant au-devant des ehevaux eomme une grèle, eeux-ei en furent tellement effirayés que le eondueteur se vit obligé de rétrograder jusqu'an village d'oì il était parti.

Les limaces sins eoquille, les eseargots ou Limarons. limaçons à eofjuille, ne sont pas des insectes, ils sont en deliors de mon plan. Mais leurs ravigges ressemblent à ceux des inseetes, se confonlent avee eux, et il ne sera pas hor's de propos de signaler quelyue moyen de les cearter. On farantit les jeunes semis des premières en les saupoudrant d'un mêlange de chaux et de cendres. Des éeailles d'huitre grossièrement brisées et semées sur le terrain les détournent aussi, paree que ees petits fragments tranchants les blessent et les arrêtent. Ide proeédé indiqué eontre les eloportes (ch. des plantes polagères) sert ì atlirer les eseargots, on les cueille aisément et l'on sien défait.

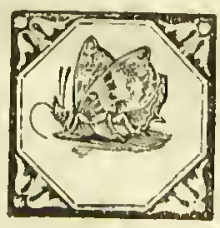





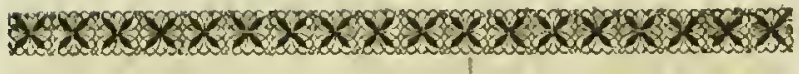

\section{CHAPITRE $x$.}

DES INSECTES QUI VIVENT AUX DÉPENS DES ANiMAUX DOMESTiQUes, DE L'HoMME ET DE NOS PROVISIONS DE MIF́NAGE.

J'ai cru devoir consaerer un ehapitre à ces sortes d'inseetes. Ils sont néeessaires à connaître. Ils nuisent à l'aģrieulture en attaquant les aides de ses travaux, et ee qui fait une partie eonsidérable de ses ressourees. Je pense, en les signalant, et en indiquant le peu de remèdes connus, ne pas m'éloiģner du but que l'Académie s'est proposé. Cet article me paraît avoir une liaison néeessaire avee le reste de ce Mémoire, qui sans cela pourrait paraitre ineomplet.

Le taon est le plus gros des insectes qui attaquent nos bestiaux. Avide de sang, plus ineommode et plus actif dans les temps pluvicux et dans les pays humides, il fatigue continuellement 
les boufs et les ehevaux; il s'enhardil quelquefois jusqu'ì piquer l'homme. Il est impossible d'indiquer aucun préservatif contre eet animal. Sa larve peu connue vit dans li terre. On eompte plusieurs espèees de taou. Ils ont deux ailes quelquefois taehetées el colorées; leurs yeux sont ornés de couleurs brillantes, et leur corps est ordinairenıent gris ou jaunâtre avee des taehes blauches on noires.

OEstredulceuf. L'oestre est aussi un diptère. Oı en distingue plusieurs espèee d'assez grosse taille, et toutes ou presque toules vivant dans leur état de larve, aux dépens de nos animaux domestiques. Liestre du breuf pond ses oufs entre les poils du dos de l'animal. La larve qui eu uaít perec la peau malgré si dureté; il s'y forme peu à pen une tumeur de la grosseur d'un ocul' de pigeon. C'est là que vit l'inseete qui ne s'est laissé qu'un petit orifiee pour eommnniquer avec l'air extérieur. Les bouviers ne s'en plaiguent pas, du moius elıez moi; je leur ai même entendı dire, que eette espèce d'exutoire eontribuait à la santé de l'animal. Dans la réalité ils ne maiggrissaient pas el ne paraissaient pas du tout sunfirir. Bose indique contre eet inseefe parasite, au eas qu'ou le trouve nuisible, de piquer la larve avec une forte épingle en la passaut à travers l'ouverture de la tumeur. Mon bouvier, quand je voulais 'avoir l'insecte, I'y faisait autre chose que de 
presser fortement les côtés de la tumeur, de manière à faire sauter l'animal en dehoo's.

I.es ehevaux sont sujets aux attayues de trois espèces de ce mềne genre. Lírestrus equinns okstrus equinus dépose ses auf's sur les jambes de devant; le cheval en se léehant les porte dans sa bouche, ils y éclosent et se glissent dans l'estomac et les intestins de l'animal où ils trouvent leur nourriture dans les humeurs qui les tapissent. Lirestrus hremorrhoidalis fait sa ponte à l'anus même, et OEstrus lim morchordalis la larve se nourrit encore dans les intestins. Il cn est de même de l'restre ulériu qui vit aussi dans obstro utcrin. le ventre des bouf's, des moutoms et autres bestiaux.L'cestrusequiuns dans son ét at de mouehest roussâtre; ses ailes d'un blanc sale sont traversćes par une bande brunc. L'e. hemorrhoidalis est brun avee la partic postéricure du corcelet ef du ventre et les pattes rousses. Celui du bouf est eoupé de bandes noires et roussâtres alternativement. Licestre de la lrebis, dont je vais parler, a le corcelet roussître et l'abdomen noirâtre marbré de gris. Les ailes de ces dernières espèces sont sans taches; L'astre de la brebis est peu velu; les autres le sont beaueoup. Ce dernier, ostrus ovis, pond son ouf dans le nez des oEstrus avis. moutons et des elìves, d'ò̀ la jeure larve se gylisse dans les sinus frontaux. C'est lài qu'il s'é4ablit. Il pénèlıe quelquefois si avant vers le cerveau, que l'opération du trépan devient 
nécessaire. II arrive même que la larve meurt dans sa retraite sans avoir la foree de sortir quand l'époque de sa métamorphose arrive. Il se forme alors des dépôts purulents qui peuvent devenir gangreneux. Dans les autres cas on injecte par les nazaux l'hule empyreumatique, remède vermifuge, extrait des eornes dux pied distillées, ou mème de simples infusions de plantes amères. Le tournis, maladie des brebis, est produit quelquefois par eet inseete, quand. il labite en nombre les sinus frontaux. Il est dû souvent aussi à d'autres eauses : quand il provient de la larve de l'oestre, on le distingue d̀ l'absenee d'inflammation, et aux éternuments fréquents et violents. Pour faice périr les larves des intestins des ehevaux on des autres animaux, il faut leur finire avaler la même huile empyreumatique on l'injeeter par le fondement si on a lieu de eroire que le siège du mal soit plutôt de ce côté. Si on est oblig̣é d'ouvrir les tumeurs des bœufs, il faut panser la plaie avee un mélange de erême de lait et le goudron, ou avee la térébenthine dissoute dans le jaune d'oeuf.

lippohosque,

L'hippobosque on mouche-rraiynée, mousque Xouche-araigné bouboine en patois méridional, s'altache au ventre Mousqu* buuboine. des elevaux, des mulets et bêtes de ce genre. Is ne penvent ordinairement s'en défendre, ni avee leur quene ni avec lenrs paftes. Ces piquâres lene donnent une violente inquiétnde dont se 
ressent quelquefois la sûreté du cavalier. Cétte mouche qui s'attache à l'hoonme nệme est assez plate, sa tête est armée d'une trompe courte et très forte et piquante. La peau de son corps, surtout du corcelet, est dure et a l'air d'une cuirasse : elle a deux ailes; sa coulcur est roụssâtre, avee quelque traits noirs.

Une espèce approchant du même genre, le melophagus ovinus, est toujours aptère, son corcelet plns étroit que eelui de la préeédente, Melophegiк oviatus. à qui d'ailleurs elle ressemble un peu, et son ventre plus léérissé de poils. Nos fermiers lui donnent le nom de lingaste qu'on donne anssi à la mitte des chiens, dont nous allons parler, quoique fort différente. Aussi ne faut-il pas faire un grand fond sur ees noms vulgai res sujets à varier suivant les loealités, et par lesquels les gens de la campague désiģnent plutôt les mềnes effets produits par divers anintaux, que lears caractères extérieurs.

Unc autre espèce ornillomyia Lhirusudinis, assez semblable ì la première, mais dont les ailes sont coupées en fer de lanee, infestent les nids des lirondelles, ce qui nons importe peu, mais aussi quelquefois ceux des pigeons. Si l'on n'y porte remède, eet inseete, ainsi que l'argas argas relloss. reflexa, s'introduit jusque dans leurs oreilles, les tourmente, lait périr les petits, et foree quelquefois les père et mère à ahandonner le 
colombier, quand on les y laisse pulluler. Il faut pour les éearter, semer dans le nid dı tabac en poudre, et en répandre sur les pigeonneaux. On connaît ees inseetes sous le nom vağue de punaise. L'argas a quelquefois jusqu' ì trois liggnes de long. Il est elliptique, assez applati; son eorps d'un gris pâle est rebordé tout autour.

lxode, Le genre ixodes, Latr., de lit famille des Hitte, mittes ou tiques, vulggairement en franẹais louTique,
Louvette. vette, tourmente aussi les animaux. Tout le monde connaît l'espèee qui s'attaelie aux oreilles des ebiens de ehasse. Fort petits quand ils sont à jeun, ils se gonflent eonsidérablement une fois remplis de sang. Les reettes indiquées eontre les poux penvent réussir eontre les petites espèees de tiques; mais il o'y a de véritablement sûres que les préparations mereurielles qui ne sont jamais sans danger, et trop elières pour être employées sur les grands animaux, tels que chevaux et bouls. Les ixodes dans leur état ordinaire ressemblent beaueoup à l'argas. Ils sont plus ovales et différemment colorés. Ils s'enfoneent quelquefois très profondénent daus la peau. Si l'on ne peut les arraelier à cause de leur quantité, et pour ne pas causer trop de douleur. à l'animal, on les fait tomber avec un pineeats imprégné d'huile d'olive ou mieux eneore d'huile de térébenthine où l'on a broyé un peu de tallae, et ils périssent. 
On appelle ricins, les poux des oiseaux, que nous nommons vulgairement pipidons, en français pouillons. Les oiseanx de basse-cour Pouilloos. en sont quelquefois tellement infectés, les poulaillers tellement pleins, que les personnes qui y entrent pour recueillir les oufs ou domer de la nourriture à la volaille en sortent couverts de ees petits insectes. Les pigeons out les leurs comme les poules. Chaque espèce d'oiseau a presque son ricin particulier. Les colombiers sont quelqnefois abandonnés à cause de la unultiplieation de ces poux, ainsi que des autres inseetes que j’ai dénommés plıs lıant. On ne peut alor's y rappeler les piggeons qu'après avoir nettoyé soigneusement l'intérieur de leur domicile, et employé pendant trois ou quatre jours les proećdés rle désinfeetion. Il faut tenir en général les poulaillers et les colombiers dans une grande propreté, y pratiquer des courants d'air, qui tempèrent la elıleur lumide qu'on y remarque souvent; que les nids soient en terre enite on en plattre, non en osier, ni en plinches; qu'il y ait loujours dius le pouIailler ou très à portée une fosse pleine de sable, ò̀ les oiseaux de basse-cour puissent se vantrer. Faites brûler dans le local, quand cela devient néeessaire, de la fleur de soufre pour tuer la vermine qui doit y ếlre lomlée, quand les poules se gralleut, mais choisissez les leures où elles sont dehors, el tenez pendaut l'upéraliou les portes et 
et les fenêtres bien fermées. C'est surtout sons les ailes, sur la tête, et les autres endroits. In corps, oì le bec et les pattes ne penvent atleindre, quil funt les chereher et les trier, si on veut le faire à la main. On iudique de les laver avec la décoction de fruits de fusain, de feuilles de noyer on de sureu, micux encore de poivre ot de staphisaigre, si ces drogues n'étaient pas trop chères pour les pauvres paysans; on bien avec un quarteron d'hellelore blane qu'on a fait bouillir dans quatre pintes d'eau jusqu'à réduetion d'unc pinłe et demie, mélange qu'on passe et qu'on employe en y ajoutant demi-onee de poivre et demi-once de tabac grrillé. (Dict. de Rosier, tom. 8.) Les vicins diffèeent des poux, par les organes de leur bouche et par leur forme ordinairement beaucoup plus alongée. Les volailles qui en sont attaquées maigrissent peu ì peu, si l'on a pas soin de les en débarrasser.

L'homme lui-ınême, malgré sa supérioritẻ et. sa domination sur tous les animaux, n'est que trop souvent humilić et aflligé par de très petits insecte parasites. Ne faut-il pas aussi consacrev quelques lignes à ees pestes domestiques? Nest-il pas ầ propos de recueilir iei quelques procédés, sans doute plus on moins connus, mais qu'on ne doit pas être fàché de retrouver à leur place. La propreté, les soins assidns, les habitations saines, (et mallıeureusement celles du pauve le sont bicn 
rarement) sont le premier remède qu'il faut Les Pous. apporter contre les poux. En effet les enfants négligés, les lionimes malpropres sont sujets presquemiquement auxattaques de eette vermine. Punaise. La punaise est plus diflieile à extirper non-selllement des hôpitaux, des eolléģes, mais même des maisons mieux soignées de l'homme aisé. On Recettes. a indiqué bien des recettes contre ce vilain animalimporté d'Asie en Europe depuis un grand nombre de sic̀eles. On peut les dire presque toutes nulles ou insuflisantes. Les gens de la campagne se servent de claies d'osier ou de eannes qưils mettent à la tête des lits : on y place même quelquefois des feuilles de harieots ou de pariétaire dont les poils un peu raides les arrêtent en les empèehant dans leur marehe. Le matin on seeoue les elaies et on tue les punaises. Cette simple méthode cst bonnc, mais il faut les passer à l'caı bouillante de temps à autre ponr anéantir les anfs qu'elles pcuvent y avoir pondu. En voyage, dans les auberges oì ees insectes importins sont presque toujours trop abondants, on peut les ćearter de son lit, en tenant une cliandelle ou lampe alluméc à proxiunité et à la lıuten' du lit, paree qu'elles eraignent et fuyent la lumière. Je trouve dans le jom'nal des connaissances utiles, 1855, mars, p. 84, un nouvea remèle contre les punaises. On le doit an hasard : il consiste, dit-on, duns 
l'attraction que la plaute vulgairement nommée passerage (lepidium ruderule des botanistes) exeree sur ces insectes. "Des éelıantilions desséehés de eette plinte, ayaut été déposés dans une elaunbre infectée de punaises, et d'oǹ rien n'avait pu les elinsser, se eouvrirent de ees insectes : presque tous furent trouvés morts, et ceux qui vivaient encore, étaient dans $\mathrm{mn}$ tel état de torpeur, quill fit possible de les jeter au feu sans qu'un seul parvint à s'échrapper. " Ge fait a besoin d'être constaté parl plusieurs expérienees. Je ne l'ai pas encore pu, la platute indiquée ne croissant pas dans les contrées que j'lralbite. M. Parmentier a déjà essayé eontre les punaises, le passerage et d'autres plautes anti-scorbutiques, soit en uature, soit en distillant et employant le sue de ees plintes. Il assure avoir réussi à les éloigner, mais tout cela ne peut les expulser ou les arrêter que partiellement. Toutes les herbes ou drogues fortes peuvent tuer les punaises, mais il fundrait qu'elles leur fussent immédiatement appliquées; la diffienlté est telle quil vaut micux les trier et les écraser; les fumigations et les lotions ne pourront jamais les détruire totalement.

On indigue contre les poux lia poudre de stuphisaigre délayée dans le vinaigre, celle de coque du levant, le tabae, diverses frietions huileuses, qui, bouchint les organes de leur 
respiralion, les font périr; une pommade eomposée de snc' de seabiense, demi-nnce; poudre d'ellebore blane, un gros et demi; térébenthine, une once; avec pareille quantité de grraisse de porc; l'ouguent grris mereuriel, et le préeipité rouge, mêlés avee de la graisse. Ces deux dernières reeettes ne sont pas sans ineonvénient et. doivent ĉtre employćes avee ménagement. Quand les poux attaquent les animaux de ménage, on les frotle avec les mêmes droğues ell nature on en déeoelion. On y einploye aussi eelles de poivre, de Lède, d'orpin ìere (Schlum nerc).

La puce est le troisicme inseete ineommode qui fatigue aussi l'lomme, saus abandonuer les bestiaux. Elle subit les trois métamorploses ordinaires anx antres inseetes, contrairement aux espëces précédentes qui vivent et croissent toujours sous la neême forıne. Dans son prẹnier ćlat, c'est un petit ver blauc on rougestle, alongé, fort agile, qui se tient dans les replis du linge de corps, surtont quand il s'y anasse un peu de clarpie. Sa nymphe se renferme dams une petite coque soyeuse. La reeherelıe de l'inseete dans ses divers ćlats, et la grande propreté, sont les seuls moyens de s'en délaire.

La piqûure des gुnếpes, et surtont de lá grosse espèce le frelon, vespa crabro, est quelquefois Guepes. Vespacrabro. infiniment daugerense pour les bestianx. On a Je Eréloo. vı des ehevaux attaehés à eỏté dı nid de ces 
animaux, souvent anssi à côté d'une ruehe d'abeilles, irrités d'une ou denx piqûres, frapper. les pierls, renverser ou fouler les nids. La fureur de ees iusecteg vient alors à son comble, et souvent le eheval ne pouvant s'échapper, meurt sous les eoups redoublés d'aiguillon. Quand le mal n'est pas à eet exeès on peut pauser et guérir aisément les tumeurs, avee de l'eau fraîclie mêlée si l'on veut de viuaigre, si les piquires sont pen de ehose. Quand elles sont plus multipliées; employez-y l'urine ehaude, l'huile et eneore le vinaigre. La même reeette peut s'appliquer aux piqûres des eonsins yui dans eertains pays tourmentent tellement les bestiaux quion est obligé de les faire vautrer dans la boue pour leur opposer une espèee de euirasse. L'alkali volatil neutralise promptement le venin de ees pelits inseetes, mais on ne peut pas l'employer aisément pour les grands animaux.

Les piqûures du seorpion sont également fàscorpions. eheuses. Nous en avons deux espèces, la commune qui se trouve partout, et le scorpio occitumus qu'on reneontre en Languedoc, surtout anx environs de Souvigna'gue. Celui-ci est plus grand, - d'un janne terue, et se trouve ordinairement sous les pierres, sá piqûre est plus mauvaise. On allire les scorpions pour s'en débarrasser, en plaçant dans les lieux obseurs qu'ils fréquentent, des pots à fond large et plats, et non vernissés, 
qu'on renplit d'eau, et qu'on ticnt un tant soit pen sonlevés an-dessns dn sol en glissant dessons quelques petites pierres. Ils se eachent dessous ees pots, attirés prar leur fraîcheur, et on les y déniche.

Les aheilles qui sont à la tête du petit nombre Les ahoulles. d'insectes qui nons sont utiles, parec quils eonpensent par les produits quils nons livrent, les maux que nous eausent les antres inseetes, les abeilles ont aursi leurs ennemis. L'énorme splinx Sphinx à tâte à têle de inort pénètre dans les mehes qui ont des onvertures trop grandes. Friand de micl, et défendu eontre les piquires par son épaisse pean et le battement de ses ailes, il eonsmme les provisions des abeilles. Denx on trois colćoptìres du genre cle'vss tronvent moyen de déposer leurs œufs sur le pollen des fleurs qne les abcilles recueillent; elles apportent avee elle leur ennemi, la larve qui en éclot dévorant les abeilles, leur Guàpes. miel et la cire. Les ģuèpes de grosse taille, im insecte hyménoptère d'un genre un pen voisin, le philauthus, saisissent et dévorent l'abeille ellemème dans les prés et sur les fleurs, sans eraindre leur aignillon, arme dont ils sont eux-mèmes liilanthys lerus aparius. alvearius. pourvis. Les clerus apiarius, alvear'ins, lencosleurospideus. Trichoders, pideus dans nos provinees méridionales, Latr., (genre Trichodes, Falor.), sont d'assez gुrands eoléoptères, alonģés, ì corcelet cn ceitr, ì antennes en massue, dont les élytres léģèrement 
velues, quelquefois presque rases, sont d'un joli rouge, variées de bandes et de faches moires.

Les phos grands ennenis des ruehes, sinon

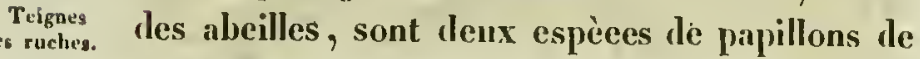
la famille des teignes. Leurs chenilles poussent les galeries ou fourreaux de soie, sons lerpuel clles vivent toujours abritées, à travers les gîteaux. Elles rougent la eire qui lenr sert de nourriture, et se repaissent anssi de uniel, an point que pour peu qu'elles se multiplient, tout est gâté, la eire rongée, et salie de leurs exeréments, le micl répandu; et les abeilles se royant obligées, de quitter tout à fait des ruches empestées; c’est une grande perte pour le propriélaire. Je erois que nos provinees méridionales y sont plus sujettes que le norl. Je sais que ehez moi il est souvent diflieile de couserver un eertain nounbre de ruehes. Les meilleurs observateurs, Réaumur, Rosier, Huher, sont fort embarrassés pour remédier au mal. Rosier eonseille de nettoyer les portions de ruehes envahies par les teignes, avant qu elles poussent leur's dégâts jusyu'au bout. Le seul moyen est de fairc passer les abeilles dans unc nouvelle ruelie. Ou est alor's le maître de la nelloyer à fond et d'extirper tolalement lont ee qui a ćlć infecté par les tcignes, en mrêlant en même lemps lenr inultiplication. Il n'esı pas tros diflieile de faire cette opéralion. Il faut, l'après Réanmur, renverser la ruelie enulou- 
magée, l'ćtablir dans une position vertieale, soit en ayant préparé une fossé qui la soutient dans cet état, soit par quelques étais. On adapte ensuite une rnelie vide sur l'ouverture de la première. On relire le support de celle-ei qui servait à la boucher dans le moment de son déplacement, et par le moyen d'une servielte, d'une uape ou autres oljets semblalules, on lutte parfaitement ensemble les denx ruehes. Il est inutile d'ivertir de prendre les moyens ordinaires pour se défendre de la piquare des abeilles qui ne supporteraient pas patiemment l'ineommodité d'un déménagement. La prineipale préeaution est de ne faire eette opération que le soir ou le matin quand elles sont ou endornies ou engourdies. Après cela on frappe avee une baģuette sur la rnelıe inférieure : les abeilles troublées la quittent alors peu à peu pour passer dans eelle qu'on a placée au-dessus. On la détache alors, on la place à l'endroit oì elle doit ètre fixée; on y apporte, on y fait entrer les abcilles trop paresseuses qui ont pu rester daus les gâtleanx, lans les reeoins de la première, quion peut ensuite netloyer à l'aise. On enploie aussi la f'nméc pour les ehasser de leur ancien domieile; et quelquefoisl'eau remplace l'effet de la baguette. Daus ee seeond cas, on peree le laut de la ruelie quion veut évacuer. On adapte à cette même parlie supéricure une ruche nouv elle. La première trempe daus un baquet diean quion renplit de 
plus en plus et qui thasse insensiblement les abeilles et les foree le quitter leur première demeure pour habiter la nouvelle. Il faut nettoyer, raeler jusqu'au bois l'aneienne ruche, avant de la faire servir, frour qu'il n'y reste ni eufs, ni ehrysalides.

Galleria crreana

La première et la plus grande espèce de ees papillons, galleria cereana, a six lignes de longueur au moins; elle est d'un gris de perle, avec un espace triangulaire sur le dos des ailes produit par une dépression en cet endroit, espaee d'un. gris beancoup plus pâle avee quelques touffes de poils eourts, relevés, qui ressemblent à de petites verrues et qui sont noirâtres. Ses antennes sont sétacées; sa bonche se termine en avant par une espèce de bee. La seeonde espèec galleria alveo-

laria est déerite et figurée daus les Mémoires de Réaumur. Elle est an moins trois fois plns petite que l'autre; sà tête est jannâtre, son front est applati et nullement linppé; ses ailes supérieures sont d'un gris uniforme un pen lustré, les inférieures sont phus pâles; elles n'enveloppent pas le corps en eylindre, mais en forme de chappe, plus larges eependant ì l'extrémité qu aux épaules. Dans nos climats plus chauds ees teignes donnent deux générations elaque année. Au commencement de juillet et en sepiembre, on peut aperenvoir les papillons à l'entrée de la rnche, le matiu ef le soir, sous son plancher et sons sa 
chemise. On peut même mettre alors ì portée de la ruche quelque pierre plate relevée d'un eôté, qui leur oflirira un abri et donnera une facilité de plus pour les détruire. On s'aperçoit de la présenee de leurs ehenilles anx gyrains de eire qui couvrent le planelıer de la ruelie. On se débarrasse plus aisément de ees parasites nuisibles, en ñ laissant pass trop longtemps séjourner la eire. Celles à hausse, par conséquent, qui donnent le moyen d'en enlever eliaque année une partie, ont un grand avantage sur les antres.

Les diverses sortes de teiģnes qui fréquentent nos maisons font beancoup de maI, si on ne snit pas attentivement leurs prog̣rès pour les arrêter à temps. Les habits de draps, les laines, les tapis, les ganitures de menbles, les fourrures, sont promptement pereés et rongés ; il en résulte des pertes inealeulables. Bose évalue eelles qu'on éprouve de la part des teignes des fourrures des fourrures. dans la ville de Paris, ì environ un demi-million. Le papillon a les ailes blanehîttres, un point noir au milieu; sa tête est grise. La teigne sàttaque mon-seulement aux fourrures, mais à tout ee qui est tissé en laine. Là linea sareitella, un pell Tines sarcite lta moius commune et plus facile à détruire, vit de la mềme manière et sur les mêmes étoffes, tapis, meulsles, ete. Une hrosse rude l'enlève avee son fourreau, du drap qu'elle habite; on peut l'écraser par le frottement de lat main; enfin en secouant 
el baltaut l'́tufle et l'exposant au soleil pendant deux on trois jours, elle tombe, se dessèche et périt. Elle a cing lignes de long dans son état de papillon comme la précédente; ses ailes sont cendrées, elle a un point blane de eliaque côté du coreclet. Ia chenille vit, comme on le sait, cachéc dans un fourreau dont le fond est de soic, et qu'elle fortifie des poils et des débris de la substanee dont elle fait sa nourriture. Elle charric ce fourrean avee elle ì mesure que les aliments lui manquent ì la place oì elle sétait fixće. Il en est de même de l'espèce précédente et de la suivante. Quand la t. sarcitella veut se métamorphoser, elle se retire avee son fourreau dans les recoins, sous les rebords, les saillies des meubles et des lambris. On peut l'y reehereher et la détruire. On la distinguera à son fourreau coloré diversement suivant les lurins de l'étolfe ou du meuble qu'elle y a adapté.

La linen vestianella vit de méme que les autres. Ses ailes sont eendrées avee le bord extérienr blane.

Tous ees papillons-teignes, ainsi que eelui dont je vais parler, se trouvent fréyuemment dans les maisons et sout attirés par la lumière auprès de laquelle ils viennent voltiger. Il ne fant nullement négliger de leur donner la clıasse pour en détruire le plus possible. 
partements du midi, celle qui fait les plus grands ravages, anx habits de drap surtout, anx laines des matelas, diffère un peu des précédentes. Son fourrean est ordinairement de pure soie; elle ne le traine pas après elle, mais elle le prolonge pour ehereher plus loin sa nourriture. Le papillon est gris-jaunâtre avee une huppe plus jaune sur la tête, je erois qu'il n'a pas eneore été déerit; il se rapproehe de la t. flavifrontella, mais il ne me parnît pas le même, les ailes de eelle-ei étant d'un gris sombre et beaneoup plus foneé. Au reste, eomme elle, elle ne se contente. pas de s'attacher à la laine, mais elle ronge les papillons dans les colleetions d'histoire naturelle, elle les détruit promptement, parce qu'elle coupe et plie des morecaux de leurs ailes pour en fortifier son fourreau. Mais quels remèdes procédés contre à des dégaìts si importants? Chaem donne sa les Teignes. reeette, elles sont presque tontes fautives. Réaumur indique l'esprit de vin en vapeur et la fumée de talsae par le moyen d'un réehaud et en la soutenant pendant vinģt-quatre h. Il sullit mềme, sui'vant eet exeellent observateur, d'enfermer avee les draps on les garnitures de meubles dans la mềne armoire, une pièee d'étoffe bien impregnée de cette fumée. Toute vapenr de plantes iieres et fortes produirait le mème effet. Les punaises sont ehassées par le même proeédé, et Réaumur assure qui on n'en trouve point dans les 
chambres qne fréquentent les fimmeurs. Mais est-il bien faeile de faire pénétrer partout ees vapeurs. J'ai éprouvé moi-mềne que le eamphre, qu'on ne peut jamais employer qu'en quantitẻ limitée, ne rénssit pas tonjours. II paraît eertain que le revers de l'étoffe, fortement empreint de savon, éearte les teignes, mais cela ne pent servir que pour les meubles. Une toile lien savonée, bien imbibée de savon, tenlue sans laisser passer l'air cxtéricur au-dessus de la eaisse ou de la jarre où l'on peut entasser les habits en été, produit le même eflet. J'ai vin plusieurs personnes se servir de jarres qui donnent une grande fraîcheur aux objets que l'on y renferme. D'autres tiennent les étoffes de laine dans des cares, des endroits frais, dans des eaisses de eyprès dont l'odeur reloute et éloiģne les insectes. Tout cela est bien, mais le micux est de secouer ses habits et ses meubles en été an moins tous les quinze jours, et de se servir en même temps d'une bonne brosse qu'on passe partout. Ce moyen m'a toujours réussi : tous les étés je porte avec moi à la eampagne tous mes lıabits d'hiver, quelque embarras que celi eanse, et je les soigne moi-même. Quant aux matelas il est inutile de dire qu'il faut remuer et rebattre en ćté ecux dont on ne se sert pas.

C'est vers le milieu ou la fin du mois d'août et jusqu’en septembre qu'on peut plus aisément 
se défaure des teignes. A celle époque il ny a plus de papillons; les elıenilles plus jeunes sont alors moins tenaees et tombent plus facilement. Réaumur a éprouvé qu'elles eraignent le suint de la laine. En effet, elles n'attaquent jamais les laines naturelles et non eneore préparées. Il a réussi à les éloigner en frottant les étoffes avec la graisse ou l'Inile des toisons reeueillie sur l'eau ou on lés a lavées, avec cette même eau à un dégrvé de chaleur très prononé, ou enfin mênze avec une toison grasse. D'après ses expériences l'odeur de l'essence de térébenthine, enfermée avec ees teignes, les fait promptement périr. On frotte les meubles, les draps, les fonrrures, avec me brosse qu'on en a imprégnée : on place dans les armoires on les eaisses qui les renferment, des fenilles de papier, des morecaux d'étofie, des linges qui en sont imbibés et qu'on multiplie suivant la capaeité du loeal. Au bout de vingtquatre heures les teignes meurent sufforpées.

Les pelleteries, les plinmes, les housses des clievaux, sont sujettes à être rongées par les larves de quelques coléoptères. Les unes sont ovales, velues surtont vers leur queue qui est ornée de trois on quatre bonquets de poils qui s'épanouissent de temps en temps en éventail; leur longueur n'est que d'une ligne et demie. L'autre est: longue, minee, et ronde comme uu petit serpent : sa quene a anssi nne pefite aigrette, 
mais les poils du corps sont fort courts, sa tête est ronde et assez grosse; sa coulcur rousse ou rouille de fer; sa longuenr de deux lignes et demie ou trois lignes : les unes et les autres ont six pattes peu apparentes. Outre les soins et la recherelıc assidue, et l'abri dans les endroits frais, il n'y a que l'ean bouillante on an moins bien clıude, on la elıaleur du four qui puisse faire périr ees insectes. On peut eneore employer Yhuile de térébenthine ou un gros de sublimé-corrosif dissous dans l'esprit de vin et mêlé dans une pinte d'eau : on soulève le poil des peanx ou des pelleteries avec un peigne, puis on imbibe leur racine avec la liquenr et on les laisse séeher ensuite. Les premières larves donnent denx ou trois espèces du genre anthréne, petits animaux à corps ronds, à antennes en massue très courtes, dont les élytres grises ou noires sont variées de taches on de ligines ondoyantes Antbrenus pimpinellar, junnâtres ou gुrisâtres : anthrenus pimpinella, vcrbasci, musaorum. Elles se tronvent en grand nombre, dans ee dernier état, sur les fleurs des champs et aussi très souvent dans les inaisons. On a une grande peine, dans le midi surtout, à éviter leurs ravages dans les collections d'histoire naturelle. La seeonde larve dont j'ai parlé doune naissance ì une espèce de coléoptère de la même launille on trilıı naturelle. C'est le plimms Ialro. Il a de longues antennes à articles 
très distinets : son corcelet est étroil et comme Itiaus latro. divisé en denx on quatre lobes; son alıdomen avec les élytres qui le reeouvrent est arondi et assez boubé, hérissé de poils raides parsemés, sa couleur est d'un brıı quelquefois jaunâtre. Il uait en plein liver depuis la fin de novembre; on le tronve dans les maisons, et e'est alors qu il fait sa ponte.

Les bois des menbles, les boiseries, sont percées par les larves des vrillettes, an point de tomber quelquefois en porssière. La peinture à l'huile et au vernis est le seul moyen de les en préserver, si ce n'est aussi en les exposant à des fumigations réitérées d'acide sulfirique. L'anobium on vrillette, est ovale, bien alongée, à antennes dont les ilemiers artieles sont plus gुros, Auobiuin pertinax. Paniceum, Ciastaneum. très longs et chacun un peu en inasse; sa tête est enfoneće sous le coreelet qui lui-même est ordinairement bossu en capuelion, selon l'espèce : elle est d'un gुris un peu roussâtre. Elle se laisse tomber contrefaisant le mort dès (ju'on la touche: anobium pertinax, paniecum, castaneum.

Les hois dé eonstruetion sont aussi snjets à dre attaqués par les larves de beaneoup d'in- deronstruction. seetes, surtont de coléoptères. On les engarantit. en les laissaut tremper quelque temps dans l'eau de mer, on mienx encore dans l'eau donee chargoée d'irlum. Lai larve du lymexylon navale s'élail tellement multipliée ì Toulon, dans les ehantiers 


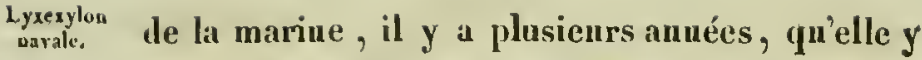
avait eausé de grands dommages. Elle est fort longue et grèle; le coléoptère est alongé luimême, d'un fiauve pâle, avee la tête, le bord extérienr des élytres et lenr extrémité, noirs : eettc dernière couleur s'étend un peu plus dans le mâle, les antennes sont assez conrtes. Cet inseete est très commun dans les forêts de chêne du nord de TEurope.

Les provisions domestiques, le lard et le fromage prineipalement, attirent anssi des inseetes qui les rongent et les dégradent. Le premier est attaqué par une larve velue à poils assez longs, à six pattes, de forme semi-cylindrique, de six lignes de longucur, qui donne naissance à un dermeste, dermestes lardarius, eolćoptère remarquable par ses élytres, dont la première moitié est d'un gris cendré et le reste noir, ses antennes courtes en masse, son ventre blanehâtre orné de taches noires. Une chenille vit aussi dans le lard : clle a la peau raide et luisante, d'un brun roux, sa marche est lente, son aspect rappelle plutôt une larve, un iïle, qu'une chenille. Wlle se transforme eependant en un papillon rapproché des tinéites. Il est gris avee des ondes noires, ses palpes sont avaneés, et ses ailes en toit forment le triangle. On prétend que la même ehenille s'cst trouvée quelquefois dans les intestins des enfants, se nourrissant dn ehyle; 
et Linné qui eite ec f'ait, ajoule que èest la plus dangereuse espèce de vers intestinaux; aglossa Aglosya
pinguioalis pinguinalis est le nom que lui donne Latieille.

Les mittes qui rongent le fromage, et suppléent par leur nombre à leur infinimeut petite taille, sont eonnues de tout le monde. Les vers verstufromage sauteurs du fromage ne sont pas moins eonnus : ils proviennent d'une petite mouehe, un peu alongée, très noire, à ailes trausparentes, couelićes l'une sur l'autre le long du eorps, et qui saute clle-même autant qu'elle vole. Enfin la larve d'une assez petite espèee de coléoptère necrobia rufipes, de trois lignes de long; ainsi que lin- Necrobiarufipes secte lui-même parvenu à son dernier état, infeste le fromage, surtout quand il s'altère et s'aiggrit. Ce coléoptère est ovale, sa partie antérieure un peu plus étroite que les élytres, ses antennes à peu près comme les dermestes, et sa eoulcur d'un bleu violet.

La blatte des euisines, blatta orientalis est un inscete incommode, dégoûlant et très mulBl $\lrcorner$ tha oricotalis tiplié. Il abonde dans les boulangeries, aupròs des elıeninées de euisine. Il ronge et salit tous les objets propres à notre nomriture. Tantôt aptère, tantôt muni d'ailes sous des espèces de. demi-élytres sa forme est presque ovale et extrémement applatie, sa couleur noire, ses aulennes longues, ses pattes hérissées de petils piquants. Lilher In fait disparaitre dans les climals du 
nord; chez nous nue température plus donee entretient toute l'année son existence. On les empoisonne en mêlant de la suic aux sulbstances dont elles eherehent à se nourrir. On leur tend des pièges, tels, qu'une planche relevée de deux liģnes sous laquelle elles se réfugient dans le jour et avee laquelle on les écrase; une poiggnée de farine ou un morecau de lard mis sur un support nu milien d'un vase alongé, à moitić r'empli d'eau, dont on lenr rend l'alsord facile et où clles se noyent. Les ehats, les belettes, leur font la ehasse. Leurs oulfs sont gros et faciles à remarquer et à détruire. La blatte est du même genre que le liakerlae qui, sous la zône torride et dans les navires, deviennent une peste dont il est presque impossible de se débarrasser.

Il faut bieu aussi dire un mot de la mouche irritans. commuue, insecte bien ineommode, et dn stomoxys irritans on monelic piguante, tellement semblable à l'extérieur à la première, que sa trompe aiguë la distingue presque uniquement, et qu'en général on les confond ensemble, d'où vient eette opinion vulgaire que les mouches ne piquent qu'en automne. Celle-ci habite phis les elamps que les maisons. Le micl, la poix, l'ean-de-vie tr'ès faible et snerée, l'cau de savon, en eonvrant le vase d'un papier peré d'un trou d'uu ponce de diamètre et le frottant en dedans de sirop ou de miel, attirent les premières; elles 
s y prement et périssent. La mort anx mouches qui est dn eobalt pulvérisé est eneore plus eflicace; mais, si elle est mćlćc d'arsénic, on ne doit l'employer qu'avee préeaution.

Daus toute l'Angleterre on réussit ì défendre les ehevaux de l'importunité dles mouehes, en les frottant avee de l'ean dans laquelle on a fait détremper des feuilles de noyer.

La inouehe de la viande, musca vomitoria, grosse espèce blenattre, y dépose ses oufs ; elle

Mouche de la viande, vomitaria. la devine à l'odeur et la reeherche avidement: sa larve la ronge et l'altère. Il faut pour s'en défendre suspendre la viande dans un lieu olsscur où il y ait un eourant d'air, on dans une chambre dout les fenêtres au lien de vitres soient garnis de eannevas, paree que l'air lui est néeessaire. Un garde-manger ordinaire consistant en eadres bien fermés, garnis de cannevas, remplit le même oljjet. On sait que la viande altérée peut ètre revivifiée et rissainie en la faisant bonillir avee quelques morceaux ou de la poudre de eharbon. Une autre espìee le mouche est vivipare, ses larves vivent aussi sur la viande.

Une antre petile monehe on moneheron, Musca collaris. musca cellaris, se trouve en abondanee partout on il y a du vin ou dn viraigre. Sa larve vit clans la lie et tout ee qui fermente, même les fruits à demi-sees. Hille contribue sonvent à l'altération vles vins. Il n'y a l'autre remède que de tenir 
exaetement bouchés tons les vaisseanx et les vases on bouteilles qui renferment ees liquides. C'est ponr ne rien omettre que je nomme tons ces inseetes. On ne connaît d'autres remèdes eontre eux, que les soins jassidus, tenir le lard, le fromage, les autres provisions, ì eouvert pour empêelıer la ponte des aufs de ces inseetes, et dans un loeal plutôt see qu'humide. 


\section{CHAPITRE NI.}

DES INSECTES ENNEMIS DES AUTRES INSECTES.

Nous nous plaignons de ees pelits animaux 'ui nons entourent el nons nuisent. Nons essayons divers moyens. de les combattre, et nous les trouvons presque toujours iusuffisants. Nous murmurons peut-être contre la providence, et eependant ì eôté de tant d'inseetes dévastateurs, elle a placé un pareil nombre d'ennemis qui les pour'suivent cux-mêmes, les dévorent, lenr tendent les embîclies et ne sont ocenpés, par leur intérêt propre, qu’à les détrnire. đe erois done conelure utilement eet opuseule, en firsant connaître ees anxiliaires qui ue demandent qu à être favorisés, et n'ont besoin pour faire lenr offiee, ni de soins, ni de direction de notre part. Connaissonstes lone, ne les confondons pas avec nos vrais ennemis qui sonvent leur ressemblent 
beineoup, éparp̧uons-les, conservons leur la vie, fliand ils tombent entre nos mains.

Les chenilles, nons l'avons vu, nous font beaucoup de mal. Elles sont très nombreuses en espèces, quoiqne toutes cependant ue nuisent pas. On a nommé ichneumons ou mouches-ichneumons, un inseete lyyménoptère, dont les femelles sont armées d'une tarière plicée à l'extrémité de lour ventre; tantôt courte, tantôt trìs longue, elle leur sert à déposer leurs oufs : c'est sur la peau même des chenilles qu'elle les attachent. La larve qui en sort pénètre et vit dans leur intérieur, clle ne mange d'abord que le corps graisseux. Lil chenille continuc à vivre et à grrossir tant que les organes essentiels ne sont pas attaqués; elle parvient même souvent ì se elangुer en chrysalide; mais enfin elle meurt et l'ielnenmon en sort ou en forme de lirve ou en inseete parfail. et ne laisse que la peau de lir chenille. Les espèces de ce grenre sont excessivement nombreuses. J'en ai reconnu près de ciny cents très distinetes dans un seul canton de nos départements méridionaux. Se erois que le savant Gravenlorst qui en a fait fuaraitre, il y a quelques amées une mono. graphic enropuesunc, en déeril dans eet ouvrage plus de douze cents, ef vient encore de finiro paraitre mu supplégurut. An reste, non-senlement ils en renlent anx chenilles; mais tontes les larves de coléplipes ol quelques-mes dhyménoptères 
sont sujettes à leur servir de pâture; et eombien d'enuenis n'avons-nous pis eomptés dans ees deux elasses. La fanille des ichneumons comprend plusieurs genres que nous déerirons en peu de mots. Les figures achèveront de les faire eonnaitre au lecteur. Le genre connu sous le nom propre d'ichncumon a leux antennes ordinairement épaisses, sétaeées et un peu eontournées en spirale, quatre ailes nues dont les inféricures plus petites, la tête. et le coreelet peu diflérents des autres liyménoptères, l'abdomen ovale un tant soit peu applati, tenant au coreelet, par un pédidieule court, mais nimee comme dans la plupart des genres de celte famille; le eorps se termine dans la femelle par un aiguillon on tarière épaisse et courte, qu'on n'aperçoit pas du premier eoupd'xil, paree qu'il est à peine saillant. Cet aiguillon est composé de trois parties, les latérales servant de fourreau ì l'intermédiaire, qui elle-même composée de deux lames serrées et. aiguës, sert ì conduire l'ouf' jusqu'au gîte que la mère lui destine, sur le corps de quelque elienille. Lit grandeur des iclınemnons varie beaueoup; les plus grands ont un pouce et demi, quelquesuns n'ont que deux ou trois lignes. Leurs couleurs varient suivant les espèes, du jaune et du rouge jusqu'au noir, et plus souvent elles sont mélangées dans le même iudividı. Les pimpla sont alongées et eylindrique, l’abdomen n’est pas 
pédieulé, l'aiguillon des femelles est toujours long, quelquefois beaucoup plus que leur eorps. C'est à l'aide de eette tarière qu'elles pénètrent jusqu'aux larves et aux chenilles les plus eachées dans l'intérienr du bois ou dans les replis des

crypre. feuilles. Les cryptes ont le ventre épais et rehondi en dessus, leur aignillon est assez long; leurs antennes plus fines que daus liehnenmon pro-

oghion. prement dit. Les ophion, au eontraire, ont l'abdomen eomprimé sur les eôtés, taillé comme en forme de faux, et tenant an eoreelet par un long pédieule. Quelques ggenres de la même famille ne sont eomposés que de petites espèees, mais souveut leurs larves vivent en foule dans Microgaster. une senle ehenille. Tels sout les microgaster de Latreille. Il n'est pas rare de reneontrer dans la eampagne, ou autour des restes d'une mallicureuse ehenille, ou même eontre quelque tige de chaune, un petit paquet reeouvert d'mn eoton soyeux jaune ou blane; e'est l'amas des petites coques qu'ont filé ees ichneumons en quittant une seule elenille, et de lì sortiront en foule de petits inseetes ailés. Les autres genres out tous un air de famille cui les fera aisément reeonnaître.

De très petits inseetes, voisins de la famille des iehneunons, vivent anssi dans le eorps des ehenilles, et ordinairement en troupe. Ils rongent. égalenent lintérienr de plusieurs larves, par exemple de eelles qui minent les boiseries, et du 
ver des branches de l'olivier; je erois bien du moins les $y$ avoir surprises. Cette antre famille a le nom de cinips. Iuenrs antennes coudées et courtes, leur abdomen raceourei et sessile, les séparent des iehneuntons; leur tarière et leurs mours les en rapprochent; eette tarière est quelquefois aussi longue proportionnellement que eelle des cryptus. Le ventre de quelques cinips est eomprimé sur les côtés et presque de la forme d'une lentille; dans les autres, il est au contraire, triangulaire et applati en dessus, earéné en dessous. Leur eonleur est ou d'un noir luisant, on d'un vert doré, bronzé et très brillant.

Trois petites espèees d'lıménoptères, siģnalés par Olivier, dans son traité sur la conservation Cérapliron domestigne des gyrains, comme vivant anx dépens des teignes de nos greniers, et le cćraphron domestique déerit par M. Th. Say, eomme enneni des mêmes teignes, appartiennent ì la tribı des einips.

Plusienrs larves de mouches d'assez grosses espèees vivent aux dépens des ehenilles de la même manière que les iehneumous. Les plus grosses elıenilles, eelle du graud paon, les sphinx, sont priueipalement la proie de ees mouehes, toutes assez semblables daus leur état parfait à la monehe de la viande.

Les pueerons ont aussi leurs eunemis, des ennemis de plusienrs sorfes, qui ne se donnent 
pas une grande peine pour aller ehereher leur Nusca larvarum proie. Ce sont les mouches aphidivores, musea Ilémérobe. larvarum, Falbr. el antres; la larve del'hémérobe Lion
des pucerons. appelée par Réaumur le lion des puecrons; et celles de presque toutes les espèces de eoecinelles, sorte de coléoptères. Toutes vivent au milieu de ces faibles et stupides animaux, les dévorant les uns après les autres, sans qu'ils aient l'air de s'en douter et quilis songent ì fuir la mort qui les menace de près. Ia larve aphidivore est molle, sans paltes, mais donnaut des mouvements asse $z$ vifs à ses premiers anneaux terminé par nn pelit bee aigu quin forme à lui seul sa tête; le devant de son corps est ordinairement plus aminci que la partic postérieure, mais il change de forme au gré de linseete qui fait souvent rentrer sa tête et ses premiers anneaux, et les raecoureit. Devenue adulte, sa pean se durcit et lui forne une espèee de eoqne l'où sort la mouche qui vient à son tour pondre ses oufs au milieu d'me nouvelle famille de pucerons. Ces mouches nombreuses en espèces, ont ordinairement le corps varié de diverses conlenrs, jaunes, blanehes, fauves, noires.

On compte deux on trois espèces d'hémérobe. C'est un genre approchint des libelules on demoiselles. Ses ailes amples par rapport ì la taille de l'insecte qui n'a que quatre à cinq lignes de longy, sont fines comme de la gaze, blanches dans une espèee, réticulées forlement de uervures 
verdàtres dans une antre; elles forment le toit sur le corps de linseete qu'elles dépassent; les antennes sout très lonģues et sétacées : les yeux sont d'un brillant métallique. L'odeur que répandent autour d'eux ees petits animaux est nanséabonde et semblable à celle des exeréments. On voit souvent sur les plantes les nenfs de eet insecte: ils sont petits, très blanes, implantés au bout de tiges eapillaires qui sont ordinairement rapproelıées à leur base, et forment des faiseeanx. La larve qui en sort dévore à soul aise les pueerons. Elle est alonģée; ses eôtés sont frangéés dans quelques espèces, sa tète armée de deux mâchoires avaneées et erochues. Linne d'elles est remarquable par l'art avee lequel elle se fait une enveloppe, une eonverture élevée, avee les restes mêmes, les déponilles des pueerons; elle semble couverte d'une sorte de moisissure.

Les larves des eoecinelles travaillent ì découvext. Elles sont assez agyiles, alongées, avec six pattes antérieures un peu lougues. Leur corps Bêtu ì Dieu. est varié ordinairement de eoulenrs différentes, vache i Dicu. et ģarni de quelques tubereules élevés. La plus catarinette. grande et la plus cominune, celle de la coceinella septem-punctata est d'inn gुris eendré avec quelques points uoirs et quelques taehes jannes. Elle mange les pucerons, surtout eenx des fèves, vivant an milieu d'enx, et elıoisissant ì son gré ses vielimes qui u'ont gitrde de lui richapper. 
Quand son premier état est passé, elle fixe sa queuc contre une tige, un unur, clle s'y change en elurysalide. Flle est alors d'une forme entre la ronde et la triangulaire; clle est jauuâtre, pieotée de noir; clle donue naissance à un eoléoptère tuès arrondi et assez bombé, conuu de tous les agriculteurs sous les noms vulgaires de bête à Dieu, vaehe à Dieu, eatarinette en patois. C'est un insecte préeicux à eause de la frrande destruetion qu'il fait des puecrons : il faut done le conserver dans les jardius, dans les ehamps, et se garder de l'erreur de quelques jardiniers que j’ai vu persuadés que ees petits animaux apportent les pucerons sur les plautes, parce qu'ils les y roient au milieu de ees insectes. Il y a une graude quantité d'espèees de eoecinelles, toutes de la même forme, vivant presque toutes de la même manière, distinctes seulement les unes des autres par la couleur et le nombre des points ou des taelies de leurs élytres. Toutes doivent être regardés par l'ayriculteur comme d'utiles anxiliaires.

Fourmilion, Le fourmilion, formicaleo, myrméléon, Forinicale'o. eaché au foud de son trou eonique, erensé dans Myrućléon. un sable moloile, attaque sa proic à son passage, et détruit beancoup de fourmis et de petits insectes. Il se elınge en une mouche ou espèce de demoiselle à quatre grandes ailes diaphanes unais marouées de quelques taches et de nervures 
noirâtres. Elles sont d'une eonsistance noius solide que eelles des libellules ou demoiselles ordinaires, et se balaneent ou flottent davantage autour du corps. La tête est ornée de denx antennes médioerement longues et en massue.

Une larve de diptère saisit les petits inseetes Leptis vermileo par une manocuvre semblable à eelle du four-Musca vermileo milion. Il se ehange en mouehe (leptis vermileo $\begin{gathered}\text { Nemotèle } \\ \text { vertion. }\end{gathered}$ musca vermileo, Limn. némotéle verlion, Degeer), semblable à une tipule, l'albdomen alongé, jaunâtre, avec des rangs de taelıes noires.

Les hyménoptères, que Réaumur a appelé guêpes-ielıneumons, que les entomologisistes modernes nomment sphex, pompile, pélopée, Pumpile, ammopleile, ete., ne nourrissent leurs pelits, Pelopée. dont les nids sont ordinairement erensés en terre Ammophile. ou paitris de boue et appliqnés aux nurailles, que de ehenilles, de larves, d'araignées, qu'elles vont saisir et qu'elles entassent daus ees repaires où la jeune larve s'en nourrit à son aise. Tous ees inseetes sont remarguables par leur aignillon acéré, leurs jambes longues, les antennes presque tonjours en spirale, le ventre séparé souvent dn eoreelet par un pélienle plus ou moins minee, plus ou moins long, quelquefois eomme un fil. Plusieurs sortes de gunêpes proprement dites, les guêpes maęonnes, nour- Guêpermaconaw rissent de mème leurs petits.

La mante, mantis oratoria, mantis religiosa, 
Mimtis oratoria mantis uana, mantis pauperalu, vulgairement
religiosa, nana,

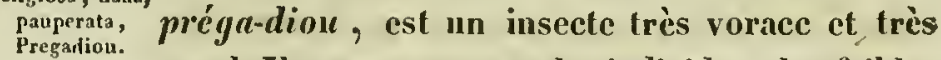
cruel. Il attaque souvent les individus plus faibles de sa propre espèce ou du moins de son genıe, il épargne encore moins les autres insectes. Vivant uniquement de proic, il détruit un grand nomlure de ceux qui nous nuisent. Cet animal est fénéralement connu; il est remarquable par sès deux graandes pattes crochnes et armées de piquants qüil dirige en avant de sa tête, tantôt réunies, fantôt étendues de côté. Lua première position lui a lait donner le nom de religiosa, etc., la seconde lui avait fait attribuer par les ancicins le don diudiquer le chemin aux voyaz̧curs, comme élant doué d'un instinct propliétique. Son ventre est gros, large, ovale, ses ailes et ses élytres assez amples le recouvrent. Il est de la classe des santerelles, quoique dépourvu de la faculté de saufer. Mes quatre espèces que je viens d'iudiquer ont des formes à pen près semblables.

Libellules,

Les libellules de toutes les sortes font une De moigelles gucre coutinuclle à tous les insectes ailés. Rapides daus leur vol, elles fondent sur cux avee me promptitude infatigahle. Cesont, dit Linné, les éperviers des insectes.

Les Carabirues. Sur la surface de la lerre, une nombreuse trilun de coléoptries rapaces, la famille des earabiques, vit aussi de proie, et taudis que les 
libellules donnent la chasse aux inscetes ailés, cenx-ei poursuivent avee un acharnement exeité par le besoin et la voraeité, tous eeux qui rampent sur le sol. Quelquès-uns de ees inseetes sont de très grande taille, le plus grand nombre d'une stature médiocre; leur forme est plus ou moins ovale, leurs élytres assez fortes et dures, le coreelet presque earré, quelquefois en eoeur, les antennes filiformes et it artieles distinets, les mandibules fortes et tranchantes : leur couleur est quelquefois métallique; plus souvent noire; quelques-uns sont tachetés de ronge on de fanve. Le earaetère prineipal de tonte eette famille est d'avoir à eôté des hanches postérieures, un moignon qui semblerait eommeneer une seeonde paire de euisses.

J'ose à peine recommander l'araignée eomme ennemie des insectes. Fandra-t-il laisser dans nos maisons, dans nos fermes, ses toiles sales et hideuses? Il est eertain qu'elles sont fiites pour arrêter et faire périr beancoup d'insectes. Mais n'ont-elles pas aussi d'autres ineonvénients? Je ne déeide rien. Au resie, eette famille est très nombreuse en genres et en espèces qui habitent les ehamps, ne salissent rien; la plupart ne font pas de toile et gyaghnent leur vie à détruire beancoup d'inseetes. An moins épargnons, n'ẻcrasons pas eelles-ei; nous y gagnerons sans auseun doute. 


\section{$-214-$}

Iei finit ma tìehe. Je le rćpète encore; j’ai cru devoir rassembler dans un même eadre, tout ee qui eoncerne les inseetes nuisibles, quels qu'ils soient. J'espère que dans eette vue on excusera ee qu'on pourrait taxer de trop de prolixité. J'ai cherehé à être utile, j’ai cru ne devoir rien négliger; telle est mon exeuse.

Je pense que quelques fignres d'inseetes, et le tableau synoptique que je joins iei, pourront faciliter les recherehes, et présenter un eoup d'œil gyénéral des objets traités dans le Mémoire.

pir. 


\title{
TABLEAU SYNOPTIQUE
}

\author{
ou
}

\author{
TABLE ALPHABÉTIQUE
}

DES Matiéres CONTENUES DANS LE MÉmoIRE.

(Le eliffre romain indique le chapitre et le chiffre arabe indique la page).

\section{A.}

Abeillcs, X, 187. Leurs ennemis, X, 187.

Acrydium Lincola, migratorium, stridulum, italicum, IX, 158-159.

Aglaope infausta, IV, 74.

Aglossa pinguinalis, X, 199.

Aleyrodes chelidonii, VII, 136.

Altica oleracca, III , 67. - VII, 137.

Altises, VII, 137. Recette contre les altises, Vil ,

137. Leurs cufs, VII , 137.

Alucitc des grains, I, 16, 22.

Ammophile, XI, 211.

Anthonomus pomorum, V, 95.

Anobium, X, 197.

Anthrènes, X, 196.

Apion cyaneum, V, 96.

Araignces, XI, 213.

Argas reflexa, X, 179. 
Artichaux, VII, 133. Ses ennemis, VII, 133.

Asperges, VII, 132,

Altelabe bleu, V, 95.

Attelabus cuprirostris, VII, 138.

Aulne, VI, 114. Ses ennemis, VI, 114.

B.

Barbarotte, VIII, 136, 145.

Balaninus cerasorum, V, 94. Nueum, VI, $10 \%$.

Baris ehloris, VII. 138.

Bête à Dieu, XI, 209.

Betterave, VII, 133.

Blatta orientalis, X, 199.

Blé, étuve, lavage, saison du vannage, remuer les blés, eau louillante, ventilateur, sacs isolés, nettcté des greniers, recette, I, 20, 23, 25, 26, 27, 28, 29, 31, 32.

Boiseries, X, 197.

Bois de construetion, $\mathbf{X}, 197$.

Bostrichus sex dentatus, II, 35.

Bombyx chrysorrhea, V, 80, 109. Neustria, V, 81. Dispar, V, 85. Proeessionea, VI, 103. Pithyocampa, VI, 105.

Boucerle, oliviers boucerlous, II , 52.

Bruchus pisi, VII, 141.

Cadelle, canadelle, I, 15, 19, 29.

Calandra granaria, Calandre , I, 17, 18.

Cantharide, II, 38.

Capricorncs, VI, $102,108$.

Carabiques, XI, 212. 
Catarincttc, XI, 209.

Casside verte, VI; 132.

Cecidomyia destruetor, I, 10. Pyri, V, 99. Div sainfoin, VIII, 149.

Ceraphron domestique, I, 32. - XI , 207.

Cercopis, VIII, 143.

Cetoine aurata, stictica, hirta, V, 97.

Chanere de l'olivier, II, 52.

Chaplun, II , 37 .

Charanson du blé, I, 17, 24. Du prunier, V, 96. Des poinmes, V, 95. Du pommier, V, I.96. Du poirier, V, 96. Gris, V, 95.

Chatte, ehatte-pelcuse, I, 18.

Chenille mineuse de l'olivier, II, 38. De l'olive, II, 41. Comnune, V, 79. [Du noyais de pèche, $\mathrm{V}$, 93. Des ehataignes, V, 94. Des fruits sees, V, 94. A livré, V, 81. - VI, 10\%. A oreilles, V, 85, 107. De l'orme, VI, 109. Remide contre les chenilles, IV, 83. Chenille [sur le ehêne, VI, $10 \%$. Des pois, des haricots, VII, 141.

Chermes de l'olivier, II, 44, 49. De la vigne, III, $55,61,65 . D u$ pèeher, du prunier, du figuier, $\mathrm{V}, 99$, 100. De l'oranger, VI, 115.

Chou, VII, 134, 138. Choufleur, VII , 136.

Chrysonela papuli, VI, 114. Tremulo, VI, 114. A 10 points, VI, 114.

Cigale, VI, 113.

Cimex ornatus, festivus, oleraceus, VII, 136.

Cinips , 1, 32. - XI, 206.

Ciron, II, 34.

Clerus":apiarius, alvearius, lucospidcus, X , 187.

Cloporte, VII, 131.

Cloque, X, 161, 169.

Coccinelle, XI , 208, 209. 
Cochylis roserana, III, 56.

Coupe-bourgeon, III , 63.

Colaspis barbara, VIII, 144, 148.

Colza, VII, 136, 137, 138.

Cosson, I, 17, 24.

Cossus, gate-bois, ligniperda, VI, 110 ,

Coton de l'olivier, II, 46.

Courconçon, VII, 141.

Courtilière, VIII, 124.

Cousins, X, 186.

Criocere, VII , 132. Du Lys, VII, 132.

Criquets, IX, 151.

Cryptophagus beta, VII, 133.

Crypte, XI, 206.

Curculis pruni, V, 95. Mali, V, 96.

D.

Demoiselles, XI, 212.

Dermeste, X, 198.

E.

Echenilloir, V, $8 \%$.

Engraisse-poule, III, 63.

Ers, VII, 141.

Eumolpus vitis, III, 63, 66. Obscurus, VIII, 144.

F.

Fausse-teigne des grains, 1, 15.

Fausse-chenille de l'amandier, IV, 69. 
Fives, VII, 141.

Formicaleo, Fourmilion, XI, 210.

Fourmis, VI, 116. - IX, 169. Fourmis de visite, $\mathrm{X}, 171$.

Frélon, X, 185.

Fromage, X, 198.

\section{G.}

Galleruea calmariensis, VI, 109. Alni, VI, 114.

Galleria cereana, alveolaria, X, 190.

Gazé (le), IV, 72, 76.

Guêpes, guêpe-frèlon, V, 101. - X, 185, $18 \%$. guëpes-iehneumons, ennemies des larves et des chenilles, XI, 211. Guêpe-maçonne, XI, 211.

Gond, I, 18.

\section{H.}

Hamaticherus, heros, miles, VI, 102.

Uanneton, III, 65. - V, 97. - VII, 123. - VIII, 148. - IX, 172.

Hémérobe, XI, 208.

Hepiale du houblon, VI, 112.

Huublon, VI, 112.

Hippobosque, $\mathrm{X}, 1 \% \mathrm{~s}$.

Hylesinus oleiperda, II , 34 .

Hyponomeuta padella, V, 89.

Hypera variabilis, VIII, 143.

\section{I.}

Iehneumon, ennemi des chenilles, XI, 204.

Insectes des fruits sers', V, 94. Des noix, V, 94. 
liile terrestre, I, 12.

Ixodes , X , 180.

L.

Laire, VIII , 131.

Lamia tristis, V, 102.

Lard, X, 198.

Lentilles, VII, 141.

Leptis vermileo XI, 211.

Lestremie, I, 10.

Libellules, ennemies des inseetes ailés, XI, 212.

Limaçons, IX, 173.

Lingaste X, 179.

Lion des pueerons, XI, 208.

Lisette, III , 63, 66.

Locusta verrueivora, viridissima, gigantea, ephippiger, IX $, 156,157,160$.

Louvette, X, 180.

Lueane, cerfvolant, parallélipipède, V, 100. - VI, 107.

Luzerne, VIII , 143.

Lydus, IV ; 69 , 75.

Lygreus apterus, VII, 135.

Lys, VII, 132.

Lytta vesicatoria, II, 38.

Lymoxylon navale, X, 198,

\section{M.}

Mais , VII ; 131.

Man, III , $63,65$.

Mange-pire, V, 102.

Mante, XI, 212.

Melolontha eulgaris, V, 97. - IX , 172. 
Melons, VII, 131.

Melophagus ovinus, X, 179.

Microgaster, ennemi des chenilles, XI, 206.

Misoxylus mali, IX, 163.

Mille, X , 180, 199.

Moine, II , 33.

Mouchc brassicairc, VII, 139. - De la viande, vomitoria, cellaris, du vinaigre, $\mathrm{X}, 204$. - Mort aux mouches, $\mathrm{X}, 201$. - Mouchc parasite des chenilles, X, 207. - Mouche-araigne, X, 178.

Mousque boubouine, X, 178.

Mourre pounchu, VIII, 144.

Musca lincala, I, 20. - Larvarum, XI , 208.

Museau pointu, VIII, 144.

Murier, VI, 103.

Mylabre a croix blanche, VII, 141.

Myrmelion, XI , 210.

N.

Navette, VII , 136.

Navets, VII , 132.

Necrobia rufipes, X, 199.

Négril, VIII, 146. - Moyen de destruction, VIII, 147.

Némotile verlion, XI, 211.

Noctua ou Noctuc ochroleuca, I, 12. - Scgetis, I,

13. - VII , 73. - Armigera, VII , 74..-Brassica, pronuba, pisi, VII, 120. - Oleracca VII, 122.

- Psi, V, 85. - Noctue le la laitue, VII, 122.

- C. nigrum, VII, 122. - Tragopogonis, de l'oseille, VII, 122. - Exoleta, aquilina, ruris, crassa, VII , 123. 
0.

OEstre du bauf, uterin, equinus, hammorroidalis, ovis, $\mathrm{X}, 176,17 \%$.

OEillet, VII , 140.

Ophion, ennemi des chenilles, XI, 206.

Orge, I, 20.

Ornithomya hirundinis, $\mathrm{X}, 179$.

Oryctes grypus, nasieurnis, II , 33. - VIII , 148.

Oscinis du ble, I , 10. - Olex, II , 46, 50.

Osier, VI , 67, 68.

Otiorhynehus niger, II, 37.

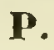

Papillon des grains, 1, 16, 22.

Papillon, grande tortue, polychloros, V, 86.

Paehygaster, pachygaster merillionalis, II , 37.

Pastcl VII, 135.

Pelleteries, X, 195.

Pelopée, ennemi des insectes, XI, 211.

Peree-oreillc, VII , 140.

Peuplier, peuplier blanc, VI, 113.

Phalona ulmaria, VI, 115. - Brumata, V, 82.Divers procédis contre elle. - Phalana defoliaria, V, 84.

Philantus apiovrus, 187.

Phloiotribus olcœ, II, 43.

Pieris cratogi, IV , 72, 76. - Brassica, VII , 134.

- Rapa, VII, 134.

Pigeons, X, 179.

Pimpla, ennemi des chenilles, XI, 290. 
Pipidons, X, 181.

Pique-brot, III , 63.

Plusia gamma, VII ; 117. - Chalcites, VII, 120.

Polydrusus pyri, V, 95.

Pompile, XI, 211.

Pou, X, 183.

Pou volant, I, 16. - De l'olivier, II , 44.

Poules, X, 181.

Pouillons, X, 181.

Prégadiou, XI, 212.

Procris ampelophaga, III, 59.

Psylla olece, II, 46.

Ptinus latro, X, 197.

Puce, X, 185.

Pucette, VII, 141.

Puceron, VII, 141. - IX, 160. - Leur histoire, IX, 160. - Souffet à vapeur, IX, 165. - Note, IX , 164. - Remeddes , IX , 164. - Puceron lanigere, puceron du pommier, IX, 163. - Remèdes contre ses dégäts, essence de charbon de terre, IX, 163. - Puceran du poirier, V, 98.

Pucerotte, VII, 137.

Punaise du chou, VII , 81.- Punaise domestique, X, 183.

Pyralis, pyrale de la vigne, III, 56. -. Recherches de M. Audoin, III, 59. - Oporana, liolmiana, gnoneana, III, 88. - Pomana, III, 93. - Plugiana, III, 94. - Chlorana, VI, 115. - Uncana, VIII, 149.

\section{lR.}

Ricettes, IV, 7\%. - V , 92. - VII, 141.-X, 164.

Receltes de M. Tatin, IX, 16\%.

Rhinneres, II, 33.- VIII, 118. 
Rhynchites betuleti, III, 64, 66. - Bacchus, III, $64,65,-$ V. Notc, III, 60.

Rivin, X, 181 .

S.

Saperde oylindrique, V, 101.-Carcharius, vculatd, populnea, scalaris, linearis, trcmula, VI, 113. Sauterelles, IX, 151. - Leurs ravages; procédès pour les détruire, IX, 152.

Scarabe rhinoccros, VIII, 148. - Scarabcus punctatus, VII, 131 .

Scorpion, X , 186.

Sésic, VI, 112.

Sinodendron muricatum, II, 35. - Cylindrique, V, 101.

Sphinx atropos, tête de mort, II , 35. - X, 187.

- Ligustri ,. II , 36. - Elpénor, III, 55, 62, Dc la vigne, III , 55, 62.

Sphex, enncmi des insectcs, XI, 211.

Stomoxys irritans, X, 200.

T.

Taon, X, 175.

Taragnon, II, 34.

Taille-sébe, VII , 140.

Taupc-grillon, VII, 124. - Sa chassc, VII, 120. - Autre chasse, VII, 129.

Tcigne des ruches, X, 188. - Dcs fourrures, sarcitella, X, 191. - Vestianella, X, 192. - De nos départcments, X, 192. - Procélćs contre les teignes, X, 193.

Tenebrio molitor, I, 29. 
Tenthrède du cérisier, V, 96. - De la rave, VII, 139, Tephritis cerasi, V, 95.

Tigre, V, 98.

Tinea elutella, I, 14. - Ambiguella, III, 56.

Tingis, pyri, V, 98.

Tipule des prés, VII, 140.

Tique, X, 180.

Tiquet, VII, 137.

Tonsures, VIII, 148.

Tortrix pilleriana, III, 61 .

Trichodes, X, 187.

Trifle, VIII, 145.

Tremble, VI , 113.

Trogosita caraboides, I, 19.

Turc, III , 63.

\section{V.}

Vache à Dieu, XI, 209.

Fer du blé, I, 9, 20. - Prćcautiunt contre le ver,

I, 20. - De l'olive, II , 46, 50. - Ver blanc.

III , 65. - VI , 103. - IX , 172. Des chataignes,

V, 94. - Des prunes, V, 94. - Des pommes,

de la péche , V , 93. - Des glands, noisettes, noix, VI , 107. - Ver gris, VII , 12.. - Di trèfle,

VIII, 146. - Ver sauteur du fromage, X, 199.

Vespa crabro, V, 101. - X , 185.

Vinaigrier, XI , 213.

Vrillettes, X, 197.

\section{Z.}

Zeuzera asculi, VI, 111.

FIN DE LA TABLE ALPHABÉTIQUt. 



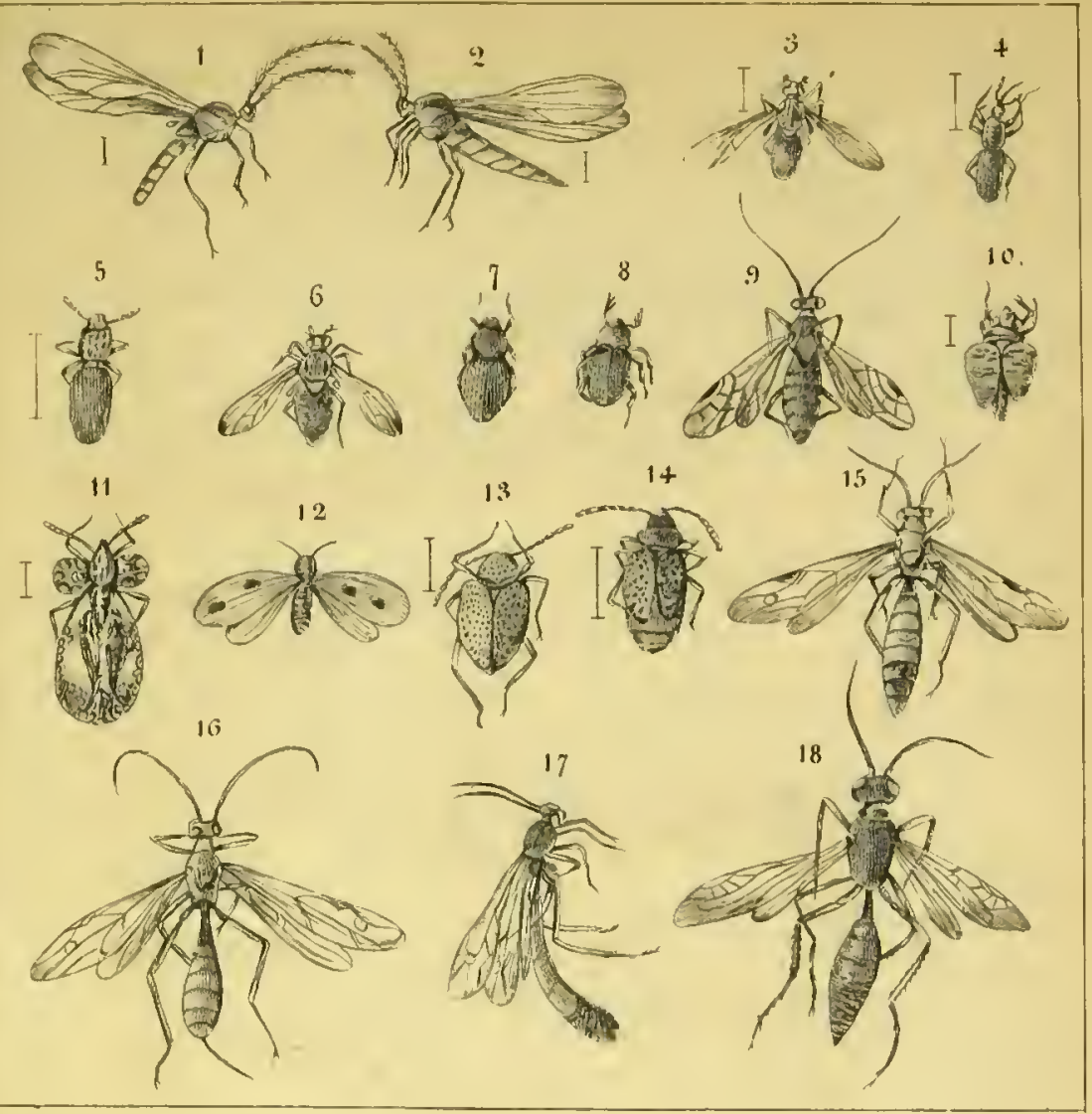

1. Hourherens dis ves du bled, wriale. : Le usinus fernelle. 3 ascinis wh bled.

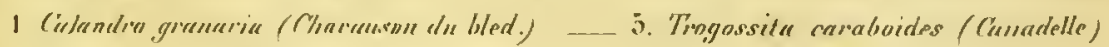

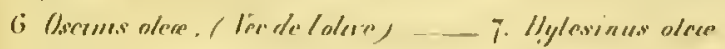
8 Mloialoduse where?

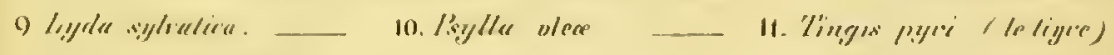

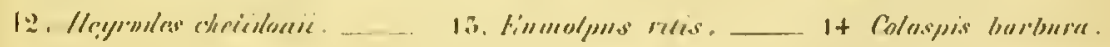

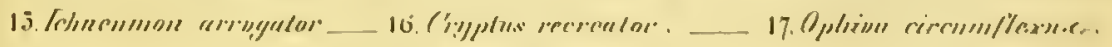

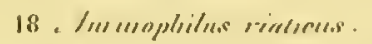

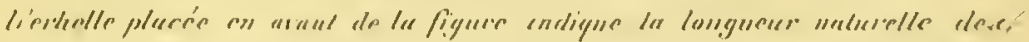

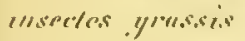








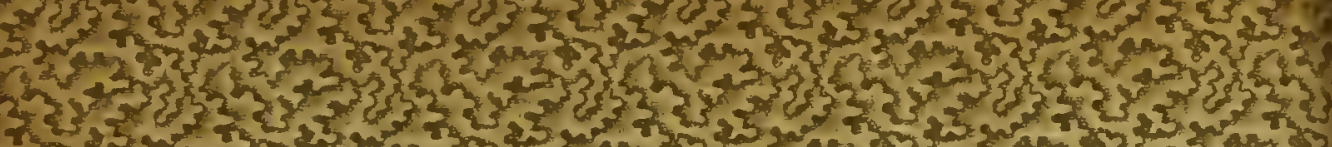

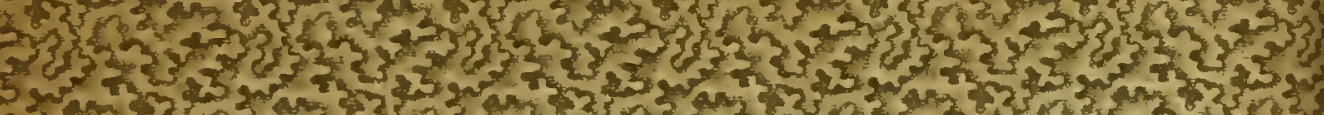

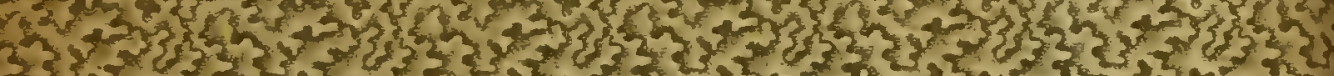

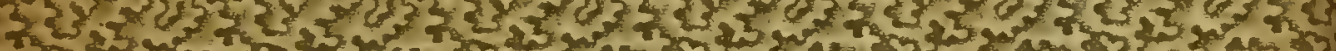

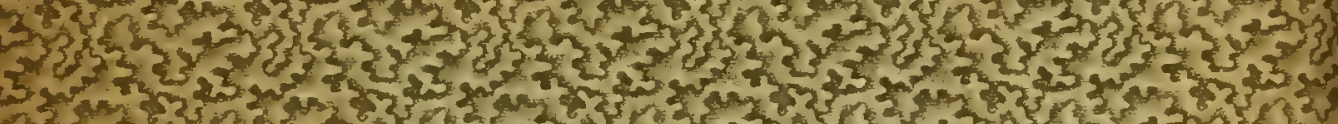

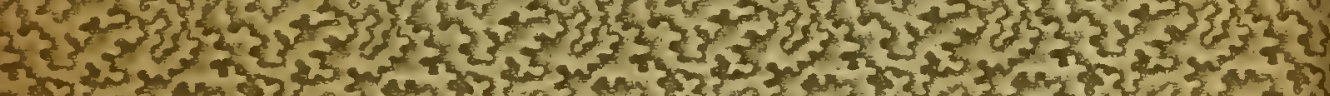

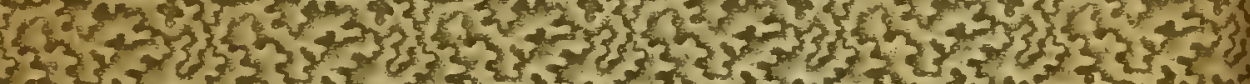

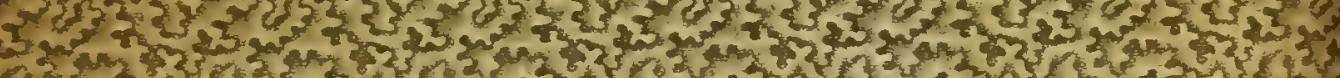

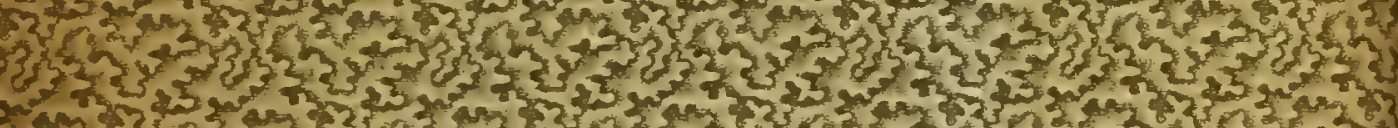

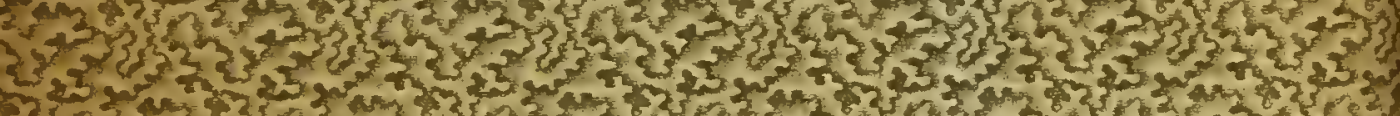

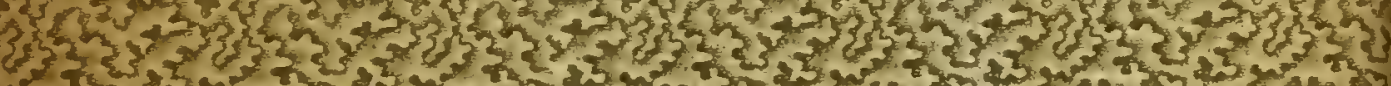

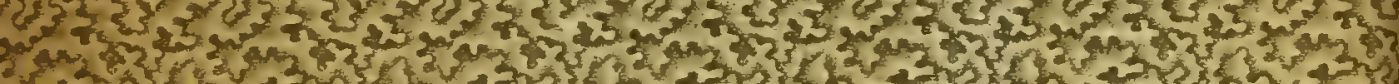

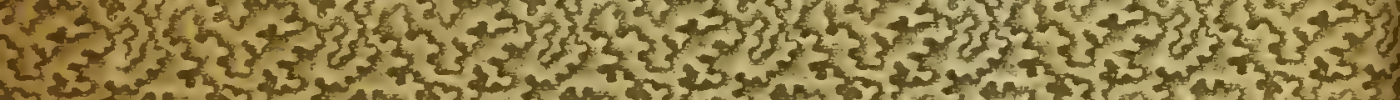

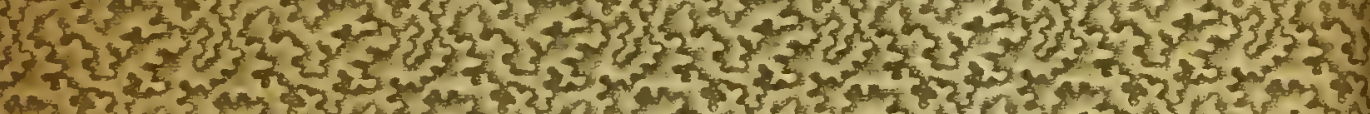

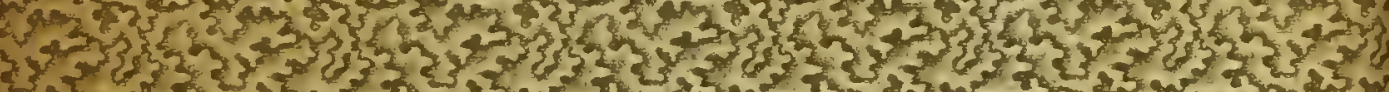

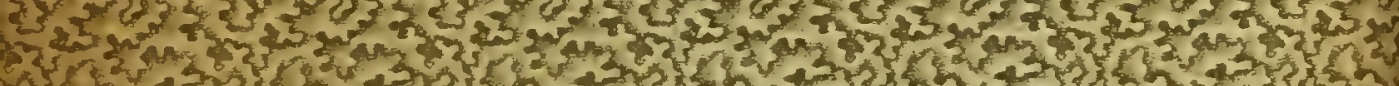

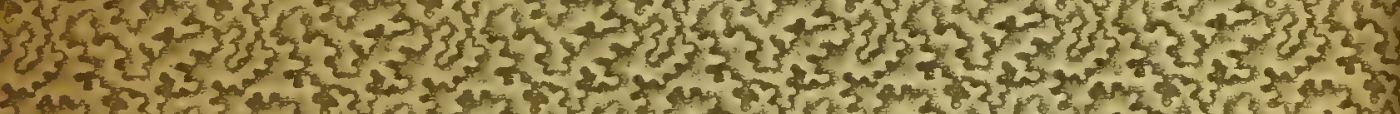

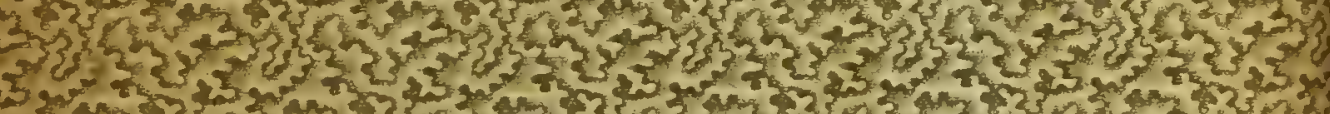

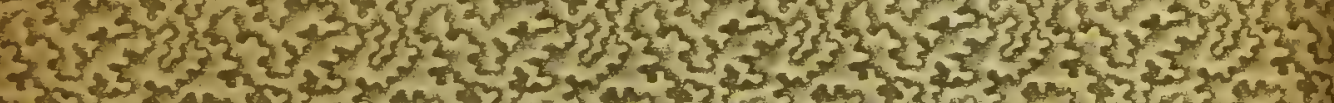

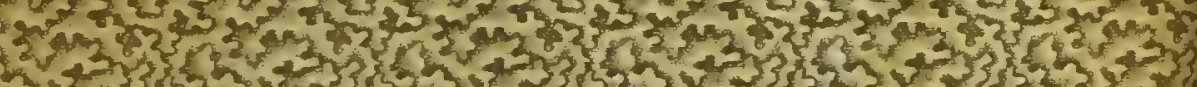

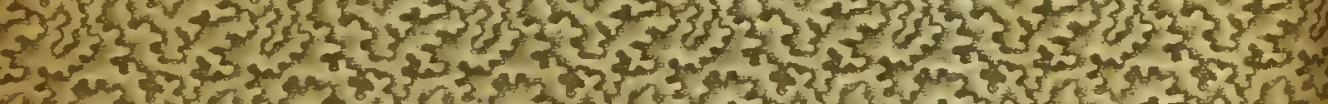

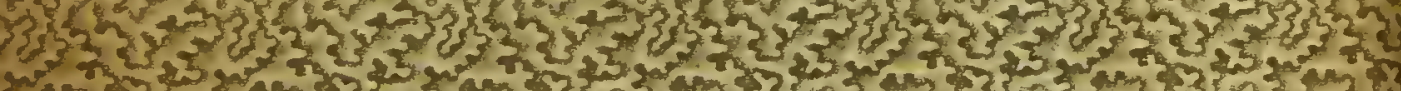

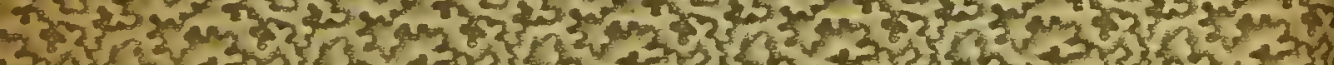

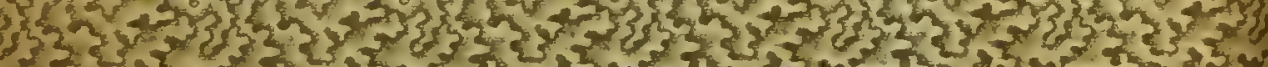

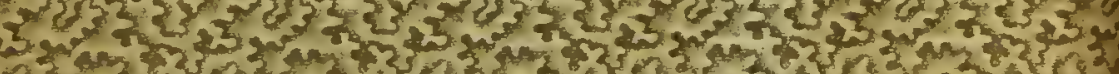

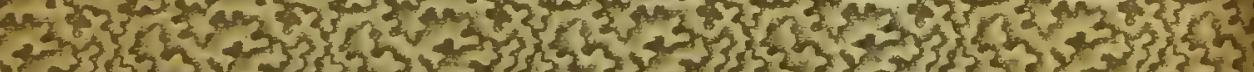

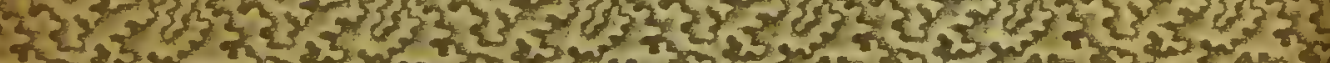

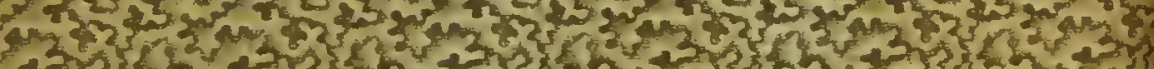

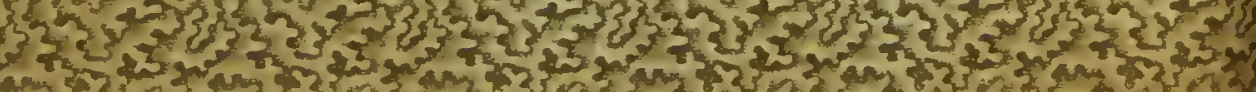




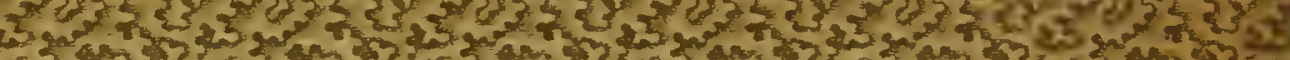

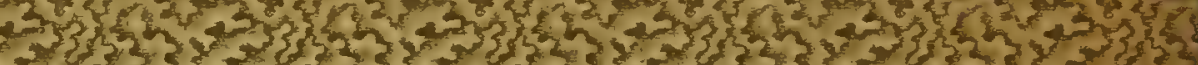

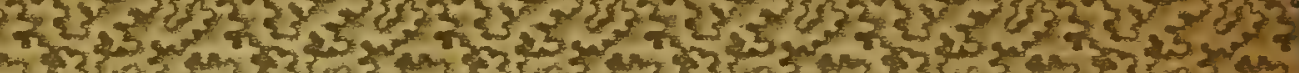

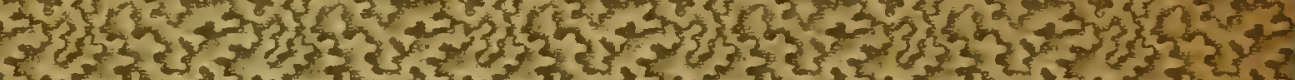

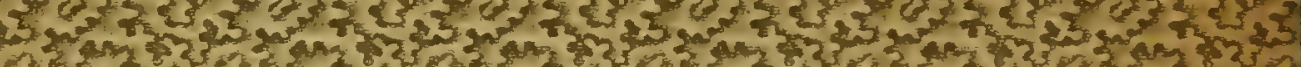

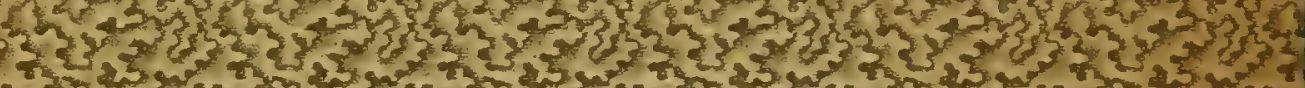

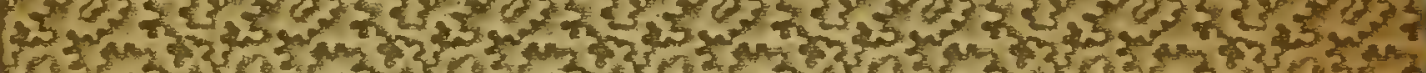

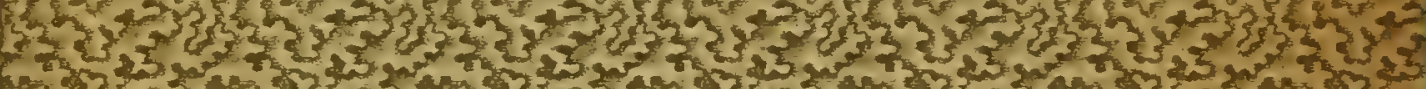

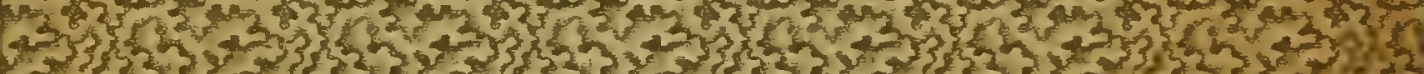

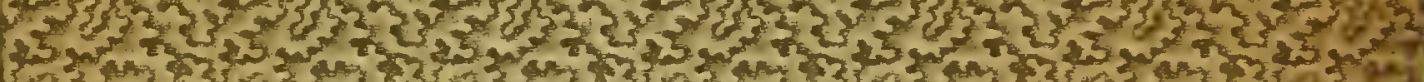

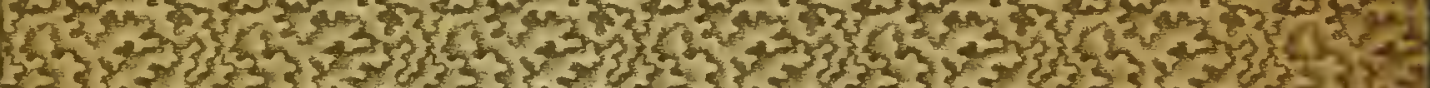

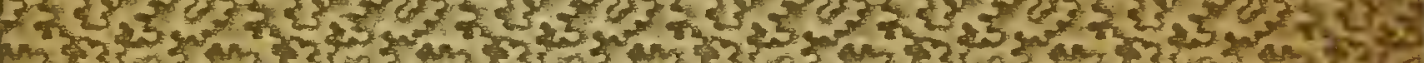

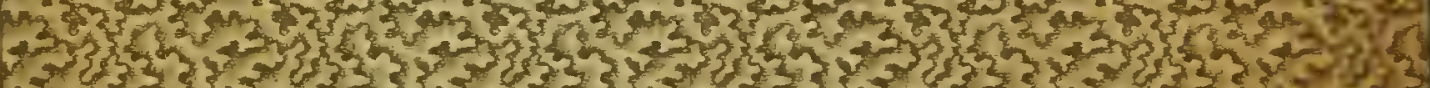

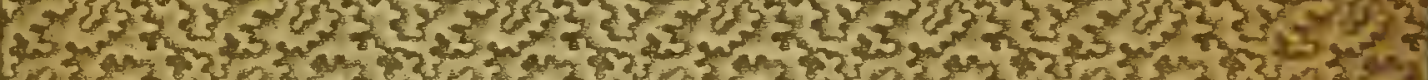

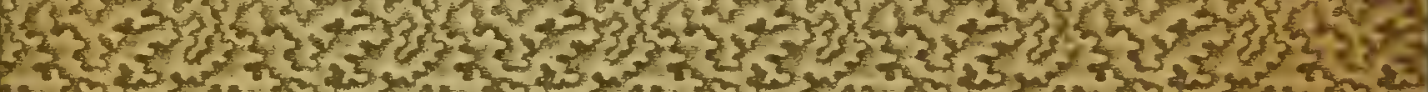

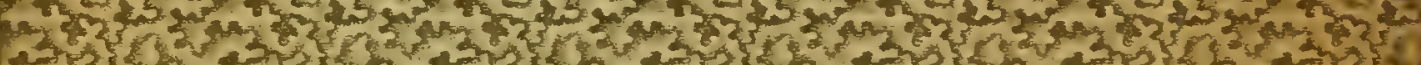

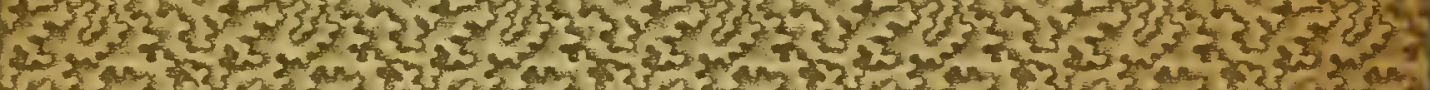

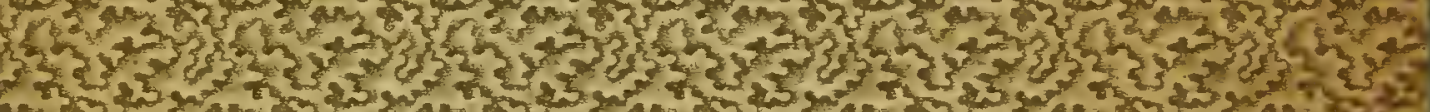

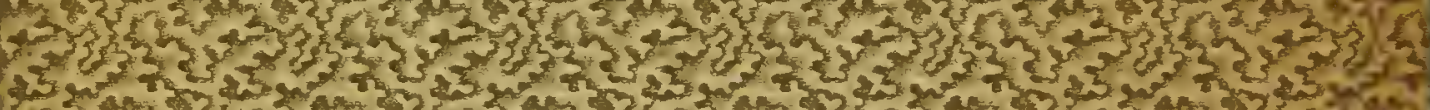

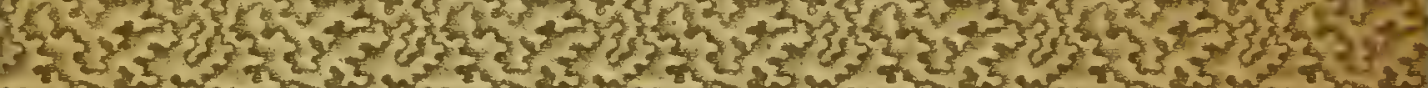

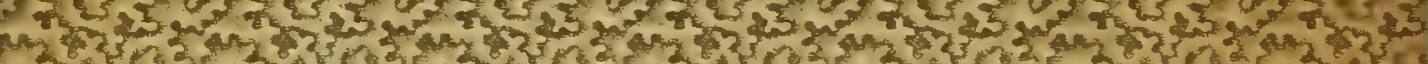

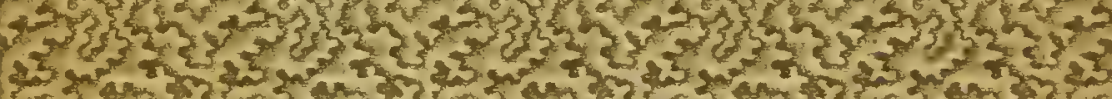

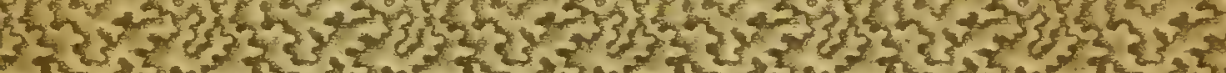

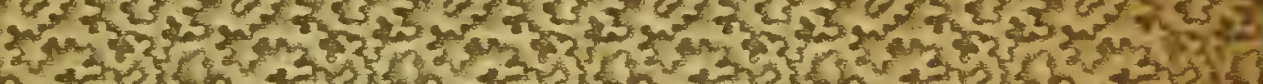

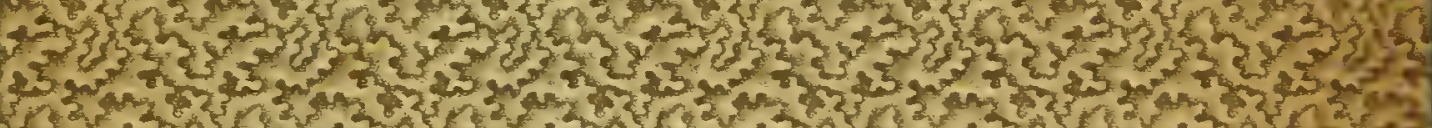

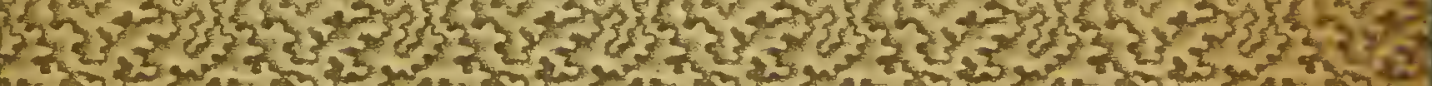

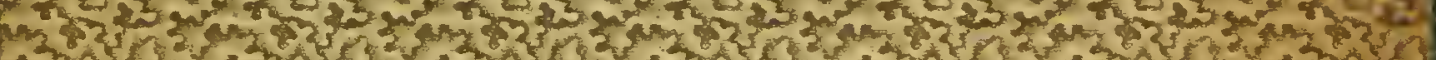

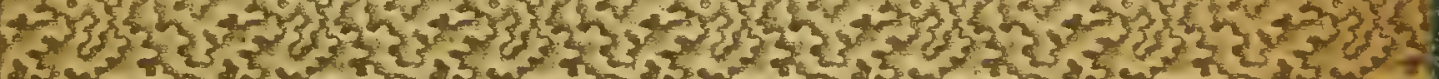

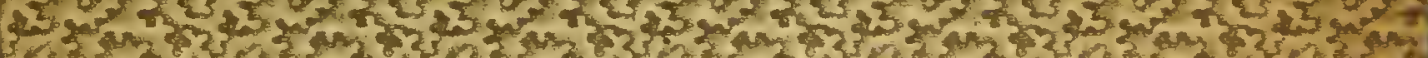

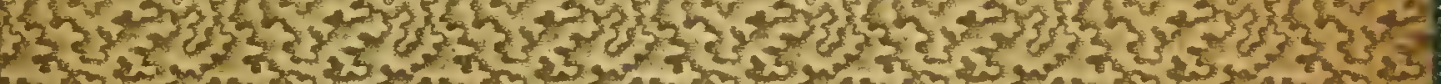

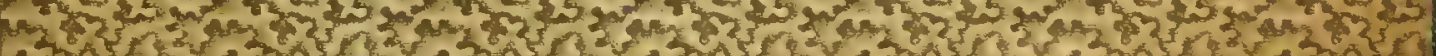

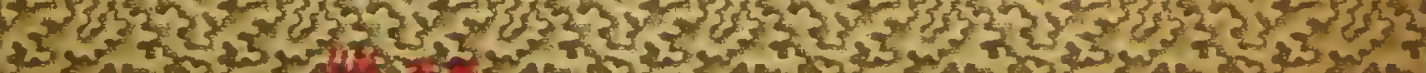

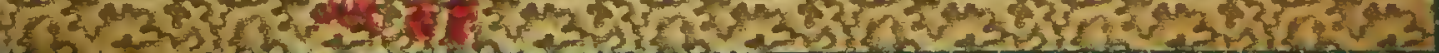


13 3. $0 .+2$

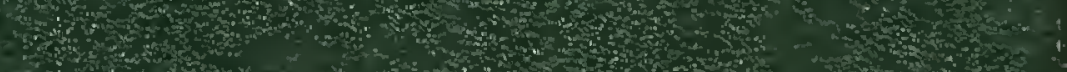
r.t. 